\title{
Parasitism and cooperation
}

\section{in the nests of carrion crows}

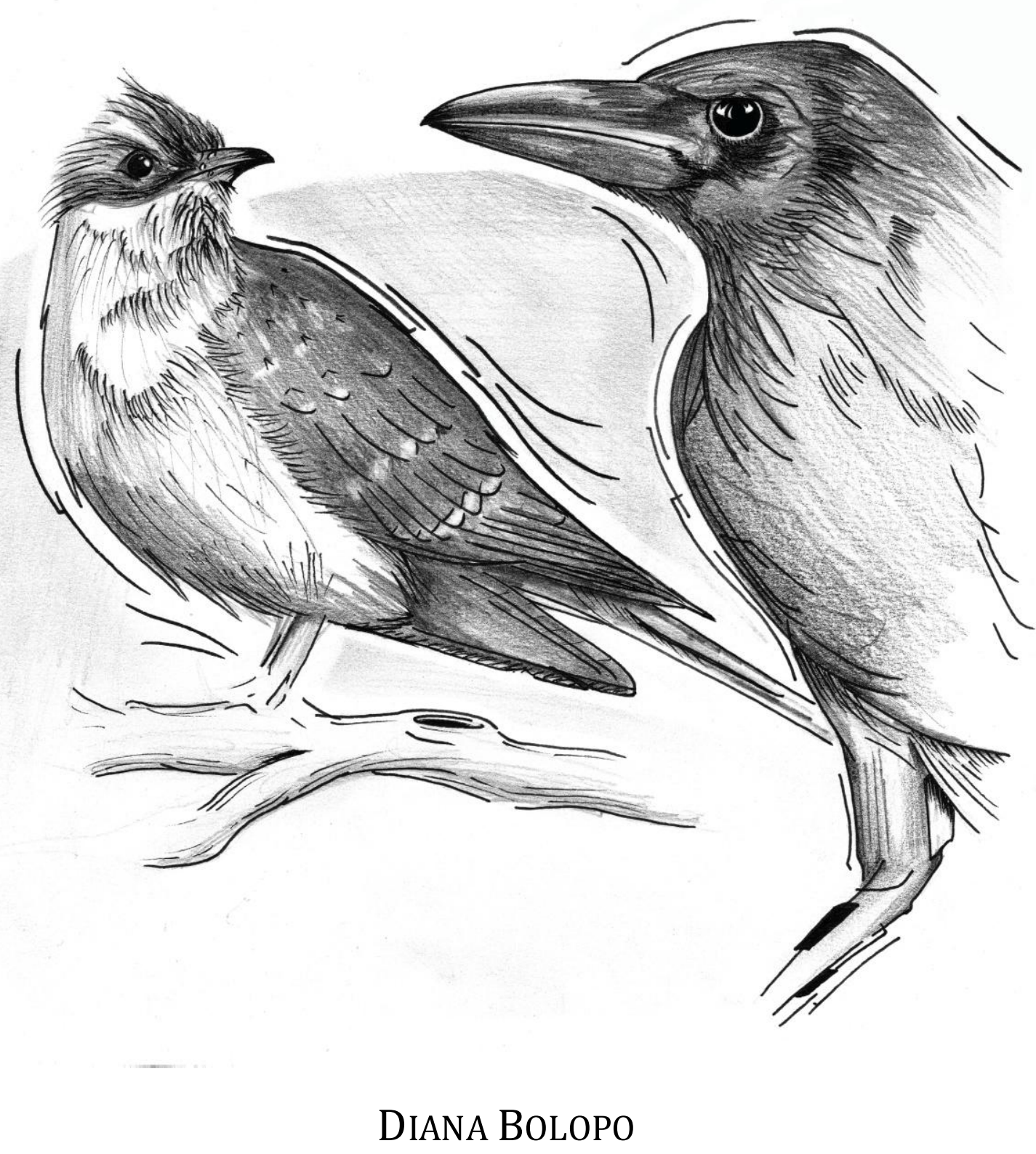

Universidad de Valladolid 2014 


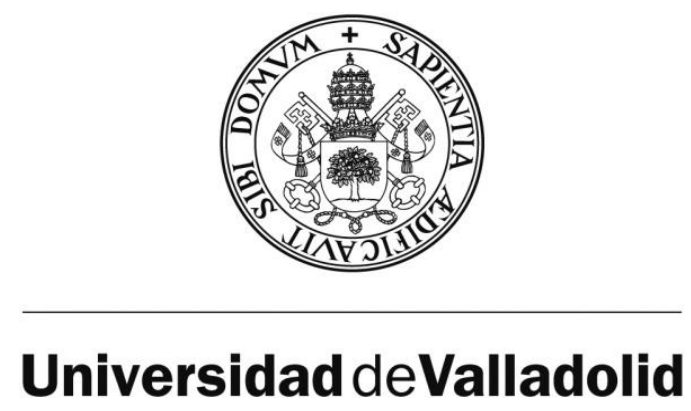

Escuela Técnica Superior de Ingenierías Agrarias

Departamento de Ciencias Agroforestales

Área de Zoología

\title{
TESIS DOCTORAL: \\ Parasitism and cooperation in the nests of carrion crows
}

Presentada por Diana Bolopo para optar al grado de doctora por la Universidad de Valladolid

\author{
Dirigida por: \\ Vittorio Baglione \\ Daniela Canestrari
}


To my family 


\section{ABSTRACT}

Parasites may become a serious threat to the health of the hosts and to their reproductive success. Birds in particular may also suffer from brood parasites, which are bird species that lay their eggs in the nest of other species, so that the foster parents raise the parasitic chicks. In Northern Spain, carrion crows Corvus corone form cooperatively breeding groups and they are the preferred host of the brood parasitic great spotted cuckoo Clamator glandarius, unlike in the rest of the Paleartic where the magpie Pica pica is the primary host.

First, I carried out a comparative study of the mating system of the great spotted cuckoo through genetic analyses in two separated areas on Spain. I found that cuckoo's mating system may change depending on the density of the parasitic population: the higher the density, the higher the frequency of polygamy. I also found females laying in nests of both hosts, at both locations, which indicates that there are no host-specialized gentes of great spotted cuckoos. This result rules out the possibility that great spotted cuckoo's preference for crows in the northern population was due to the prevalence of a specific gens.

Second, I showed that the outcome of the interaction between the great spotted cuckoo and its host may vary between parasitism and mutualism depending on predation pressure. The analyses of a long-term data showed that that in years with high predation rate, parasitized nests produced more fledglings than non-parasitized ones. Experimental manipulations confirmed the causal link between the presence of a cuckoo in the nest and a decrease in the rate of brood predation. Great spotted cuckoo nestlings produce a malodorous cloacal secretion 
when harassed. Repellence tests on model species belonging to the three groups of crow nest predators, i.e. mammals, corvids and raptor birds, proved the deterrent effect of these secretions. Chemical analyses revealed that this substance contains a mix of compounds that are known to repel birds, mammals or both groups, giving farther support to the anti-depredatory function of cuckoos' secretion.

Furthermore, I studied how the costs of brood parasitism for the carrion crows may change over the nesting period. Although it has been shown that cuckoo parasitism poses costs to crows by, for example, reducing hatching success, I showed that the exaggerated begging intensity of the cuckoo chicks allows 10-15 days old crow nest mates to reduce their begging intensity, without negative consequences on the intake of food provisioned by the adults. We suggest that decreased begging may benefit the crow chicks. For host offspring, the cuckoo nest mate may be an ally rather than an "enemy", as soon as they grow big enough to compete efficiently for food against the parasite.

Finally, I studied how crows perform nest sanitation, which is thought to be the precursor behaviour of parasitic egg rejection by the hosts of brood parasites. Maintaining the nest clean is an important task to minimise possible parasitic infections, which may reduce chick survival and therefore adults' breeding success. I found that nest sanitation was mainly performed by the breeding females. I suggest that females may do so not only for the sake of the brood, but also to avoid own infection. Indeed, they spend more time in the nest than any other group member (only females incubate and brood) and are therefore more exposed to parasites and pathogens that live in the nest. 


\section{TABLE OF CONTENTS}

$\begin{array}{ll}\text { ABSTRACT } & 4\end{array}$

TABLE OF CONTENTS

CHAPTER 1:_INTRODUCTION 9

Avian brood parasitism: What it is and how it evolved. 9

$\begin{array}{ll}\text { How do brood parasites choose their hosts? } & 10\end{array}$

$\begin{array}{ll}\text { Behaviour at the nest of the parasitic chicks } & 11\end{array}$

$\begin{array}{ll}\text { Host-parasite coevolutionary arms race } & 12\end{array}$

$\begin{array}{ll}\text { Great spotted cuckoo and its Paleartic hosts } & 13\end{array}$

$\begin{array}{ll}\text { Introduction to the chapters } & 16\end{array}$

Chapter 2: Mating system of the great spotted cuckoo,

$\begin{array}{ll}\text { a comparative study } & 16\end{array}$

Chapter 3: From parasitism to mutualism: unexpected interactions between

$\begin{array}{ll}\text { a cuckoo and its host } & 17\end{array}$

Chapter 4: The high begging intensity of great-spotted cuckoo nestlings $\begin{array}{ll}\text { favours crow nest-mates } & 18\end{array}$

Chapter 5: Nest sanitation in cooperatively breeding carrion crows $\quad 18$

CHAPTER 2:_MATING SYSTEM OF THE GREAT SPOTTED CUCKOO, A $\begin{array}{ll}\text { COMPARATIVE STUDY } & 20\end{array}$

$\begin{array}{ll}\text { Abstract } & 20\end{array}$

$\begin{array}{ll}\text { Introduction } & 21\end{array}$

$\begin{array}{ll}\text { Material and methods } & 24\end{array}$

$\begin{array}{ll}\text { Study sites } & 24\end{array}$

Host species $\quad 24$

$\begin{array}{ll}\text { Field data collection } & 25\end{array}$

$\begin{array}{ll}\text { Molecular analyses } & 25\end{array}$

$\begin{array}{ll}\text { Parentage analyses } & 27\end{array}$

$\begin{array}{ll}\text { Results } & 30\end{array}$

$\begin{array}{ll}\text { Molecular analyses } & 30\end{array}$ 
$\begin{array}{ll}\text { Mating system } & 33\end{array}$

$\begin{array}{ll}\text { Discussion } & 37\end{array}$

CHAPTER 3:_FROM PARASITISM TO MUTUALISM: UNEXPECTED INTERACTIONS BETWEEN A CUCKOO AND ITS HOST

$\begin{array}{ll}\text { Abstract } & 41\end{array}$

$\begin{array}{ll}\text { Introduction } & 42\end{array}$

Material and methods $\quad 43$

Study area and population $\quad 43$

Long-term data on parasitism rate and reproductive success 44

Cuckoo transfer experiment $\quad 45$

$\begin{array}{ll}\text { Repellence tests } & 47\end{array}$

$\begin{array}{ll}\text { Statistical analyses } & 48\end{array}$

$\begin{array}{ll}\text { Chemical analyses } & 50\end{array}$

$\begin{array}{ll}\text { Results and discussion } & 54\end{array}$

CHAPTER 4: HIGH BEGGING INTENSITY OF GREAT-SPOTTED CUCKOO NESTLINGS FAVOURS LARGER-SIZE CROW NEST-MATES 69

$\begin{array}{ll}\text { Abstract } & 69\end{array}$

$\begin{array}{ll}\text { Introduction } & 70\end{array}$

$\begin{array}{ll}\text { Material and methods } & 73\end{array}$

$\begin{array}{ll}\text { Study area and population } & 73\end{array}$

$\begin{array}{ll}\text { Nest survey and video-recording } & 74\end{array}$

$\begin{array}{ll}\text { Analysis of video-recordings } & 75\end{array}$

$\begin{array}{ll}\text { Statistical analyses } & 75\end{array}$

$\begin{array}{ll}\text { Measures of begging behaviour. } & 76\end{array}$

$\begin{array}{ll}\text { Crow vs cuckoo begging intensity. } & 76\end{array}$

$\begin{array}{ll}\text { Provisioning decisions in parasitized nests. } & 77\end{array}$

Crow begging intensity and feeding rate in parasitized vs non-parasitized $\begin{array}{ll}\text { nests. } & 79\end{array}$

$\begin{array}{lr}\text { Ethical note } & 80\end{array}$

$\begin{array}{lr}\text { Results } & 80\end{array}$ 
Begging intensity in parasitized nests.

$\begin{array}{ll}\text { Provisioning decisions in parasitized nests. } & 80\end{array}$

Crow begging intensity in parasitized and non parasitized nests. 83

Provisioning of crow chicks in presence and absence of cuckoos. 83

Discussion 86

Food allocation in parasitized nest 86

Effect of a cuckoo chick on begging and food intake of crow chicks 88

What is the cost of sharing the nest with a parasite for crow chicks? 90

\section{CHAPTER 5: NEST SANITATION IN COOPERATIVELY BREEDING CARRION CROWS}

Abstract

Introduction

Material and methods

Study area and population

Bird banding

Data collection

Food supplementation experiment

Statistical analyses

Results

Discussion

Division of labour among group members?

Why did breeding females clean more? 


\section{CHAPTER 1:}

\section{Introduction}

According to Price (1977) a parasite is "an organism that lives in, or on another living organism, obtaining from it part or all of its organic nutriment, commonly exhibiting some degree of structural modification, and causing some degree of damage to its host". Broad definitions of parasites like this one include most taxa, from viruses to insects, but do not accurately describe brood parasites. This behaviour can be found among birds and fish (Payne 1977; Sato 1986), and involves the manipulation and use of host individuals, either of the same or different species, by the parasite for raising its own offspring.

\section{Avian brood parasitism: What it is and how it evolved.}

Avian brood parasites lay eggs in the nests of other bird species and the foster parents incubate the parasite's eggs along with their own and feed the parasitic chicks. Adopting this particular breeding strategy presents two main advantages: (1) Reducing the risk of predation: Nest predation is a major threat to breeding success for birds and having offspring raised in several nests increases the probability that some will survive.. (2) Overcoming limitations of parental care: Providing a sufficient amount of parental care is a limiting factor to the number of young that birds can produce. The lack of parental duties allows the female parasite to lay more eggs and produce more chicks than she could obtain with her own parental care. 
Three breeding strategies may have been the precursors of brood parasitism (Payne 2005): (1) Egg laying in neighbouring nests of the same or different species. This "facultative brood parasitism" occurs for example in the Black-billed cuckoos, Coccyzus erythropthalmus and yellow-billed cuckoos, Coccyzus americanus (Fleischer et al. 1985). (2) Egg tossing by females, in communal breeding species where several pairs share the same nest. With this behaviour, females increase the chances that the brood that is cared for by the entire group contains some of their own offspring (i.e. anis Crotophaga spp and guira cuckoos Guira guira (Vehrencamp et al. 1986; Macedo 1992; Payne 2005)).

(3) Usurpation of the nest of other species to lay own eggs and care for own young (i.e. Chestnut sparrows Passer eminibey (Betts 1966; Payne 1969)).

\section{How do brood parasites choose their hosts?}

The suitability of a bird species as host depends on several ecological and biological factors (Sealy et al. 2002) such as: (1) Nests structure and location, which should be readily accessible to the parasite. (2) High population density, to provide the parasite with many opportunities for laying eggs. (3) Incubation, type of food provided and nestling period that match the needs of the parasite and allow a correct development of the parasitic chicks. The combination of these variables may cause host choice to vary in space and time (Teuschl et al. 1998; Langmore \& Kilner 2007).

Host choice may be determined by imprinting on the foster parents at an early stage in the parasite's life (Payne et al. 2000), so that in the adulthood the 
parasite seeks and parasitizes nests belonging to the same species that raised itself. This process may lead to host-specific preference of female parasites and, eventually, even to genetic differentiation of host-specific races or gentes. The occurrence of gentes has been reported several times, for example in the common cuckoo Cuculus canorus (Gibbs et al. 2000) and the screaming cowbird Molothrus rufoaxillaris (Mahler et al. 2009), where each race of females uses a specific host or group of them.

\section{Behaviour at the nest of the parasitic chicks}

The chicks of many brood-parasitic species remove host's eggs from the nest, within a few hours after hatching ("evicting parasites", e.g. common cuckoo Cuculus canorus and Horsfield's bronce cuckoo Chrysococcyx basalis (Davies 2000; Payne 2005)). Expulsion of potential competitors guarantees exclusive parental care and therefore a substantial increase of survival for the parasite. Another evicting strategy of parasitic nestlings is to kill host young soon after hatching, as it happens in the greater honeyguide Indicator indicator (Spottiswoode \& Koorevaar 2012). Non-evicting parasitic chicks, on the other hand, grow up together with the young of their host. They often outcompete their nest-mates by monopolizing the food brought by the foster parents, causing the death of host chicks by starvation. This strategy is often shown by parasites that use hosts of equal or larger size that would be physically impossible to evict from the nest (Payne 2005). Examples of non-evicting parasites include crested cuckoos Clamator spp, common koel 
Eudynamys scolopacea and brown-headed cowbirds Molothrus ater (Davies 2000; Krüger 2007).

For the parasitic chicks the lack of related nest-mates determines the absence of indirect costs of within-brood competition, which favours the evolution of strategies that maximize the success of the individual parasitic chick (Godfray 1995; Lichtenstein 2001). Exaggerated begging behaviour, for example, is a decisive tool to force foster parents to increase food provisioning or to compete for food against host nest-mates in non-evicting species (Kilner \& Johnstone 1997; Soler 2001; Parker et al. 2002). It has been shown that a single common cuckoo chick calls loudly and often enough to simulate the entire brood of its host species in order to stimulate its foster parents to bring more food (Davies 2000). Also, the combination of larger size and exaggerated begging of brown-headed cowbird chicks, in nests of indigo buntings Passerina cyanea, leads host parents to preferentially feed the parasitic chicks over their own (Dearborn 1998).

\section{Host-parasite coevolutionary arms race}

Coevolution is the genetic adaptation between interacting species, over evolutionary time. The interactions between avian brood parasites and their hosts have become classic examples and model systems to test predictions of coevolutionary arms race hypotheses (Clayton \& Moore 1997; Rothstein \& Robinson 1998; Davies 1999; Stokke et al. 2002). Several adaptations and counteradaptations between brood parasites and their hosts have been identified. For example, hosts often mob the parasite in the proximity of the nest and/or toss 
parasitic eggs out of the nest (Payne et al. 1985; Duckworth 1991). In turn, parasites respond evolving mimetic eggs and laying strategies that help overcoming host harassment (Oien et al. 1995; Moksnes et al. 1995). However, host defences vary with the risk of being parasitized and the costs of egg rejection (for misrecognition of parasitic eggs and with consequent ejection of own eggs) (Lotem et al. 1995; Davies et al. 1996).

Some host species, however, do not show defences against brood parasitism (Krüger 2011). Two hypotheses explain this: the evolutionary lag and the evolutionary equilibrium hypotheses. Evolutionary lag hypothesis predicts that hosts may lack the genetic variation that would allow evolutionary selection of defences against parasites (Rothstein 1990), probably due to relatively recent contact between the antagonistic species. Evolutionary equilibrium hypothesis, on the other hand, suggests that hosts refrain from exhibiting their defences because costs outbalance (Davies 1999; Krüger 2011).

\section{Great spotted cuckoo and its Paleartic hosts}

The great spotted cuckoo Clamator glandarius is an obligated non-evicting brood parasite of the Cuculidae family (Payne 2005) and has been studied broadly in the Iberian Peninsula (Soler 1990, 2003; Soler et al. 1995c, 1998, 2011, 2014;

Soler \& de Neve 2013). It is a trans-Saharan migrant that arrives to the South of Spain at the beginning of February. After breeding, adults leave their breeding areas at the middle of June, while juveniles depart from July until the first week of August (Soler et al. 1994). Magpies Pica pica are the main host in the Paleartic, 
whereas carrion crows Corvus corone corone are used as secondary host when magpie nests are not yet available; choughs Pyrrhocorax pyrrhocorax and jackdaws Corvus monedula are only sporadically used (Cramp 1985; Soler 1990).

Most of the research on great spotted cuckoo focused on host-parasite interactions with magpies and has been carried out in Southern Spain. Great spotted cuckoos evaluate parental quality of the hosts according with the size of their nests, and they choose the largest nests to lay (Soler et al. 1995a). The ability of the magpies to reject alien eggs varies among populations depending on the parasitic pressure (Soler et al. 2000). Mafia behaviour performed by the great spotted cuckoo, namely the destruction of all host eggs if rejection of cuckoo egg occurs, also alters the decisions of egg expulsion of the magpies (Soler et al. 1995c). Two white papillae on the gape of the great spotted cuckoo chicks act as supernormal stimulus, so host parents feed preferentially parasitic chicks over their own young (Soler et al. 1995b), which usually results in monopolization of the food by the cuckoo chicks and starvation of their nest-mates. These studies show the fine adaptations of the great spotted cuckoo to parasitize magpies. However, less work has been carried out on parasite's interactions with carrion crows. It has been shown that the breeding success obtained with this secondary host is lower than with magpies due to decreased nestling survival as cuckoos cannot monopolize the food and starve to death larger crow nest-mates (Soler et al. 2002).

Contrary to expectations based on previous knowledge, a recent study shows that in a population in Northern Spain the carrion crow is the main host of the great spotted cuckoo, although magpies are abundant (Roldán 2011). 
Surprisingly, in this population, crows also prove to be the least profitable host for great spotted cuckoos, and magpies did not show better defences against the parasite. Carrion crows breed in unassisted pairs throughout Europe but they present cooperative breeding groups in the $75 \%$ of the territories in the Northern population (Baglione et al. 2002a), and in the 66.7\% in Southern Spain (Canestrari et al. in prep.). Helping behavior of the crows has been extensively studied in the Northern population (Baglione et al. 2002a, 2010; Canestrari et al. 2005, 2008a, 2008b) and it has been shown that helpers may protect against brood parasitism by the great spotted cuckoo (Canestrari et al. 2009).

It is in that Northern population in Spain (León: $42^{\circ} 37^{\prime} \mathrm{N}, 5^{\circ} 26^{\prime} \mathrm{W}$ ) where the majority of the present work is carried out. The broad knowledge of the ecology and behaviour of carrion crows (Bolopo et al. 2009; Baglione et al. 2002a, 2002b, 2006; Canestrari et al. 2007, 2010, 2012) and the high level of parasitism suffered, provide good opportunities to study the interactions between the carrion crow and the great spotted cuckoo. Carrion crows are twice the size of great spotted cuckoos, and this characteristic makes the study system a particularly interesting one. Little is known on the outcome of interaction between a brood parasite and a larger size host and theoretical predictions are largely untested. For example it has been suggested that the parasite may profit from the "begging assistance" of their larger host nest-mates if it is eventually able to obtain most of the food brought to the nest thanks to their exaggerated levels of begging (Kilner et al. 2004). On the other hand, the intense begging of a parasitic chick may stimulate parents to visit the nest more often, which may in turn benefit host chicks if they can successfully compete for food with the parasite (Kilner et al. 2004; Rivers et al. 
2010). However, the generality of these hypotheses is currently difficult to assess. In this thesis I 1) describe the genetic mating system of the great spotted cuckoo through a comparative study across populations; 2) I study the effect of cuckoo's exaggerated begging on within brood competition for food; 3) I test whether and how having a cuckoo chick in the nest may be beneficial for the crows; 4) I analyze within group individual contribution to nest sanitation in crows, a behaviour that is believed to be a precursor of alien egg rejection and therefore linked to the evolution of host defence against brood parasites.

\section{Introduction to the chapters}

Chapter 2: Mating system of the great spotted cuckoo, a comparative study

Mating systems of brood parasites have been proved to be highly variable across populations and across years within the same population (Alderson et al. 1999a; Woolfenden et al. 2002; Strausberger et al. 2003). Therefore, in order to obtain a broader view of the mating system of the great spotted cuckoo I carried out a comparative study across years and populations in the North (León) and South (Guadix) of Spain. I used blood samples from adults and chicks of great spotted cuckoos from the two different study sites to carry out paternity analyses by using, previously described and newly developed, microsatellite markers in order to: a) describe the variability of the mating system in space and time. b) Investigating the existence of host-specialized races among great spotted cuckoo females. 
Chapter 3: From parasitism to mutualism: unexpected interactions between a cuckoo and its host

Brood parasitism predicts selection for defensive behaviours of the hosts that usually suffer partial or total loss of their own brood. Carrion crows however lack adaptations against brood parasitism (Soler et al. 1999b, 2002) suggesting that the costs of parasitism are very reduced or even balanced with the benefits. I explored the possible existence of benefits for the crows derived from the presence of a parasitic chick in the nest in terms of defence against nest predators. This chapter is based on both observational and experimental data to test this hypothesis, and reports on: a) Analyses of a 16-year data set to study the effect of presence of a parasitic chick on crow reproductive success. b) Experimental transfer of cuckoo hatchlings into synchronous non-parasitized nests, in order to experimentally test for a causal link between the presence of a parasitic chick and decreased nest failure. c) Analyses of the potential defensive function of malodorous cloacal secretions that cuckoo hatchlings produce when disturbed, through repellency tests on model species belonging to the three groups of crow nest predators. d) Chemical analyses of the components of the secretions to identify the possible existence of known caustic and repulsive compounds that may deter predators. 
Chapter 4: The high begging intensity of great-spotted cuckoo nestlings favours crow nest-mates

Success in the competition for food at the nest is a key factor in order to achieve fledging for non-evicting parasitic chicks. Great spotted cuckoo nestlings are raised alongside host young and they are able to starve to death magpie chicks by monopolizing the food. However, they seem unable to outcompete bigger crow chicks, which are often raised successfully together with the cuckoo (Soler et al. 2002; Canestrari et al. 2009).

In order to investigate parasite-host interactions in the nests of carrion crows, I used video-recordings at the nest of carrion crows to test: a) whether cuckoo chicks beg more than host chicks. b) whether cuckoo's begging affects adult provisioning behaviour. c) whether the presence of a cuckoo chick alters crow's begging behaviour and/or adults' provisioning rates.

Chapter 5: Nest sanitation in cooperatively breeding carrion crows

Birds are exposed to infections of other parasites too. Parasitic infections may affect host fitness, by directly affecting host reproduction capability and survival, and/or by decreasing the survival of their descendents. The risk of parasite transmission in nests of cooperative breeding birds may be particularly high, due to the presence of multiple carers. Therefore, nest sanitation should be an important task to carry out that may require specialization by some group members. Besides, eliminating parasitic organisms and other harmful substances and items present in the nest structure and in the chicks' feces is thought to be a 
precursor of rejection of parasitic eggs of brood parasite hosts (Guigueno \& Sealy 2012).

I used video-recordings at the nest of carrion crows to describe and measure sanitation behaviours to: a) analyze the factors that influence individual contribution to each particular task. b) investigate whether labour is divided within the group and whether individuals specialize in any particular task by combining data on sanitation and chick provisioning. c) test whether nest sanitation is a flexible response to current environmental conditions and whether there is trade off with other activities. 


\title{
CHAPTER 2:
}

\section{Mating system of the great spotted cuckoo, a comparative study}

\begin{abstract}
Studies on mating systems based only on behavioural observations are often inconclusive without genetic verification, particularly in obligated avian brood parasites, where lack of parental care hinders the identification of the putative parents of nestlings. In addition, brood parasites can exhibit a large variability of the mating system both in space and time that single population and/or short term studies cannot grasp. We developed new microsatellite markers and carried out genetic analyses to compare the genetic mating pattern of the great spotted cuckoo Clamator glandarius in two populations located in the North and South of Spain. Parentage analyses showed high levels of polygamy in both studied populations, contrary to previous results that reported on prevalence of monogamy in the southern population. We suggest that the differences were caused by the increase in population density, which increases the probability of intraspecific encounters and therefore the opportunities for mating. We also found that a greater number of mates increased the number of offspring produced in males as well as in females, for which multiple mating may enhance egg fertilization along the lengthy laying period. Our data, combined with previous reports, uncover the behavioural plasticity on great spotted cuckoo's mating system that may be associated to large fluctuations in population density.
\end{abstract}


Chapter 2 - Mating system of the great spotted cuckoo

\section{INTRODUCTION}

The mating system of a species is defined by both social and genetic patterns. In birds, behavioural observations are usually suitable to investigate the former, but DNA parentage analyses are often needed to shed light on the latter. Indeed, genetic techniques have often revealed that social monogamy can be accompanied with high levels of genetic polygamy, as a consequence of extra-pair copulations that are virtually impossible to be observed in the field (e.g. Westneat 1987a, 1987b).

A special challenging case is the mating systems of obligated avian brood parasites, which lay their eggs in the nests of other species and have their offspring raised by foster parents. Due to the parasitic strategy, the association between male and female for nest building, egg incubation and care of the chicks is no longer needed, hindering the identification of reproductive bonds by field observations. The reduction of the benefits of stable pair-bonds also allows more opportunities for extra pair copulations that may increase the levels of polygamy (Emlen \& Oring 1977; Yokel 1986; Hauber \& Dearborn 2003). Furthermore, the lack of parental care favours a larger temporal and geographic plasticity of the mating systems to adapt to variations of socio-ecological factors, such as host species composition and population density of both hosts and parasite (Hauber \& Dearborn 2003). As a result, field observations on brood parasites, unlike parental species, typically provide little information on the putative parents of any particular nestling. Genetic information is also difficult to collect, because each parent may have its offspring spread over large areas. 
Due to these limitations, understanding brood parasites' mating systems remains elusive. Results of studies based on behavioural observations in some species such as the Diedrick cuckoo (Chrysococcyx caprius: Payne 1973), the orange-rumped honeyguide (Indicator xanthonotus: Cronin \& Sherman 1977) and the pin-tailed whydah (Vidua macroura: Barnard \& Markus 1989) are inconclusive without molecular verification. The use of genetic techniques, instead, may uncover complex patterns within the same species. For example, in the common cuckoo (Cuculus canorus) Jones et al. (1997) found almost total genetic monogamy in populations of England and Japan, whereas Marchetti et al. (1998) described genetic polygamy to occur in $47 \%$ of males and $17 \%$ of females in the Japanese population. Studies on brown headed cowbirds (Molothrus ater) showed different results in the same study area depending on the duration of the sampling period. A one-year study (Alderson et al. 1999a) showed almost exclusively genetic monogamy (only 2 out of 11 males were polygamous), whereas a six-year study (Woolfenden et al. 2002) reported on extensive polygamy (on average, 58\% of males and $31 \%$ of females produced offspring with more than one individual). The difference has been attributed to behavioural plasticity of this brood parasite in response to variations in population density (Woolfenden et al. 2002). Alderson et al. (1999b) combined behavioural and genetic data on cowbirds, suggesting an equivalence between social and genetic mating system. However, they also observed sexual interactions between adults that did not reproduce together, showing the difficulty to accurately describe the mating system in this species, even within the same population. Horsfield's bronze cuckoo genetic mating system was found to be monogamous, or sequentially monogamous in the case of males 
(Langmore et al. 2007), in contrast with theoretical assumptions of increased polygamy in brood parasites. This strict monogamy was caused by the defence of breeding ranges by the females that reduced the opportunity for extra pair mating as predicted by Emlen \& Oring (1977). The great spotted cuckoo (Clamator glandarius), however, also presented a relatively low level of genetic polygamy (around 30\%), despite female breeding ranges largely overlap (Martínez et al. 1998a).

Apparently, the variability of results and the divergence from theoretical predictions are caused by several social and environmental conditions that influence the mating decisions of brood parasites and by their remarkable behavioural flexibility (see Hauber \& Dearborn 2003 for a detailed review of the expected differences in the mating systems between obligate brood parasites and parental species). This characteristic makes difficult to understand the mating system of a given species with single population studies (Strausberger et al. 2003) and/or short term studies (Woolfenden et al. 2002). This study focus on the great spotted cuckoo, which has been previously described as a highly monogamous species (Martínez et al. 1998a). We provide a broader view of its mating system by carrying out a genetic comparison between two populations located in the North and South of Spain. The great spotted cuckoo is specialized in parasitizing corvid species. The main hosts are the magpie Pica pica and the carrion crow Corvus corone in the southern and northern populations respectively (Soler et al. 2002, Canestrari et al. 2009, Roldán et al. 2013). We developed new microsatellite markers and carried out genetic analyses of adults and chicks, and compared the results with previous findings on the southern population (Martínez et al. 1998b). 
Chapter 2 - Mating system of the great spotted cuckoo

\section{MATERIAL AND METHODS}

\section{Study sites}

The study has been carried out in two rural areas of Spain: Guadix, in the South $\left(37^{\circ} 18^{\prime} \mathrm{N}, 3^{\circ} 11^{\prime} \mathrm{W}, 35 \mathrm{~km}^{2}\right)$ and La Sobarriba, León, in the North (42 $37^{\prime} \mathrm{N}$, $5^{\circ} 26^{\prime} \mathrm{W}, 45 \mathrm{~km}$, “León” hereafter). Guadix is a plateau of cereal crops with sparse vegetation that includes plantations of almond trees Prunus dulcis and holm oak Quercus ilex patches and uncultivated land. León is characterized by a mosaic of crops, meadows, poplar Populus nigra and pine Pinus spp plantations, scrubs, oak Quercus pyrenaica and holm oak Quercus ilex patches, and uncultivated land. In both sites there are stable and overlapping populations of the two main host species of great spotted cuckoos: magpies and carrion crows.

\section{Host species}

Magpies breed in pairs, build large nests (around $40 \mathrm{~cm}$ of diameter), mainly in holm oak and almond trees in Guadix (Soler et al. 2002; Roldán et al. 2013) and in scrubs, brambles and thorny bushes in León, and may re-nest once after a breeding failure (Birkhead 1991). Crows breed cooperatively in $75 \%$ of the territories in León (Baglione et al. 2002a), and in the 66.7\% in Guadix (Roldán et al. 2013). For details on helping behavior of the crows see Baglione et al. 2002b, 2006 and Canestrari et al. 2005, 2008a, 2008b. Crows build their nests in the upper third of trees (mostly pines, poplars and oaks in León, and holm oaks and almond trees 
in Guadix). Upon nest failure at early stage, crow may re-nest up to 2 times in León (Canestrari et al. 2008b) whereas they rarely do so in Guadix (Roldán et al. 2013).

\section{Field data collection}

We surveyed all carrion crow and magpie nests from March until the end of the breeding season in 2009 in Guadix and in 2009-2010 in León. Hereafter we will refer to the studied populations as Guadix09, León09 and León10. Each nest was visited every 3-4 days to record laying date of the first host egg, laying date of the first cuckoo egg, hatching success of both host and parasite and number of chicks fledged. When cuckoo chicks were 4 days old we obtained a small sample of blood (50-100 $\mu \mathrm{l})$ from their brachial vein.

We captured cuckoo adults at both sites with mist nets and playback calls in cuckoo feeding areas (pine plantations). Each individual was marked with numbered metallic rings, measured and bled $(\sim 100-200 \mu$ l of blood from the brachial vein).

\section{Molecular analyses}

We used an ammonium acetate precipitation method (Nicholls et al. 2000) to extract DNA from the blood samples. We amplified 6 microsatellite markers (Cgl1, Cgl2, Cgl3, Cgl4, Cgl5 and Cgl6) previously published (Martínez et al. 1998b) and five new loci specifically developed for this study (Cgln2, Cgln7, Cgln9, Cgln10 and Cgln14) (Table 1). The new markers were characterized from a genomic 
library produced by GenoScreen, Lille, France (www.genoscreen.fr). One $\mu g$ of genomic DNA was used for the development of microsatellites libraries through 454 GS-FLX Titanium pyrosequencing of enriched DNA libraries as described in Malausa et al. (2011). Briefly, total DNA was mechanically fragmented and enriched for AG, AC, AAC, AAG, AGG, ACG, ACAT and ATCT repeat motifs. Enriched fragments were subsequently amplified. PCR products were purified, quantified and GsFLX libraries were then carried out following manufacturer's protocols and sequenced on a GsFLX PTP. QDD software was used to design primers. We tested 20 primers pairs for polymorphism using 8 unrelated individuals; those that were found to have three or more alleles were used in parentage analyses.

Table 2.1. New microsatellite loci isolated from great spotted cuckoo (Clamator glandarius)

\begin{tabular}{|c|l|l|l|}
\hline Locus & Size & Repeat motif & Primer sequences \\
\hline \hline Cgln2 & $158-208$ & ${\text { (TTGTG })_{18}}$ & $\begin{array}{l}\text { Forward: CAAAGTGATCATTACTGCCTTG } \\
\text { Reverse: ACCTTCCTCAAACTGCTGGA }\end{array}$ \\
\hline Cgln7 & $182-210$ & $(\text { ATCC })_{12}$ & $\begin{array}{l}\text { Forward: CACTAGGAGAATTTGAAAGGCA } \\
\text { Reverse: } \text { TCTCAGAGAAGCAGAACCTCG }\end{array}$ \\
\hline Cgln9 & $136-188$ & $(\text { CTAT })_{20}$ & $\begin{array}{l}\text { Forward: AATGACCTTAAGTGTACTGGAAAGC } \\
\text { Reverse: TGAAAAGCAAAATGACCTTCA }\end{array}$ \\
\hline $\operatorname{Cgln} 10$ & $134-182$ & $(\text { TGGA })_{12}$ & $\begin{array}{l}\text { Forward: CATCTCGGGTCACTCCCA } \\
\text { Reverse: AAAGAAGACTACCTAGCAAGCCC }\end{array}$ \\
\hline
\end{tabular}


Amplification of all markers was carried out using $20 \mu \mathrm{L}$ reactions

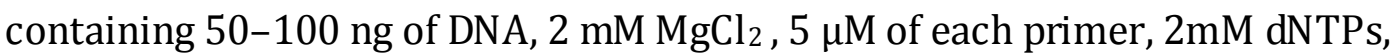
$0.05 \mu \mathrm{L}$ Taq polymerase and 10x manufacturer`s reaction buffer. PCR profile of the new markers was: 1 cycle of $94^{\circ} \mathrm{C}$ for $120 \mathrm{~s}$, then 30 cycles of $94^{\circ} \mathrm{C}$ for $30 \mathrm{~s}, 60{ }^{\circ} \mathrm{C}$ (annealing) for $30 \mathrm{~s}$ and $73{ }^{\circ} \mathrm{C}$ for $30 \mathrm{~s}$, and finishing with 1 cycle of $72^{\circ} \mathrm{C}$ for $120 \mathrm{~s}$. All samples were genotyped with an ABI 3130 sequencer and the size of alleles scored with Genescan software (Applied Biosystems).

CERVUS 3.0 (Kalinowski et al. 2007) was used to calculate observed and expected heterozygosities, polymorphic information content (PIC) and combined non-exclusion probabilities for the first and the second parent (Table 2) from the samples of some of the adults, presumably unrelated, captured in each population (42 in Guadix09, 25 males/17 females; 9 in León09, 6 males/3 females; and 13 in León10, 8 males/5 females). We tested deviation from Hardy-Weinberg equilibrium (HWE), and estimated the frequency of null alleles using Genepop 4.2 (Rousset 2008). Sexing of adults was carried out by using the P2/P8 (Griffiths et al. 1998) and 3007F/3112R (Fridolfsson \& Ellegren 1999) sex linked markers.

\section{Parentage analyses}

We used COLONY v2 (Jones \& Wang 2010) to assess relatedness between dyads of chicks (full siblings, half siblings or unrelated) and to establish paternal and maternal assignments. COLONY considers the full pedigree structure and applies a maximum-likelihood procedure to assign parentage and sibship relationships and to reconstruct genotypes of unsampled parents. We confirmed 
the consistency of the results by performing eight replicate runs, with a different random number seed, for each population (León09, León10 and Guadix09). The remaining parameters were kept constant in all runs, i.e. medium run length, full likelihood estimation with medium precision. We allowed male and female polygamy because previous studies showed some degree of polygamy in this species (Martínez et al. 1998a, 1998b). Genotyping error was set on 0.05 based on previous results. Markers Cgln2 and Cgln9 showed deviation from HardyWeinberg equilibrium due to high frequency of null alleles (Table 2); we corrected this by setting a dropout rate equivalent to null alleles frequency, as recommended by the author of COLONY (Wang, pers. com.).

To compile the results, only those assignments of parentage or sibhip with $p$ values $\geq 0.95$ that were present in at least 5 of the 8 runs were used. We first assigned offspring to the candidate males and females (i.e. adults captured), and then, according to these results, we used sibship relationships to form full and half sibling groups. 
Table 2.2. Details of all microsatellites used: number of alleles $\left(\mathrm{N}_{A}\right)$, observed $\left(\mathrm{H}_{0}\right)$ and expected $\left(\mathrm{H}_{\mathrm{E}}\right)$ heterozigosities, probability values for Hardy-Weinberg equilibrium test ( $\mathrm{P}_{\mathrm{HW}}$, values in bold indicate locus out of the HW equilibrium, after applying Bonferroni correction, and their null alleles estimated frequencies are in brackets), mean polymorphic information content (Mean PIC), and combined nonexclusion probabilities for the first (Non-Exc $1^{\text {st }}$ ) and the second (Non-Exc $2^{\text {nd }}$ ) parent, for each population.

\begin{tabular}{|c|c|c|c|c|c|c|c|c|c|c|}
\hline & & \multicolumn{3}{|c|}{ León09 } & \multicolumn{3}{c|}{ León10 } & \multicolumn{3}{c|}{ Guadix09 } \\
\hline & $\mathrm{N}_{\mathrm{A}}$ & $\mathrm{H}_{\mathrm{O}}$ & $\mathrm{H}_{\mathrm{E}}$ & $\mathrm{P}_{\mathrm{HW}}$ & $\mathrm{H}_{\mathrm{O}}$ & $\mathrm{H}_{\mathrm{E}}$ & $\mathrm{P}_{\mathrm{HW}}$ & $\mathrm{H}_{\mathrm{O}}$ & $\mathrm{H}_{\mathrm{E}}$ & $\mathrm{P}_{\mathrm{HW}}$ \\
\hline \hline Cgl1 & 7 & - & 0.53 & - & - & - & - & 0.64 & 0.63 & 0.279 \\
\hline Cgl2 & 6 & 0.22 & 0.66 & 0.012 & 0.75 & 0.71 & 0.148 & 0.64 & 0.72 & 0.320 \\
\hline Cgl3 & 13 & 1.00 & 0.83 & 1.00 & 0.77 & 0.83 & 0.719 & 0.74 & 0.80 & 0.855 \\
\hline Cgl4 & 17 & 0.88 & 0.85 & 0.962 & 0.92 & 0.86 & 0.901 & 0.88 & 0.80 & 0.813 \\
\hline Cgl5 & 5 & 0.38 & 0.43 & 0.384 & 0.46 & 0.49 & 0.526 & 0.48 & 0.44 & 1.00 \\
\hline Cgl6 & 4 & 0.25 & 0.23 & 1.00 & 0.23 & 0.21 & 1.00 & 0.52 & 0.49 & 0.165 \\
\hline Cgln2 & 9 & 0.63 & 0.89 & 0.136 & 0.77 & 0.78 & 0.562 & 0.59 & 0.79 & $\mathbf{0 . 0 0 2}$ \\
& & & & & & & & & & $(0.116)$ \\
\hline Cgln7 & 7 & 0.63 & 0.73 & 0.583 & 0.58 & 0.68 & 0.297 & 0.76 & 0.75 & 0.765 \\
\hline Cgln9 & 14 & 0.63 & 0.79 & 0.299 & 0.39 & 0.72 & 0.009 & 0.49 & 0.84 & $<0.001$ \\
\hline Mean PIC & & & & & & & & & & $0.187)$ \\
\hline Cgln10 & 8 & 0.75 & 0.73 & 1.00 & 0.92 & 0.79 & 0.979 & 0.74 & 0.76 & 0.199 \\
\hline Ngln14 & 17 & 1.00 & 0.90 & 0.842 & 1.00 & 0.92 & 0.899 & 0.90 & 0.86 & 0.975 \\
\hline Non-Exc 15t & & 0.024 & & & 0.015 & & & 0.009 \\
\hline
\end{tabular}




\section{RESULTS}

We surveyed a total of 133, 95 and 33 host nests in León09, León10 and Guadix09, respectively. The carrion crow was the main host in León (two-tailed Fisher's exact test León09 p<0.0001, León10 p<0.0001, Table 3), whereas in Guadix parasitism rates were similar for both hosts (two-tailed Fisher's exact test $p=0.601$, Table 3$)$. The average $( \pm S E)$ number of cuckoo eggs per nest was highest in Guadix09 both in crow nests (Kruskal-Wallis $\mathrm{H}=9.41, \mathrm{df}=2, \mathrm{p}=0.009$; Table 3) as well as in magpie nest, though in the latter we did not find a significant difference among populations probably because of small sample of parasitized nests in the northern populations (Kruskal-Wallis $\mathrm{H}=3.52, \mathrm{df}=2, \mathrm{p}=0.172$; Table 3).

\section{Molecular analyses}

We genotyped a total of 137 chicks (see Table 3 for details) and 64 adults (mean number of loci amplified per individual $=9.20$, range 7-11). Mean allelic richness per locus was 9.73 (range 4 - 17). Average \pm SE expected and observed heterozygosities for all loci and populations were $0.70 \pm 0.03$ and $0.66 \pm 0.04$ respectively, PIC was around 0.6 , non-exclusion probability for the first parent was $<0.025$ and for the second parent $<0.0015$ (see Table 2 for specific values for each population). 
Table 2.3. Sample sizes in the three populations.

\begin{tabular}{|l|c|c|c|c|c|c|}
\hline & \multicolumn{2}{|c|}{ León09 } & \multicolumn{2}{c|}{ León10 } & \multicolumn{2}{c|}{ Guadix09 } \\
\hline & Crow & Magpie & Crow & Magpie & Crow & Magpie \\
\hline \hline Surveyed nests & 70 & 63 & 61 & 50 & 17 & 16 \\
\hline Parasitism level & $65.7 \%$ & $15.9 \%$ & $70.5 \%$ & $18 \%$ & $94.1 \%$ & $87.5 \%$ \\
\hline $\begin{array}{l}\text { Number of cuckoo eggs per nest } \\
\text { (max number at the same nest) }\end{array}$ & $2.08 \pm 0.19$ & $1.30 \pm 0.15$ & $1.72 \pm 0.19$ & $1.67 \pm 0.24$ & $3.50 \pm 0.59$ & $3.57 \pm 0.96$ \\
$(6)$ & $(2)$ & $(8)$ & $(3)$ & $(8)$ & $(10)$ \\
\hline Number of chicks sampled & 49 & 12 & 18 & 10 & 16 & 32 \\
\hline $\begin{array}{l}\text { Max number of chicks per nest } \\
\text { belonging to same female }\end{array}$ & 4 & 2 & 1 & 2 & 2 & 2 \\
\hline $\begin{array}{l}\text { Max number of females laying } \\
\text { in the same nest }\end{array}$ & 3 & 1 & 2 & 2 & 2 & 6 \\
\hline $\begin{array}{l}\text { Percentage of chicks sharing } \\
\text { nest with offspring of other } \\
\text { female }\end{array}$ & $69.4 \%$ & $0 \%$ & $50 \%$ & $40 \%$ & $63.6 \%$ & $73.3 \%$ \\
\hline
\end{tabular}

\section{Families reconstruction and host use}

We identified a total of 20 full sibling groups: 6 in Guadix09, 9 in León09 and 5 in León10. Thirteen groups comprised siblings raised by the same host species (10 groups by crows and three by magpies). The remaining seven groups had siblings raised by different hosts (mixed groups hereafter), showing that the same female parasitized both crows and magpies (Table 4). Among half sibling groups across populations, the percentage of mixed groups varied between 25 and 88.9\% ( $\mathrm{n}=59$, Table 4). Multiparasitized nests were found at both study sites and in both hosts. We found the same female could lay up to 4 eggs in the same nest and that up to 6 different females laid eggs in the same nest (Table 3). However, note that we could not assign parentage to unhatched eggs and that therefore the levels of multiparasitism could have been slightly underestimated. The longest 
laying period found of a cuckoo female was 37 days in Guadix09, 45 days in León09 and 42 days in León10.

We delimited the breeding areas of those individuals that laid eggs in three or more nests, and measured their overlap, by using 100\% minimum convex polygons (MCP). The average percentage of overlap \pm SE for females was $26.5 \pm$ 17.4\% $(n=5)$ in Guadix09, $30.9 \pm 18.2 \%(n=5)$ in León09 and 9.7 $\pm 5.1 \%(n=3)$ in León10. These values represent minimum estimates, because they are based only on a fraction of the total number of breeders identified in the parentage analysis (for females, 22.7\%, 19\% and 19.1\%, for Guadix09, León09 and León10 respectively, Table 5). The average percentage \pm SE of overlap among breeding ranges of males was $36.5 \pm 19.8 \%(n=3)$ in Guadix $09,45.3 \pm 15.7 \%(n=7)$ in León09 and $4.53 \pm 1.51 \%(n=2)$ in León10 (Table5). 
Table 2.4. Full sibling and half sibling groups composition: mean $n$. individuals $=$ mean e number of siblings that form a group $\pm \mathrm{SE}$ (range in brackets); Crow groups $=$ number of groups whose members were found only in crow; Magpie groups = number of groups whose members were found only in magpie nests: Mixed groups $=$ number of groups whose members were found in nests of the two host species (percentage of the total number of groups in brackets).

\begin{tabular}{|l|c|c|c|c|c|c|c|c|c|}
\hline & \multicolumn{3}{|c|}{ Full sibling groups } & \multicolumn{2}{c|}{ Maternal half sibling groups } & \multicolumn{2}{c|}{ Paternal half sibling groups } \\
\hline & León09 & León10 & Guadix09 & León09 & León10 & Guadix09 & León09 & León10 & Guadix09 \\
\hline \hline $\begin{array}{l}\text { Mean n. } \\
\text { individuals } \\
\text { (range) }\end{array}$ & $\begin{array}{c}3.44 \pm 0.31 \\
(2-8)\end{array}$ & $\begin{array}{c}2.00 \pm 0.00 \\
(2)\end{array}$ & $\begin{array}{c}3.00 \pm 0.24 \\
(2-6)\end{array}$ & $\begin{array}{c}4.09 \pm 0.36 \\
(2-9)\end{array}$ & $\begin{array}{c}2.50 \pm 0.12 \\
(2-4)\end{array}$ & $\begin{array}{c}3.89 \pm 0.28 \\
(2-8)\end{array}$ & $\begin{array}{c}4.50 \pm 0.36 \\
(2-10)\end{array}$ & $\begin{array}{c}2.86 \pm 0.14 \\
(2-4)\end{array}$ & $\begin{array}{c}3.08 \pm 0.25 \\
(2-7)\end{array}$ \\
\hline Crow groups & 7 & 2 & 1 & 7 & 2 & 0 & 6 & 3 & 1 \\
\hline $\begin{array}{l}\text { Magpie } \\
\text { groups }\end{array}$ & 1 & 1 & 1 & 2 & 1 & 1 & 0 & 1 & 5 \\
\hline $\begin{array}{l}\text { Mixed } \\
\text { groups } \\
\text { (percentage) }\end{array}$ & $11.1 \%)$ & $\begin{array}{c}2 \\
(40 \%)\end{array}$ & $(66.7 \%)$ & $\begin{array}{c}3 \\
(25 \%)\end{array}$ & $\begin{array}{c}5 \\
(62.5 \%)\end{array}$ & $\begin{array}{c}(88.9 \%) \\
(40 \%)\end{array}$ & $\begin{array}{c}3 \\
(42.9 \%)\end{array}$ & $\begin{array}{c}7 \\
(53.8 \%)\end{array}$ \\
\hline
\end{tabular}

\section{Mating system}

We inferred the number of adults breeding in the study area from the parentage analyses (Table 5). Of these, 2 males and 2 females from Guadix09, 6 males and 2 females from León09, and 5 males and 1 female from León10 had been actually captured and genotyped. The average number of offspring per adult \pm SE was $2.19 \pm 0.26$ at Guadix09, 2.22 \pm 0.31 at León09 and $1.80 \pm 0.16$ at León10. There was a moderate degree of promiscuity in the three populations as both sexes had multiple mates (average number of mates \pm SE: $1.67 \pm 0.14$ at Guadix09, 
1.42 \pm 0.12 at León09 and 1.48 \pm 0.11 at León10, Table 5). We found no significant difference between the sexes in the average number of mates (two tailed t-test $=$ 0.28, $\mathrm{df}=41, \mathrm{p}=0.78$ at Guadix09; $\mathrm{t}=0.23, \mathrm{df}=53, \mathrm{p}=0.82$ at León09 and $\mathrm{t}=0.36$, $\mathrm{df}=29, \mathrm{p}=0.72$ at León10), the number of offspring assigned (two tailed t-test = 0.02, $\mathrm{df}=41, \mathrm{p}=0.99$ at Guadix09; $\mathrm{t}=0.09, \mathrm{df}=53, \mathrm{p}=0.93$ at León09 and $\mathrm{t}=0.32$, $\mathrm{df}=29, \mathrm{p}=0.75$ at León10), the number of offspring per mate (two tailed t-test = 0.17, $\mathrm{df}=41, \mathrm{p}=0.86$ at Guadix09; $\mathrm{t}=0.43, \mathrm{df}=53, \mathrm{p}=0.67$ at León09 and $\mathrm{t}=0.59$, $\mathrm{df}=29, \mathrm{p}=0.56$ at León10) and the percentage of monogamous individuals (twotailed Fisher test , $\mathrm{p}=1.0$ at Leon09, $\mathrm{p}=0.57$ at Leon10 and $\mathrm{p}=1$ at Guadix09; Table 5). The percentage of monogamous individuals of both sexes in the northern populations (28.6 \% in León09 and 26.7 \% in León10) doubled that of Guadix09 $(13.6 \%)$, although the difference did not reach statistical significance probably due to low sample size (after pooling León09 and León10, Fisher Exact Test p = 0.2).

Table 2.5. Breeding success and mating characteristics of the adults inferred from the genetic analyses. $\mathrm{N}=$ number of individuals inferred; mean $\mathrm{n}$ offspring = average $\pm \mathrm{SE}$ number of offspring per adult (range), mean $n$ mates $=$ average \pm SE number of mates per adult (range); mean $\mathrm{n}$. offs/mate $=$ average number \pm SE of offspring per mate; $\%$ monogamy $=$ percentage of individuals with two or more offspring that mated only with one partner (sample size in brackets).

\begin{tabular}{|l|c|c|c|c|c|c|}
\hline & \multicolumn{2}{|c|}{ León09 } & \multicolumn{2}{c|}{ León10 } & \multicolumn{2}{c|}{ Guadix09 } \\
\hline & Males & Females & Males & Females & Males & Females \\
\hline \hline $\mathrm{N}$ & 28 & 27 & 15 & 16 & 21 & 22 \\
\hline $\mathrm{N}$ offs (range) & $\begin{array}{c}2.18 \pm 0.37 \\
(1-8)\end{array}$ & $\begin{array}{c}2.26 \pm 0.41 \\
(1-9)\end{array}$ & $\begin{array}{c}1.87 \pm 0.29 \\
(1-4)\end{array}$ & $\begin{array}{c}1.75 \pm 0.23 \\
(1-4)\end{array}$ & $\begin{array}{c}2.19 \pm 0.34 \\
(1-7)\end{array}$ & $\begin{array}{c}2.18 \pm 0.39 \\
(1-8)\end{array}$ \\
\hline $\begin{array}{l}\mathrm{N} \text { mates } \\
\text { (range) }\end{array}$ & $\begin{array}{c}1.39 \pm 0.15 \\
(1-4)\end{array}$ & $\begin{array}{c}1.44 \pm 0.16 \\
(1-4)\end{array}$ & $\begin{array}{c}1.53 \pm 0.19 \\
(1-3)\end{array}$ & $\begin{array}{c}1.44 \pm 0.18 \\
(1-3)\end{array}$ & $\begin{array}{c}1.71 \pm 0.17 \\
(1-3)\end{array}$ & $\begin{array}{c}1.64 \pm 0.21 \\
(1-4)\end{array}$ \\
\hline N offs/mate & $1.57 \pm 0.22$ & $1.46 \pm 0.14$ & $1.19 \pm 0.06$ & $1.24 \pm 0.06$ & $1.27 \pm 0.09$ & $1.25 \pm 0.07$ \\
\hline \% monogamy & $30 \%(10)$ & $27.2 \%(11)$ & $14.3 \%(7)$ & $37.5 \%(8)$ & $15.4 \%(13)$ & $11.1 \%(9)$ \\
\hline
\end{tabular}


The number of offspring per adult increased with the number of mates, in all populations, showing positive Bateman's gradients for both sexes (males at Guadix09: $\mathrm{F}=12.41, \mathrm{df}=1,19, \mathrm{p}=$ 0.002; females at Guadix09: $\mathrm{F}=38.51, \mathrm{df}=1,20$, $\mathrm{p}<0.001$; males at Leon09: $\mathrm{F}=11.77, \mathrm{df}=1,26, \mathrm{p}=0.002$; females at Leon09: $\mathrm{F}=$ 19.34, $\mathrm{df}=1,25, \mathrm{p}<0.001 ;$ males at Leon10: $\mathrm{F}=36.80, \mathrm{df}=1,13, \mathrm{p}<0.001 ;$ females at Leon10: $\mathrm{F}=40.26, \mathrm{df}=1,14, \mathrm{p}<0.001$; Figure 1), without significant differences between sexes $(\mathrm{t}$-value $=0.16, \mathrm{df}=39, \mathrm{p}=0.88$ at Guadix09; $\mathrm{t}=0.12, \mathrm{df}=51, \mathrm{p}=$ 0.91 at León09 and t = 0.26, df = 27, p = 0.80 at León10 J.We found 2 females and 1 male in Guadix09 and León09, and 1 female in León10 that alternated matings with two different mates, suggesting promiscuity rather than sequential monogamy. 
Figure 2.1. Bateman's gradients of each population (a Guadix09, b León09, c León10): annual reproductive success (number of offspring) as a function of mating success (number of genetic mates with which at least one offspring was obtained). Lineal tendency solid lines correspond to males and dotted lines to females.
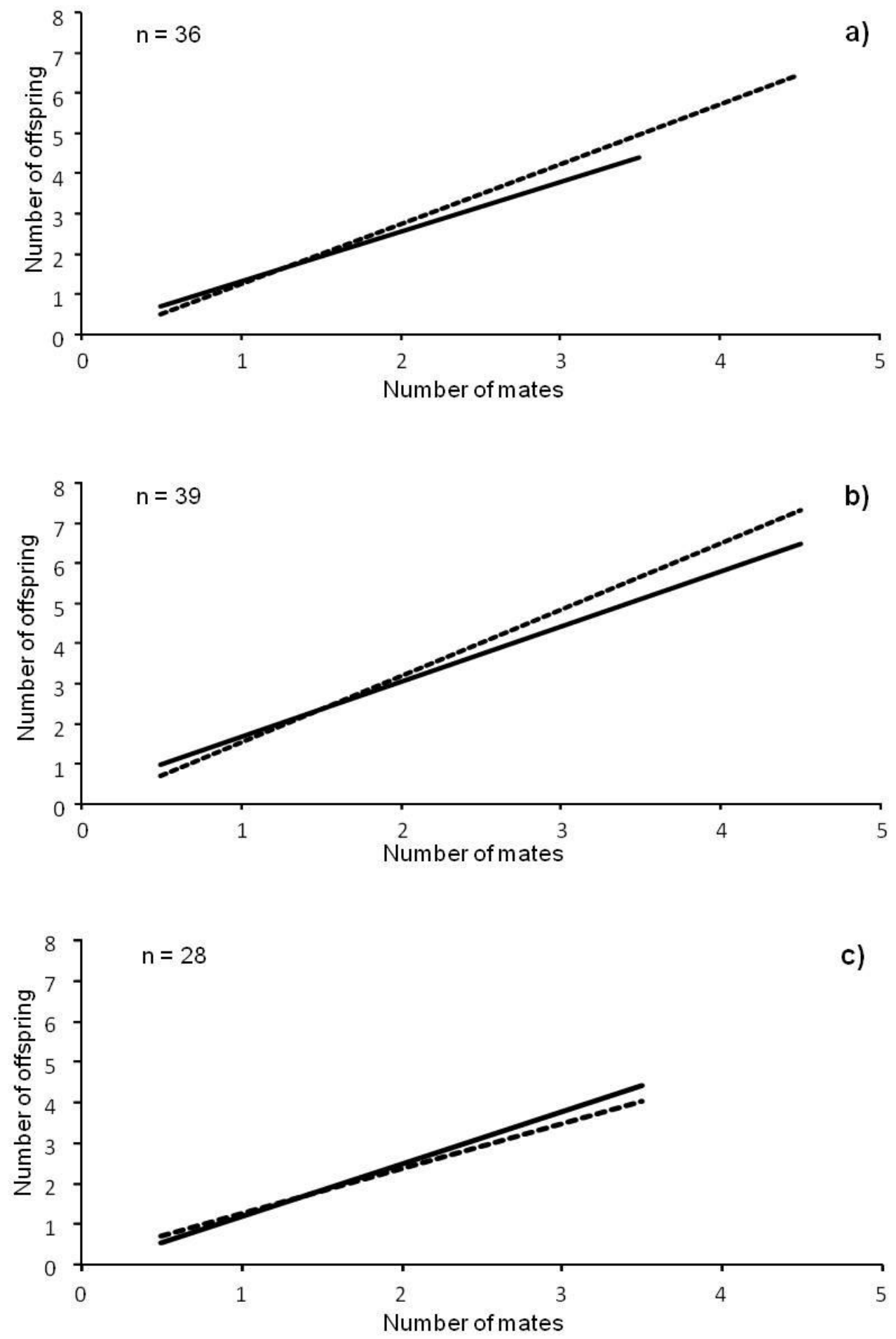
Chapter 2 - Mating system of the great spotted cuckoo

\section{DISCUSSION}

The parentage analyses showed that the genetic mating system of the great spotted cuckoo was mostly polygamous. This result differs from Martínez et al. (1998b) who had previously reported on $70 \%$ of individuals being genetically monogamous at the Guadix study site. The levels of monogamy found in the present study were much lower, especially at Guadix09 (13.6\%). We suggest that these differences were caused by variations in great spotted cuckoo population density. The probability of intraspecific encounters increases at higher densities, enhancing the opportunities for mating and hence the level of polygamy. Proxies of cuckoo population density like the proportion of parasitized nests and the average number of eggs laid per nest indicate a sharp increase of cuckoos at Guadix from Martínez et al. (1998b) to the present study (51\% of parasitism and 2.28 eggs/nest vs $87.5 \%$ of parasitism and 3.57 eggs/nest, respectively in magpie nests). Data on parasitism in crows also confirm a dramatic increase of cuckoos during the last two years in the same area (proportion of parasitized nests in $2007=11 \%, 2008=$ 54\% (Roldán et al. 2013), and $2009=94.1 \%$, this study). The comparison between northern (León09 and León10) and southern (Guadix09) populations (this study) also fits the denso-dependent scenario, with larger proportions of monogamous individuals in the less dense cuckoo populations. However, this results needs to be taken with caution because the difference did not reached the statistical threshold, probably because of small sample size. It should be noted that our results on the genetic mating system do not rule out social monogamy in the great spotted cuckoo. Indeed, preliminary results on radio-tracked individuals (Bolopo unpublished) show that cuckoos may maintain seemingly social pair bonds 
throughout the breeding season. Therefore, the coexistence of polygamous genetic mating and social monogamy is a possibility that needs to be explored in future research.

Because of lack of parental care, brood parasites may change mating partners during the breeding season without negative consequences on their reproductive success (Hauber \& Dearborn 2003). Bateman's gradients in the great spotted cuckoo showed that increasing the number of mates enhanced the number of offspring produced, not only for males, but, surprisingly, also for females. Multiple mating in males allows fertilization of more eggs and it is therefore a suitable strategy for increasing fitness. Conversely, the causes of this positive Bateman's gradient in females are less clear. The most plausible benefit of polyandry for female great spotted cuckoo is ensuring egg fertilization. As cuckoo females lay eggs for a longer period than nesting species, they may need to mate with several males to ensure continuous fertilization. Also, multiple mating may prevent a fitness loss due to encounters with partially or totally infertile males and may allow females to keep searching, throughout the entire breeding season, for the most compatible genetic matches to copulate with. Resources provided by the males, like food or host nests, are to be excluded, because territorialism seems to be absent in this species. Indeed, extensive overlap among breeding areas was reported by Martínez et al. (1998a) and confirmed by our data.

Our results suggest that great spotted cuckoos are truly polygamous rather than sequentially monogamous. Indeed, we found adults that alternated fertilization with two different partners, although we do not know how long females store sperm and whether they use the sperm of different mates 
consecutively. Sequential monogamy in Horsfield's bronze cuckoo males (Langmore et al. 2007) is accompanied by non-overlapping breeding ranges of the females and by late-arrival females replacing early-arrival ones, allowing males to mate sequentially with females of both groups. In the great spotted cuckoo, conversely, a large overlap of breeding ranges in both sexes and a likely synchronous arrival of adults favours polygamy rather than sequential monogamy, at least during years and/or in populations of high cuckoo density.

In this study, we found no evidence of specialization of great spotted cuckoo females on different host species. Indeed, full siblings could be raised in nests of both magpies and crows, suggesting absence of the so called "gentes" that have been reported in other brood parasites (Gibbs et al. 2000; Mahler et al. 2009). A flexible use of host species makes sense in the great spotted cuckoo, whose suitable hosts are corvid species that breed at relatively low densities.

In conclusion, we found that the great spotted cuckoo can be highly polygamous. Our data, combined with previous reports on its mating system suggests a behavioural plasticity that may be associated to the large fluctuations in population density that are characteristic in this brood parasite (Soler et al. 1998). Future research will need to address whether and how females benefit from increased polyandry. Nuptial gifts by males have been frequently observed just before copulation (Soler 1990) suggesting that they may encourage mating. Whether males provide other kind of goods to females (e.g. help in laying, detection and/or protection of host nests) and how they try to ensure egg fertilization need to be explored. 
Thanks to Miguel González-Vélez, Benedicto González, Gianluca Roncalli and Gloria Robles for help in the field. I am also grateful to Marta Vila for sexing adult cuckoos. This study was financially supported by Spanish Plan Nacional I+D/FEDER (research project CGL2007-61940/BOS) to MS; projects CGL200801829BOS and CGL2011-27260 to VB.

This chapter is based on the following publication, which is currently in preparation:

Bolopo, D., Canestrari, D., Martinez, J.G., Macías-Sanchez, E., Roldán, M., Soler, M., Baglione, V. Mating system of the great spotted cuckoo, a comparative study. 


\title{
CHAPTER 3:
}

\section{From parasitism to mutualism:}

unexpected interactions between a cuckoo and its host

\begin{abstract}
Avian brood parasites lay eggs in the nests of other birds, which raise the unrelated chicks and typically suffer partial or complete loss of their own brood. However, carrion crows Corvus corone corone can benefit from parasitism by the great spotted cuckoo Clamator glandarius. Parasitized nests have lower rates of predation-induced failure due to production of a repellent secretion by cuckoo chicks, but among nests that are successful, those with cuckoo chicks fledge fewer crows. The outcome of these counterbalancing effects fluctuates between parasitism and mutualism each season, depending on the intensity of predation pressure.
\end{abstract}




\section{INTRODUCTION}

Interspecific avian brood parasites generally harm their hosts in two main ways. Evicting parasites eject all other eggs and hatchlings from the nest, whereas non-evicting parasites are raised alongside host offspring but usually outcompete some or all of them for food (Spottiswoode et al. 2012). Specific defences against brood parasites, including ejection of alien eggs and mobbing of parasitic adults (Kilner \& Langmore 2011) have evolved in many but not all host species (Krüger 2011). It has been hypothesized that lack of defences may be due to relatively recent contact between the antagonistic species or to hosts refraining from exhibiting their defences when costs outweigh benefits (Spottiswoode et al. 2012). Alternatively, defences might not evolve if brood parasite-host interactions can switch to a mutualism, as suggested by Smith (1968). His results from a study on giant cowbirds (Scaphidura oryzivora), however, were never replicated (Davies 2000), and brood parasite-host systems still represent a paradigm of parasitic interactions. Here we show, in a system different from Smith's, that a brood parasite can indeed provide a benefit to its host.

The great spotted cuckoo (Clamator glandarius) is a nonevicting brood parasite specialized on corvids, mainly magpies (Pica pica) and carrion crows (Arias de Reyna 1998; Soler et al. 2002). Cuckoos strongly reduce magpie reproductive success (Arias de Reyna 1998), but apparently this does not occur in crows, whose larger offspring are often raised alongside the parasite (Soler et al. 2002; Canestrari et al. 2009). Unlike magpies, crow parents do not evict alien eggs or mob parasitic adults in proximity of the nest (Soler 1990). In our study area in 
northern Spain $\left(42^{\circ} 37^{\prime} \mathrm{N}, 5^{\circ} 26^{\prime} \mathrm{W}\right)$, the great spotted cuckoo can parasitize up to $67.7 \%$ of crow nests (Canestrari et al. 2009).

We investigated (i) whether the great spotted cuckoo provides a benefit to crows and whether such benefit could derive form the ability of cuckoo chicks to deter predators with a noxious secretion that they release when harassed, as well as (ii) whether the outcome of host-parasite interaction varies across seasons, depending on the intensity of predator pressure.

\section{MATERIAL AND METHODS}

\section{Study area and population}

The study was carried out in a rural area in NW Spain where crows breed cooperatively (Baglione et al. 2005; Canestrari et al. 2008a). Nest density is constant over time, as groups hold year-round territories that are stable across years (Baglione et al. 2005). Groups are enlarged families that contain a breeding pair and 1 to 7 extra birds (mean group size $\pm \mathrm{SE}=3.2 \pm 0.08$ ) that are previous offspring that delayed dispersal and/or immigrants. Unassisted pairs occupy approximately $25 \%$ of territories. Breeding females lay 1-7 eggs (average \pm SE $=$ $4.6 \pm 0.05$ ) per breeding attempt, but about $70 \%$ of nests fail (Canestrari et al. 2008a). When failure occurs at the egg stage, crows usually re-nest (up to two times per season), whereas they rarely do so if the clutch has already hatched (Canestrari et al. 2008a). Only one successful brood can be raised every year and group size increases the reproductive success of a breeding unit (Canestrari et al. 
2008a). In the study area there is a large community of nest predators, for example wild cats Felis silvestris, genets Genetta genetta, stone martens Martes foina and, among raptor birds, goshawks Accipiter gentilis and buzzards Buteo buteo. Intraspecific predation is also common in crow nests (Cramp \& Perrins 1994), which are also threatened by other corvid species (e.g. raven Corvus corax, European jay Garrulus glandarius) (Cramp \& Perrins 1994). Great spotted cuckoos commonly parasitize crow nests, where they lay one to three eggs (average \pm SE $=$ $1.53 \pm 0.06)$ (Canestrari et al. 2009).

\section{Long-term data on parasitism rate and reproductive success}

From 1995 to 2011 at the beginning of each breeding season (end of March) we surveyed all territories in the study area to record group size. Nests were monitored to record laying date, clutch size, presence and number of parasitic eggs and hatching success. At day 30 after hatching we recorded crow nest success (presence of at least one crow fledgling) and measured and marked all fledglings. Overall, we collected complete information (clutch size, group size, laying date, hatching and fledging success) for 741 nesting attempts in 109 territories). Cuckoo relative abundance (CRA) was estimated for four consecutive years as the average proportion of visits to crow territories (for routine data collection) with visual or acoustical contact with the parasite. The median value of annual average CRA (0.025) was fitted as cut-off to distinguish between years of "high" and "low" cuckoo abundance. We placed camouflaged micro video-cameras (Canestrari et al. 2005) at 15 parasitized and 12 nonparasitized nests to record chick provisioning at days 10-15 after hatching. We measured provisioning effort as the frequency of 
feeding visits per hour. Adult crows carry food inside their crop, so that the number and size of items are not visible. We previously showed that, in nonparasitized nests, the number of feeds, i.e. events where a crow transferred food into an open chick gape, is a good estimate of the actual amount of food provisioned by a carer (Canestrari et al. 2005). However, the individual's frequency of feeds highly correlates with the frequency of nest visits, which is therefore also a suitable proxy for feeding effort (Spearman's rank correlation coefficient $R=0.81, P<0.001, n=29$ ). Because the relative amount of food delivered in any single feed is smaller for cuckoo chicks than for crow chicks, which are three times bigger, the frequency of feeds cannot be used to compare provisioning effort between parasitized and nonparasitized nest, and the frequency of nest visits was used instead.

\section{Cuckoo transfer experiment}

In spring 2009 and 2010, we transferred all cuckoo hatchlings (one-two per nest) from 17 parasitized nests to synchronous nonparasitized ones. Another 28 naturally parasitized and 24 nonparasitized nests that had reached hatchling stage were kept unmanipulated and served as controls. We did not modify crow clutch sizes in any nest because cuckoo females did not appear to damage crow eggs by laying their own (probability of loosing or having eggs damaged in parasitized nest $=0.146, n=41 ;$ nonparasitized $=0.098, n=41 ; z=0.856, P=0.392$ ) (table 1$).$ In 2012 we checked for a possible effect of the manipulation by moving one crow chick between nonparasitized nests (11 translocations), keeping 11 nonparasitized 
nests as control. A concurrent translocation for both cuckoos and crows would have been preferable, but there were not enough synchronous nests that reached the hatching stage under current levels of nest failure. This limitation, however, is unlikely to have affected our results. Two days after the translocation, we checked whether the transferred chicks were alive. Three nests where the transferred cuckoos died were excluded from the sample as well as one donor nest, which tree was logged. All bird manipulations were authorized by Junta de Castilla y León.

Table 3.1. Factors affecting the probability of losing or having eggs damaged. Year (variance component $\pm \mathrm{SD}=0.951 \pm 0.975$ ) was fitted as random factors.

\begin{tabular}{|l|l|l|l|l|}
\hline Predictors & Estimate & s.e. & Z value & $p$ value \\
\hline \hline Intercept & -10.010 & 3.715 & & \\
\hline Group size & 0.573 & 0.352 & 1.632 & 0.103 \\
\hline Clutch size & 0.597 & 0.458 & 1.304 & 0.192 \\
\hline Julian laying date & 0.062 & 0.051 & 1.202 & 0.229 \\
\hline Non parasitized & 0.000 & & & \\
Parasitized & 0.719 & 0.84 & 0.856 & 0.392 \\
& & & & \\
\hline
\end{tabular}


Chapter 3 - From parasitism to mutualism

\section{Repellence tests}

The procedure for repellence tests was adapted to each model species used. Quasi feral cats (i.e. free ranging cats that hunt year-round but that could be attracted with food) were offered during one minute 10 pieces of chicken meat (3$5 \mathrm{~g}$ each) on a cardboard tray, treated either with 10-25 $\mu$ of water or natural cuckoo secretion (i.e. a maximum of about $1 / 40$ of the average amount produced by a cuckoo). We conservatively considered the meat to be perceived as palatable if the cat ate all 10 pieces of control meat within one minute or if it bit just a single piece of treated meat. Seven hand-raised captive carrion crows served as model for corvid predators (intraspecific predation is common in this species) (Cramp \& Perrins 1994). Each bird was offered a total of six pieces of meat (three treated and three control), one piece at a time. We left the bait on a perch of the aviary compartment where the focal birds had been isolated (all birds were habituated to isolation and entered the compartment voluntarily). As soon as the bird landed on the perch close to the bait, clearly showing interest, the stopwatch started and we observed the response of the bird for one minute. We considered that the bait was 1) consumed, if the crow ate it all or part of it, or if it cached it; 2) rejected, if the bird did not touch it or drop it immediately after taken it in the beak. After each presentation the leftover of the bait were removed. The experiment with raptors birds (four peregrine falcons Falco peregrinus, one gyrfalcon Falco rusticolus, one gyrfalcon $\times$ peregrine falcon hybrid and one gyrfalcon $\times$ saker falcon Falco cherrug hybrid; all birds had been legally bred for use in falconry) was done as follows: the experimenter took one item of bait at a time in his hand and presented it to the bird sitting on its perch, keeping a distance of 5-10 cm from its head. We 
considered that the bait was 1) consumed, if the bird ate it all or part of it; 2) rejected, if the bird refused to take it or dropped it immediately after taken it in the beak. As for crows, raptors were presented six pieces of meat (three treated and three controls), each trial lasted one minute and all bait leftover were removed before proceeding with the next presentation.

\section{Statistical analyses}

Unless stated otherwise, we analysed data with mixed models using $R$ ( R Development Core Team 2010). We run Linear Mixed Models (LMM) with Restricted Maximum Likelihood for continuous dependent variables and Generalized Linear Mixed Model (GLMM) with binomial error distribution for dichotomous dependent variables. For count data (i.e. number of fledglings) we used GLMM with negative binomial distribution because a poisson distribution showed overdisperion.

First we analyzed our long term crow reproductive success data set, including year and territory identity as random terms in all models and fitting parasite status ( $0=$ nonparasitized, $1=$ parasitized $)$, group size, brood size and Julian laying date (from day $1=1^{\text {th }}$ of March) as explanatory variables. Hatching success $(0=$ no eggs hatched, $1=$ at least one egg hatched $)$ was modelled with a GLMM with binomial error distribution and a logit link function. Subsequently, a hurdle model (R Development Core Team 2010) was applied to the sample of hatched nests to investigate the variables affecting nest success $(0=$ no crows 
fledged, 1 = at least one crow fledged) and number of crow fledglings in successful nests.

Second, we investigated the effect of cuckoo addition/removal on nest success $(0=$ no crow fledglings, $1=$ at least one crow fledged $)$ entering the following explanatory terms: treatment (cuckoo removed, cuckoo added, cuckoo present in unmanipulated nest, cuckoo absent in unmanipulated nest), brood size, group size and Julian laying date. The same procedure applied to data on crow transfer experiment (third), where "treatment" had the following levels: crow chick removed, crow chick added and unmanipulated nest.

Fourth, we analysed the choice of crows and raptor birds for each piece of meat presented during the repellence test running two separate GLMMs. To explain the response variable $(0=$ bait refused, $1=$ bait eaten $)$, we fitted treatment (natural cuckoo secretion vs control) and order of presentation (1 to 6) as fixed terms and individual identity as random factor.

Finally, we analysed the effect of parasitism pressure on the annual proportion of successful non-parasitized crow nests (Asin Square-root transformed) with a General Linear Model (GLM) fitting proportion of parasitized nests and average group size as explanatory terms. The effect of parasitism on crow fledgling body conditions (body mass/tarsus length ${ }^{3}$ ) was investigated with a LMM, fitting parasite status, Julian laying date, group size, brood size, length of fifth primary feather (proxy for age) and sex as explanatory variables. Adults' provisioning effort was examined by testing the effect of the number of cuckoo chicks, total brood size and group size in a LMM. Annual adult crow survival in spring of any given year $t(0=$ dead, $1=$ alive $)$ was modelled with a GLMM fitting 
sex, age, group size, $\mathrm{n}$ of crow fledglings produced at year $t-1$ and parasite status at year $t-1$ as explanatory variables, and year and individual as random terms. The same variables were also used in a separate GLMM to analyse the number of crow fledglings produced by banded adults in any given year depending on whether they had raised a cuckoo the year before.

\section{Chemical analyses}

Volatiles collected from five separate bird secretions were analyzed using gas chromatography and mass spectrometry (GC-MS). The samples were kept in glass vials or Eppendorfs and stored at $-20^{\circ} \mathrm{C}$ until they were shipped to the Neuchâtel lab. All but one sample were kept on dry-ice during the shipment and upon arrival they were stored at $-80^{\circ} \mathrm{C}$ until they were used for the chemical analyses.

Chemical compounds were trapped with the use of four different headspace techniques, including solid-phase microextraction (SPME), microvial headspace trapping, stir bar sorptive extraction (SBSE), and dynamic headspace (DHS). To be exhaustive and to exploit the full potential of each technique, each sample was prepared and extracted using multiple parameters (incubation, agitation, duration, adsorbent, temperature, flow, etc.). In total, 76 analyses were carried out to assess the presence of volatile components and to obtain preliminary identifications based on NIST05 mass spectral library as well as PBM library search (U.S. Department of Commerce and Agilent Technologies, Inc.). 
All analyses were done with Agilent gas chromatographs (HP 6890 or Agilent 7890A) coupled to Agilent mass spectrometer detectors (Agilent 5973 or Agilent 5975C). Samples were prepared and introduced into the GC with the use of robotic multipurpose samplers (MPS, Gerstel GmBH). Compounds were separated on Agilent HP-1MS columns (30 m length x 0.25 mm i.d., and $0.25 \mu \mathrm{m}$ film thickness). In all cases, the MSD transfer line temperature was set at $280^{\circ} \mathrm{C}$ and the ion source and quadrupole temperatures were set at $230^{\circ} \mathrm{C}$ and $150^{\circ} \mathrm{C}$ respectively. Electron impact (EI) mode was used with a scanning over the mass range of 30-350.

For the SPME technique, samples were incubated in a $20 \mathrm{ml}$ vial for five minutes at $35^{\circ} \mathrm{C}$ before inserting a $100 \mu \mathrm{m}$ polydimethylsiloxane (PDMS) coated fiber (Supelco) into the headspace during 20 minutes. Afterward, compounds were thermally desorbed from the fiber during 3 minutes (splitless mode, $250^{\circ} \mathrm{C}, 6.22$ psi pressure, $200.5 \mathrm{~mL} / \mathrm{min}$ purge flow, helium carrier gas) before injection onto the GC column. The initial column temperature of $40^{\circ} \mathrm{C}$ was held for $1 \mathrm{~min}$, then was ramped $10^{\circ} \mathrm{C} / \mathrm{min}$ until $180^{\circ} \mathrm{C}$ (hold time $5 \mathrm{~min}$ ), followed by a second ramp of $10^{\circ} \mathrm{C} / \mathrm{min}$ until $220^{\circ} \mathrm{C}$ (hold time $5 \mathrm{~min}$ ), and finally a 3 min post run at $250^{\circ} \mathrm{C}$. The helium flow rate was $0.9 \mathrm{~mL} / \mathrm{min}$ (constant flow mode).

For all others headspace techniques, we used a system that was equipped with both a thermal desorption unit and a cooled injection system (TDU \& CIS, Gerstel GmBH). In each case, the TDU was used, and volatile compounds were cryofocused with liquid nitrogen $\left(-80^{\circ} \mathrm{C}\right)$ in the CIS before being heated at $12^{\circ} \mathrm{C} / \mathrm{sec}$ to $280^{\circ} \mathrm{C}$ (hold time $10 \mathrm{~min}$ ) and injected. The subsequent procedures for GC separation and MS detection were as described above. 
For one of the analyses fresh cuckoo's secretions (5 $\mu \mathrm{L})$ were placed in microvials inserts (Gerstel GmBH). Immediately after, samples were placed in the injector and kept at $30^{\circ} \mathrm{C}$ while the emitted volatiles were trapped in the TDU (splitless mode). We used different incubation times $(0.5,1,2,3,5$, or $10 \mathrm{~min})$. The CIS inlet was operated in the solvent vent mode, with a vent pressure of $12 \mathrm{psi}$, a vent flow of $50 \mathrm{~mL} / \mathrm{min}$, and a purge flow of $50 \mathrm{~mL} / \mathrm{min}$. The helium carrier gas pressure was $12 \mathrm{psi}$ (flow rate $0.7 \mathrm{~mL} / \mathrm{min}$ ) at constant flow mode. The temperature program of the GC operation was $50^{\circ} \mathrm{C}$ for $1 \mathrm{~min}$, then an increase to $200^{\circ} \mathrm{C}$ at a rate of $5^{\circ} \mathrm{C} / \mathrm{min}$ (hold time $10 \mathrm{~min}$ ), followed by a second ramp at a rate of $100^{\circ} \mathrm{C} / \mathrm{min}$ to $250^{\circ} \mathrm{C}$ (hold time $2 \mathrm{~min}$ ), and finally a $3 \mathrm{~min}$ post run at $250^{\circ} \mathrm{C}$.

For Dynamic headspace (DHS) analyses fresh secretions $(10 \mu \mathrm{L})$ were placed in $10 \mathrm{~mL}$ glass vials and extracted with the DHS device (Gerstel GmBH). Both incubation and agitation were identical for the preparation of all samples (3 min at $30^{\circ} \mathrm{C}$ and $250 \mathrm{rpm}$, respectively). Trapping was carried out at $30^{\circ} \mathrm{C}$, with constant flow of $20 \mathrm{~mL} \mathrm{~N}_{2} / \mathrm{min}$, but under varied durations $(0.5,1,2,3,5,10,15$ or 20 min). Tenax ${ }^{\circledR}$-TA was used in TDU Liners as adsorbent. To avoid possible condensation, a transfer heater was set at $100^{\circ} \mathrm{C}$. TDU was used in splitless desorption mode with an initial temperature of $30^{\circ} \mathrm{C}$ increasing quickly $\left(720^{\circ} \mathrm{C} / \mathrm{min}\right.$ ) to $280^{\circ} \mathrm{C}$ (hold time $3 \mathrm{~min}$ ). The CIS inlet was operated in the solvent vent mode, a vent pressure of $9.79 \mathrm{psi}$, a vent flow of $50 \mathrm{~mL} / \mathrm{min}$, and a purge flow of $50 \mathrm{~mL} / \mathrm{min}$. In the column, helium pressure was $9.79 \mathrm{psi}$ (flow rate $1.2 \mathrm{~mL} / \mathrm{min}$ ) at constant flow mode. The oven program was $50^{\circ} \mathrm{C}$ for $0.5 \mathrm{~min}$, then an increase to $180^{\circ} \mathrm{C}$ at a rate of $10^{\circ} \mathrm{C} / \mathrm{min}$ (hold time $5 \mathrm{~min}$ ), followed by a second ramp at a rate of $10^{\circ} \mathrm{C} / \mathrm{min}$ to $220^{\circ} \mathrm{C}$ (hold time $5 \mathrm{~min}$ ), and finally a $2 \mathrm{~min}$ post run at $250^{\circ} \mathrm{C}$. 
PDMS stir bars (Twister ${ }^{\circledR}$, Gerstel $\mathrm{GmbH}, 10 \mathrm{~mm}$ length, $0.5 \mathrm{~mm}$ film thickness) were suspended above sample recipient during $0.5,1,2,3,5,10,15$, and 20 min. The whole system was placed in a glass container, hermetically closed. Passive trapping occurred at room temperature $\left(23^{\circ} \mathrm{C}\right)$. Compounds were desorbed in TDU in splitless mode, starting at $30^{\circ} \mathrm{C}$ for $0.5 \mathrm{~min}$, and then $60^{\circ} \mathrm{C} / \mathrm{min}$ to $250^{\circ} \mathrm{C}$ (hold time $3 \mathrm{~min}$ ). The PTV inlet was operated in the solvent vent mode, a vent pressure of $14 \mathrm{psi}$, a vent flow of $50 \mathrm{~mL} / \mathrm{min}$, and a purge flow of $50 \mathrm{~mL} / \mathrm{min}$. The helium carrier gas pressure was 14 psi (flow rate $0.7 \mathrm{~mL} / \mathrm{min}$ ) at constant flow mode. The GC program started with an initial temperature of $50^{\circ} \mathrm{C}(1 \mathrm{~min})$, then increased to $160^{\circ} \mathrm{C}$ at a rate of $5^{\circ} \mathrm{C} / \mathrm{min}$, immediately followed by a second ramp to reach $200^{\circ} \mathrm{C}\left(3^{\circ} \mathrm{C} / \mathrm{min}\right.$, hold time $\left.10 \mathrm{~min}\right)$, and a third ramp at a rate of $100^{\circ} \mathrm{C} / \mathrm{min}$ (finally $250^{\circ} \mathrm{C}$, hold time $3 \mathrm{~min}$ ). A $3 \mathrm{~min}$ post run at $250^{\circ} \mathrm{C}$ was carried out.

Corresponding controls to all samples/recipients/methods were carried out in order to determine which of the compounds were not of cuckoo origin. These air contaminants, plasticizers, etc. were excluded from the analyses. In addition, a blank analysis was conducted between each real sample in order properly to clean the system.

Overall, more than 60 chemical compounds were found in the different secretions collected from five cuckoos. Some compounds were detectable only for one sample and we arbitrarily chose to focus on the 29 compounds that were present in at least three samples. In order to confirm the identities of these main compounds, we analyzed pure standards (Sigma-Aldrich \& Fluka) for each of them. Confirmations were obtained by comparisons of retention times as well as mass 
spectra. In all cases the preliminary identifications were found to be correct. Figure 2 shows a typical chromatogram obtained with the SPME method that contains most of these major odorous compounds.

\section{RESULTS AND DISCUSSION}

Our analyses of the long-term data set show that the seeming lack of cost of raising cuckoos on crow reproductive success resulted from the combination of two counterbalancing effects. Parasitized and nonparasitized nests had similar probability of reaching the hatching stage [0.771 and 0.731 respectively; $z$ score (z) $=0.264, P=0.792, n=741$ ] (table 2). Once the eggs hatched, parasitized nests were more successful (that is, more likely to produce at least one crow fledgling) as compared to nonparasitized nests (probability of success $=0.764$ and 0.538 respectively; $\mathrm{z}=2.94, P=0.003, \mathrm{n}=550$ ) (table 2). However, among nests that were successful, those containing a cuckoo chick produced fewer crow fledglings than those without cuckoos (average \pm SE. $=2.073 \pm 0.139$ and $2.564 \pm 0.064$ respectively; $z=-2.670, P=0.008, n=312$ ) (table 2 ). Overall, throughout the 16 seasons, parasitized and non-parasitized broods did not significantly differ in number of crows fledged $(1.584 \pm 0.149$ versus $1.379 \pm 0.068$ respectively; $z=0.390$, $P=0.694, n=550$ ), though results suggest a slight benefit from raising a cuckoo. 
Table 3.2. Factors affecting $(a)$ hatching success, $(b)$ fledging success (i.e. at least one crow produced) of hatched broods and $(c)$ number of crow fledglings raised in successful broods. Year $(a$ : variance component $\pm \mathrm{SD}=0.138 \pm 0.372 ; b$ :

$0.363 \pm 0.602 ; c: 1.909 \mathrm{e}-08 \pm 0.0001$ ) and territory identity ( $a: 0.425 \pm 0.652 ; b$ : $0.007 \pm 0.086 ; c: 1.834 \mathrm{e}-08 \pm 0.0001$ ) were included as random terms

\begin{tabular}{|l|l|l|l|l|}
\hline Predictors & Estimate & SE & $Z$ value & $P$ value \\
\hline \hline (a) Intercept & 1.629 & 0.635 & & \\
\hline Group size & -0.005 & 0.080 & -0.060 & 0.952 \\
\hline Clutch size & -0.005 & 0.090 & -0.053 & 0.958 \\
\hline Julian laying date & -0.007 & 0.006 & -1.174 & 0.241 \\
\hline Non parasitized & 0.000 & & & \\
\hline \hline (b) Intercept & 0.12 & 0.643 & & \\
\hline Group size & $\mathbf{0 . 2 4 1}$ & $\mathbf{0 . 0 8 2}$ & $\mathbf{2 . 9 5}$ & $\mathbf{0 . 0 0 3}$ \\
\hline Clutch size & -0.011 & 0.088 & -0.12 & 0.904 \\
\hline Julian laying & $\mathbf{- 0 . 0 1 5}$ & $\mathbf{0 . 0 0 7}$ & $\mathbf{- 2 . 2 0}$ & $\mathbf{0 . 0 2 8}$ \\
\hline Non parasitized & 0.000 & & & \\
\hline \hline (c) Intercept & 0.56 & 0.311 & & \\
\hline Group size & $\mathbf{0 . 0 6 2}$ & $\mathbf{0 . 0 3}$ & $\mathbf{2 . 0 4}$ & $\mathbf{0 . 0 4 1}$ \\
\hline Clutch size & $\mathbf{0 . 1 6 3}$ & $\mathbf{0 . 0 4 2}$ & $\mathbf{3 . 9 1}$ & $<<\mathbf{0 . 0 0 1}$ \\
\hline Julian laying & $\mathbf{- 0 . 0 1 7}$ & $\mathbf{0 . 0 0 4}$ & $\mathbf{- 4 . 4 1}$ & $<<\mathbf{0 . 0 0 1}$ \\
\hline Non parasitized & 0.000 & & & \\
\hline
\end{tabular}


The results of the translocation experiment show a causal link between the presence of a parasitic chick and greater nest success. Among parasitized nests, those where cuckoos were removed failed significantly more often than control nests (probability of success $=0.312$ and 0.607 respectively; $z=-2.065, P=0.039$ ) (Fig. 1 and table 3), whereas among non parasitized nests, the addition of cuckoo chicks resulted in significantly increased success (unmanipulated non parasitized $=0.375$, cuckoo added $=0.714 ; z=1.984, P=0.047$ ) (Fig. 1 and table 3 ). In sharp contrast to the effect of cuckoo chick transfer, nests in which a crow chick was added showed no difference in success rate $(0.364, n=11)$ from those that were not manipulated or those from which a crow chick was removed $(0.818$ and 0.727 respectively; $n=11$ for both treatments; $z=1.707, P=0.088$ and $z=1.785, P=$ 0.074) (table 3), though the difference was suggestive of a reduction.

Figure 3.1. Probability of success of experimental and control nests ( $n=$ number of nests)

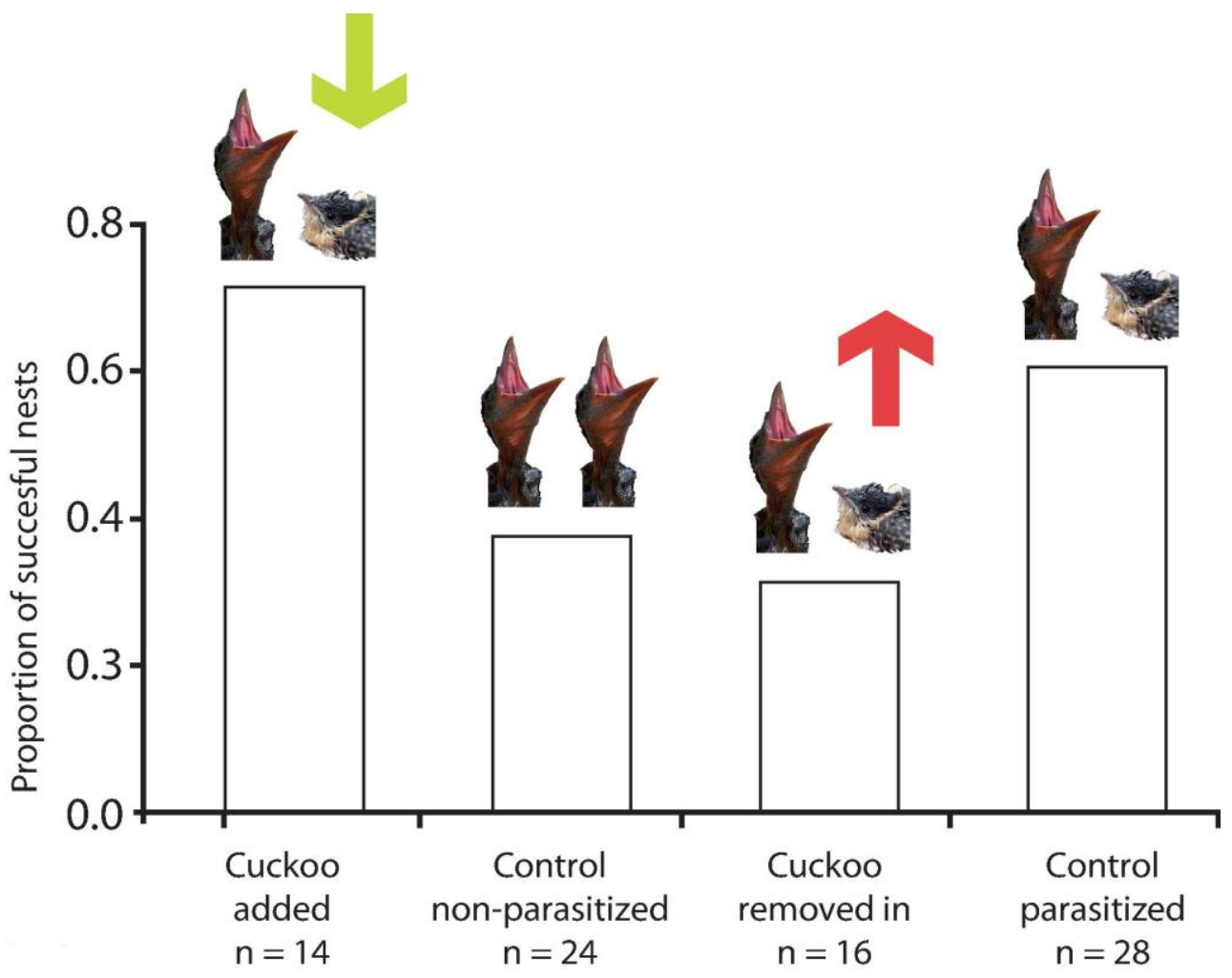


Table 3.3. Factors affecting crow nesting success (at least one crow chick fledged) in the experiment of (a) cuckoo chick translocation and (b) crow chick translocation. Territory identity (variance component $\pm \mathrm{SD}=0.015 \pm 0.124$ ) was included as random term in model (a). Relevant orthogonal contrasts for levels of experimental treatment are shown.

\begin{tabular}{|l|l|l|l|l|}
\hline Predictors & Estimate & SE & $z$ value & $P$ value \\
\hline \hline (a) Intercept & -0.231 & 2.347 & & \\
\hline Group size & 0.11 & 0.24 & 0.458 & 0.647 \\
\hline Clutch size & 0.414 & 0.28 & 1.48 & 0.139 \\
\hline Julian laying date & -0.015 & 0.035 & -0.417 & 0.677 \\
\hline Non parasitized & 0.000 & & & \\
Cuckoo added & $\mathbf{1 . 6 8 5}$ & $\mathbf{0 . 8 5 0}$ & $\mathbf{1 . 9 8 4}$ & $\mathbf{0 . 0 4 7}$ \\
\hline Parasitized & 0.000 & & & \\
\hline Cuckoo removed & $\mathbf{- 1 . 5 7 2}$ & $\mathbf{0 . 7 6 1}$ & $\mathbf{- 2 . 0 6 5}$ & $\mathbf{0 . 0 3 9}$ \\
\hline Non parasitized & 0.000 & & & \\
\hline Cuckoo removed & -0.265 & 0.794 & -0.334 & 0.647 \\
\hline Year 2010 & $\mathbf{- 2 . 0 0 1}$ & $\mathbf{0 . 5 6 4}$ & $\mathbf{- 3 . 5 4 8}$ & $<\mathbf{0 . 0 0 1}$ \\
\hline \hline (b) Intercept & 1.612 & 3.149 & & \\
\hline Group size & 0.028 & 0.282 & 0.100 & 0.920 \\
\hline Clutch size & -0.478 & 0.632 & -0.757 & 0.449 \\
\hline Julian laying date & -0.005 & 0.057 & -0.086 & 0.931 \\
\hline Crow added & 0.000 & & & \\
\hline
\end{tabular}


The most plausible mechanism driving the reduction of failure in nests with cuckoos is predator repellence by a malodorous cloacal secretion that parasitic chicks void when grabbed. This secretion is only produced by cuckoo nestlings ( 0 of 23 captured adults showed it) and can be copious (up to1.2 ml released by a 45g chick; average $\pm \mathrm{SE}=0.93 \pm 0.06 \mathrm{ml}, n=8$ ). When handling chicks, we observed voiding of the secretion in $20.8 \%$ of hatchlings ( 1 to 2 days old, $n=24$ ), $71 \%$ of nestlings of 3 to 4 days $(n=21)$ and $90 \%$ of chicks older than 4 days ( $n=59)$. At fledging, voiding of the secretion became less frequent (only two of six handled fledglings produced it).

The chemical analysis of cuckoo secretion revealed a mix of caustic and repulsive compounds, dominated by acids, indoles, phenols and several sulfur containing compounds (Fig. 2) that are known to repel mammals and birds (Lehner et al. 1976; Schafer et al. 1983; Wheeleraceto et al. 1990; Landa \& Tommeras 1997). Further chemical analyses confirmed the distinct volatile profile of a cuckoo's secretion as compared with feces of both cuckoos and crows, and its defensive function was confirmed by repellence tests. Eight of nine cats ate all 10 pieces of control meat, whereas only one of eight cats took a bite from treated meat (Fisher's Exact test, $P=0.01$ ). When we reversed the treatment for 9 of the original 17 cats, those offered control meat $(n=5)$ ate all the pieces, but none bit the treated meat ( $n=4$; Fisher's Exact test, $P<0.01)$. Crows also showed avoidance of the treated meat (proportion of eaten /cached control and treated items, 0.524 and 0.150 respectively; $z=-2.432, P=0.008, n=7$ ) (table 4 ), as did the raptors (proportion of eaten control and treated items $=0.952$ and 0.286 respectively; $z=-$ 3.355, $P=0.001$ ) (table 4). 
Figure 3.2. Chromatogram of the volatiles of cuckoo nestling secretion.1, acetic acid; 2, propanoic acid; 3, dimethyl disulfide; 4, iso-butyric acid; 5, butyric acid; 6 , pivalic acid; 7, isovaleric acid;8,2-methylbutanoic acid; 9, valeric acid; 10, a-pinene; 11, dimethyl tri-sulfide; 12, phenol; 13, caproic acid; 14, 3-carene; 15, acetophenone; 16 , p-cresol; 17,2 -nonanone; 18 , camphor; 19 , dimethyl tetrasulfide; 20, indole; 21 , skatole; 22 , 2-dodecen-1-ol; 23 , cyclic hexaatomic sulfur; 24, geranyl phenylacetate;25, 2-tridecanone. Asterisks denote air contaminants, plasticizers, etc. Relative abundance is measured in number of ions.

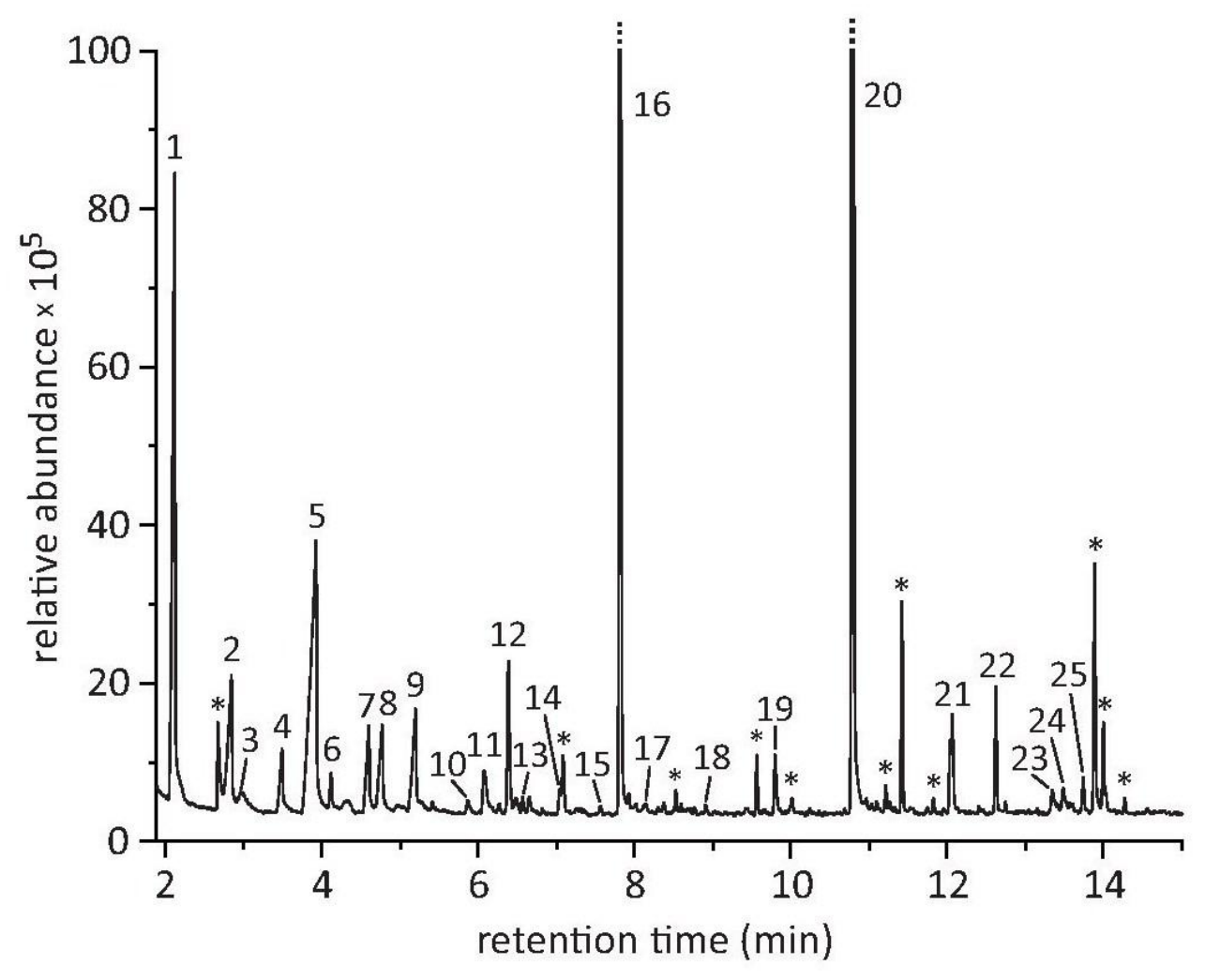


Table3. 4. Factors affecting bait acceptance in (a) carrion crows and (b) raptor birds during the repellence tests. Individual identity ( $a$ : variance component $\pm \mathrm{SD}=$ $1.879 \pm 1.371 ; b: 0.000 \pm 0.000$ ) was included as random factor in both analyses.

\begin{tabular}{|l|l|l|l|l|}
\hline Predictors & Estimate & SE & $z$ value & $P$ value \\
\hline \hline $\begin{array}{l}(a) \text { Intercept } \\
\text { Secretion }\end{array}$ & 0.491 & 1.073 & & \\
\hline $\begin{array}{l}\text { Order of } \\
\text { presentation }\end{array}$ & $-\mathbf{- 2 . 4 3 2}$ & $\mathbf{0 . 9 1 9}$ & $\mathbf{- 2 . 6 4 8}$ & $\mathbf{0 . 0 0 8}$ \\
\hline \hline $\begin{array}{l}\text { (b) Intercept } \\
\text { Control }\end{array}$ & -0.104 & 0.246 & -0.422 & 0.673 \\
Secretion & 0.000 & $\mathbf{0 . 4 4 9}$ & & \\
\hline $\begin{array}{l}\text { Order of } \\
\text { presentation }\end{array}$ & $\mathbf{- 3 . 8 2 4}$ & $\mathbf{1 . 1 4 0}$ & $\mathbf{- 3 . 3 5 5}$ & $<\mathbf{0 . 0 0 1}$ \\
\hline
\end{tabular}


Our study area hosts a large community of avian and mammalian nest predators that causes failure of $21.2 \%$ to $78 \%$ of breeding attempts annually (Canestrari et al. 2008a). In our experimental sample, unmistakable signs of predation (presence of broken feathers and/or damage of nest lining) were found in 10 of 21 nests that were inspected closely after failure. Besides, two of 13 cuckoos that were handled just before fledging showed wounds most likely caused by a predator (aggression from adult crows or fight among nestlings are excluded because in 2033 hours of video-recordings at the nest, including 300 hours at parasitized nests, we never observed such behaviours). In both cases, the cuckoo and its crow nest mate fledged successfully.

It has been suggested that brood parasites can depredate upon nonparasitized nests to force re-nesting, gaining new laying opportunities ("farming" strategy, (Arcese et al. 1996)), or can retaliate against hosts that tossed the parasitic eggs or chicks to force acceptance in the next nesting attempt ("mafia" strategy, Soler et al. (1995)). These two hypotheses are unlikely to explain the results of this study. The farming hypothesis could in theory account for lower failure of parasitized nests in the long-term data set. However, this can be excluded because: 1) nests without cuckoos had higher failure rates at the chick stage, when re-nesting is rare, but not at the eggs stage, when crows usually re-lay after failure (Canestrari et al. 2008a) and should therefore be targeted by cuckoos; 2) in contrast with the farming hypothesis, failure rate of non-parasitized nests did not differ between years with relatively low and high cuckoo abundance $[0.662 \mathrm{vs}$ 0.526 respectively; Fisher's Exact Test $P=0.29$; data comprising two years with low cuckoo abundance and two with high abundance). In addition, unlike in brown 
headed cowbirds (Molothrus ater) that can destroy host clutches (Arcese et al. 1996), annual nest failure rate of non-parasitized crow nests did not increase with annual parasitism rate, assumed here as a proxy for cuckoo abundance (Arcese et al. 1996) $(t=0.587, P=0.568, n=16$; Table 5$)$.

Table 3.5. Effect of annual parasitism rate on annual failure rate of non parasitized crow nests. Results of a GLM

\begin{tabular}{|l|l|l|l|l|}
\hline Predictors & Estimate & SE & $z$ value & $P$ value \\
\hline Intercept & 0.762 & 0.468 & & \\
\hline Average group size & 0.062 & 0.154 & 0.406 & 0.692 \\
\hline $\begin{array}{l}\text { Annual parasitism } \\
\text { rate }\end{array}$ & 0.166 & 0.282 & 0.587 & 0.568 \\
\hline
\end{tabular}

A mafia tactic (Soler et al. 1995c) could theoretically account for higher failure rate of non-parasitized nests observed in the long-term data set if we misclassified as "non-parasitized" those nests where cuckoo eggs had, in fact, been tossed out and that subsequently suffered retaliation by cuckoos. However, crows do not eject alien eggs (Soler 1990) so that this explanation can also be dismissed. Cuckoo retaliation could still have occurred in cases where we experimentally removed cuckoos from parasitized nest, causing higher nest failure compared to unmanipulated parasitized nests, but it cannot explain why addition of a cuckoo 
chick in non-parasitized nests improved nest success compared to control nonparasitized ones (Figure 1). Moreover, according to the mafia hypothesis we would also have expected nests from which cuckoos were removed to fail more often than control non-parasitized ones, because cuckoo retaliation would add up to the depredation caused by other crow enemies, but again our data do not support this prediction (probability of success of non parasitized nests $=0.375$, cuckoo removed $=0.312 ; z=-0.334, P=0.647$, Figure 1 , Table 3). In summary, neither farming nor mafia tactics provide plausible alternative explanation for the results presented in this paper.

Overall, the analyses of long-term data, the translocation experiment, the repellence tests and the chemical analyses imply that the cuckoo contributes to nest success by repelling predators. We believe that the outcome of this parasitehost interaction may depend on predator pressure and thus fluctuates among parasitism, commensalism and mutualism. Long-term data fit this conditiondependent scenario. Whereas cuckoos decrease host reproductive success at low rates of nest failure (which is a suitable proxy of nest predation rate) (Hatchwell 1999), parasitized nests produced more fledglings than nonparasitized nests during breeding seasons with high nest predation (Spearman's rank correlation coefficient $R=0.834, n=16, P<0.001$ ) (Figure 3). 
Figure 3.3. Annual difference in the mean number of crows fledged between parasitized and nonparasitized nests plotted against annual failure rate of non parasitized nests (proxy of nest predation rate). Above the zero line, the host benefits from the presence of the cuckoo.

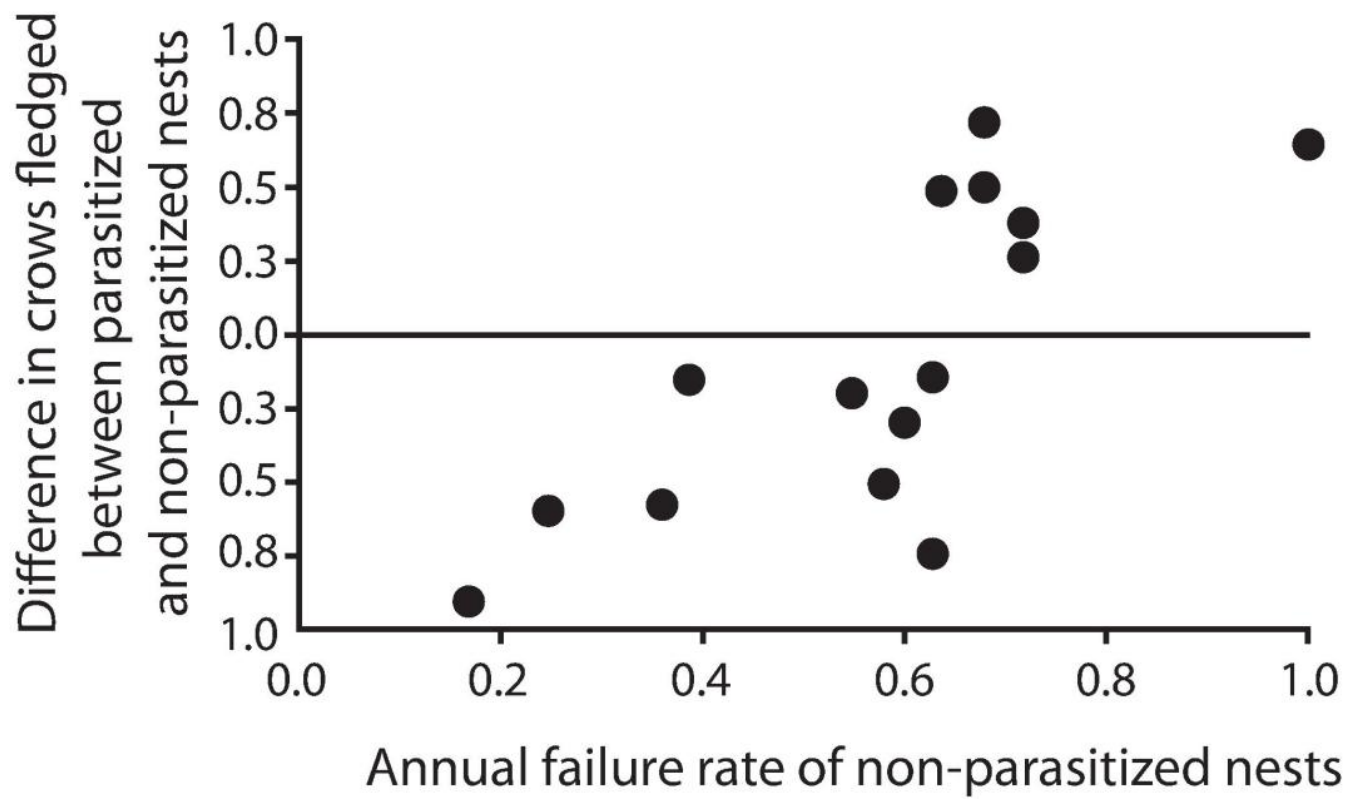

It can be argued that provisioning the cuckoo chicks may still harm the crow host by worsening the quality of its own offspring or by demanding for an exaggerated amount of care, and that these costs eventually outbalance any benefit that the parasite can provide. However, we found that (i) crow fledglings raised alongside cuckoos were not in poorer conditions compared with those brought up in absence of parasites (weight/tarsus ${ }^{3} \pm$ SE with cuckoos $=2.06 \pm 0.009$, without cuckoos $=2.01 \pm 0.004, t=1.178, \mathrm{df}=315, P=0.240, n=386)$ (table 5), and (ii) raising a cuckoo chick required substantially less effort than rearing a crow chick, as can be expected given the smaller size of the parasitic nestlings (approximately one-third of the weight of a crow) (Soler \& Soler 1991). After controlling for total 
brood size (crow and cuckoos), broods containing cuckoo chicks required significantly fewer visits per hour than nonparasitized broods $(t=-2.637, \mathrm{df}=20, P$ $=0.016, n=27$ ) (table 6). In addition, the total dependence period (nestling and post-fledging) is shorter for cuckoos (Soler et al. 1994) than for crows (Baglione et al. 2005). The analysis of data for 89 crow parents (61 males and 28 females) confirmed that raising cuckoos had no significant consequences on annual adult survival (probability of survival of parasitized adults $=0.821$, nonparasitized $=$ $0.727, z=1.355, P=0.175$ ) (table 7). Moreover, parasitized parents had not significantly lower reproductive success in the following year (average number of fledglings \pm SE $=0.818 \pm 0.234$ and $0.848 \pm 0.110$ for parasitized and nonparasitized adults, respectively; $z=-0.250, P=0.803, n=45$ males and 18 females) (table 8).

Table 3.6. Factors affecting crow nestling feeding rate

\begin{tabular}{|l|l|l|l|l|l|}
\hline Predictors & Estimate & SE & df & $t$ value & $P$ value \\
\hline Intercept & 2.408 & 1.526 & & & \\
\hline Number of carers & $\mathbf{0 . 7 5 4}$ & $\mathbf{0 . 3 4 4 4}$ & $\mathbf{2 0}$ & $\mathbf{2 . 1 9 5}$ & $\mathbf{0 . 0 4 0}$ \\
\hline Total brood size & $\mathbf{0 . 8 7 3}$ & $\mathbf{0 . 2 5 3}$ & $\mathbf{2 0}$ & $\mathbf{3 . 4 5 4}$ & $\mathbf{0 . 0 0 3}$ \\
\hline Number of cuckoo chicks & $\mathbf{- 0 . 8 9 3}$ & $\mathbf{0 . 3 3 8}$ & $\mathbf{2 0}$ & $\mathbf{- 2 . 6 3 7}$ & $\mathbf{0 . 0 1 6}$ \\
\hline
\end{tabular}


Table 3.7. Factors affecting annual breeding crow survival. Year (variance component $\pm \mathrm{SD}=2.343 \mathrm{e}-07 \pm 0.0005)$ and individual identity $(3.059 \mathrm{e}-01 \pm 0.553)$ were included as random terms.

\begin{tabular}{|l|l|l|l|l|}
\hline Predictors & Estimate & SE & $z$ value & $P$ value \\
\hline \hline Intercept & 2.028 & 0.628 & & \\
\hline Female & 0.000 & & & \\
\hline Group size & 0.025 & 0.351 & 0.07 & 0.944 \\
\hline Age & -0.123 & 0.129 & -1.004 & 0.316 \\
\hline Crow fledglings year $t-1$ & -0.137 & 0.109 & -1.257 & 0.209 \\
\hline Non parasitized & 0.000 & & & \\
Parasitized & 0.652 & 0.481 & 1.355 & 0.175 \\
\hline
\end{tabular}


Table 3.8. Effect of having raised a cuckoo chick on next year reproductive success (number of fledgling produced) on crow breeders. Year (variance component \pm SD $=0.305 \pm 0.552)$ individual identity $(1.733 \mathrm{e}-08 \pm 0.0001)$ were fitted as random factors.

\begin{tabular}{|l|l|l|l|l|}
\hline Predictors & Estimate & SE & $z$ value & $P$ value \\
\hline \hline Intercept & -1.90 & 0.544 & & \\
\hline Group size & 0.113 & 0.114 & 0.98 & 0.325 \\
\hline Age & 0.069 & 0.073 & 0.95 & 0.344 \\
\hline Crow fledged year $\boldsymbol{t}$-1 & $\mathbf{0 . 2 6 5}$ & $\mathbf{0 . 1 1 8}$ & $\mathbf{2 . 2 4}$ & $\mathbf{0 . 0 2 5}$ \\
\hline Non parasitized & 0.000 & & & \\
Parasitized & -0.099 & 0.394 & -0.25 & 0.803 \\
\hline
\end{tabular}

It has been advocated that interspecific interactions should not be strictly categorized as parasitism, commensalisms or mutualism (Bronstein 1994), because costs and benefits for each partner may vary in space and time, producing variable outcomes depending on the environmental context [for example, seed predation and dispersal (Siepielski \& Benkman 2007) and cleaning symbioses (Cheney \& Cote 2005)]. A lower predation rate of parasitized nests had also been reported in the other main host of the great spotted cuckoo, the magpie. However, the effect of cuckoo choice of the best host parents and/or territory could not be differentiated from potential effects of the presence of cuckoos (Arias de Reyna 1998). In our study, we have been able to disentangle these two drivers in carrion crows due to the results of the translocation experiment. Here, we demonstrated that the consequences of brood parasitism can be beneficial and that this benefit 
may be context-dependent, possibly preventing the evolution of host defences, particularly when a nonevicting cuckoo parasitizes a larger host.

Thanks to Hugo Robles and Javier Seoane for statistical advice, and to Gloria Robles, José M. Marcos, Cristina Núñez and Benedicto González for help in the field. Funding was provided by Spanish Plan Nacional I+D (CGL2008-01829B0S, SEJ2007-29836-E, CGL2011-27260) and Junta of Castilla y León (VA059A11-2) to VB.

This chapter has been published in a SCI journal:

Canestrari, D., Bolopo, D., Turlings, T. C. J., Röder, G., Marcos, J. M. \& Baglione, V. 2014. From Parasitism to Mutualism: Unexpected Interactions Between a Cuckoo and Its Host. Science, 343, 1350-1352. 


\title{
CHAPTER 4:
}

\section{High begging intensity of great-spotted cuckoo nestlings favours larger-size crow nest-mates}

\begin{abstract}
Avian brood parasites raised alongside host chicks generally show exaggerated levels of begging and, when they are larger than their host, they usually outcompete host nest-mates for food. Conversely, it has been suggested that, when host chicks are larger, they may benefit from the begging behaviour of the parasite, which stimulates the parents to provision the brood but can not monopolize the food brought to the nest. Here we show that, despite their higher begging intensity compared to host chicks, great spotted cuc koos (Clamator glandarius) did not outcompete larger-size carrion crow (Corvus corone corone) nestlings. Furthermore, cuckoos exaggerated begging allowed crow nest-mates to decrease their begging intensity without negative consequences on food intake. Our results suggest that host chicks may obtain an advantage from sharing the nest with a smaller brood parasite.
\end{abstract}


Chapter 4 - Begging intensity of great spotted cuckoo nestlings

\section{INTRODUCTION}

Avian interspecific brood parasitism, where females lay their eggs in the nest of another bird species and have their progeny raised by the host parents, provides an ideal model to study co-evolution (Rothstein 1990; Soler \& Soler 2000; Roldan \& Soler 2011; Kilner \& Langmore 2011; Spottiswoode et al. 2012). From the parasite's point of view, the lack of related nest mates determines the absence of indirect costs of within-brood competition, which favours the evolution of strategies that maximize the success of the individual parasitic chick (Godfray 1995; Lichtenstein 2001), such as removal or destruction of host eggs during laying (Davies \& Brooke 1988; Soler et al. 1997; Payne 2005), eviction of host eggs and chicks from the nest (Rothstein 1990; Honza et al. 2007) and killing of host nest mates by the newly hatched parasitic chick (Spottiswoode \& Koorevaar 2012). These strategies pose costs to the hosts that range from moderate (one or more host chicks can fledge) to severe (loss of the entire host clutch), generating a gradient of parasite virulence (Kilner 2005) that is likely to determine the variation in the evolution of host defences (Servedio \& Hauber 2006; Spottiswoode et al. 2012; Soler 2013), such as recognition and ejection of foreign eggs and/or chicks (Davies \& Brooke 1989; Langmore et al. 2003; Davies 2011), desertion of parasitized nests (Moskát et al. 2011; Krüger 2011) and mobbing of parasitic adults (Soler et al. 1999b; Roskaft et al. 2002; Welbergen \& Davies 2009).

Unlike the common cuckoo Cuculus canorus or the greater honeybird Indicator indicator, which respectively eject and kill all host chicks, "non-evicting" brood parasites like the great spotted cuckoo Clamator glandarius and Molothrus 
cowbirds (Soler 1990; Dearborn \& Lichtenstein 2002; Krüger 2007) may be raised alongside host's young. Within-brood competition is therefore likely to represent a key factor determining parasite's and host's reproductive success and, consequently, the direction and speed of co-evolved adaptations (Spottiswoode et al. 2012). Chick begging behaviour is considered to be an important means of scramble competition for food among nest-mates as well as a signal of individual need (Kilner \& Johnstone 1997; Soler 2001; Parker et al. 2002) that influences provisioning decisions of adults. In parasitized nests, begging strategies of host and parasitic chicks raised together may have consequences on adult provisioning behaviour. As in most birds, begging intensity in brood parasites varies with hunger (Lichtenstein 2001; Soler et al. 2012) and thus conveys reliable information on short-term needs of individual chicks. However, brood parasites consistently show exaggerated levels of begging compared to host species (Lichtenstein \& Sealy 1998; Davies et al. 1998; Dearborn 1998; Kilner \& Davies 1999; Soler et al. 1999a; Spottiswoode et al. 2012; Grim \& Honza 2001) The lack of indirect costs of within-brood competition is considered the main selective force behind this pattern, which is believed to maximize the parasite's ability to compete for food in the nest (Briskie et al. 1994). Indeed, in species in which host chicks are smaller than parasitic nest-mates, as for example brown-headed cowbirds Molothrus ater in nests of indigo buntings Passerina cyanea (Dearborn 1998) both parasite's larger size and exaggerated begging intensity lead host parents to prefer feeding parasitic chicks over their own offspring, which often starve. Besides influencing within-brood competition, parasites' exaggerated begging may also stimulate the foster parents to provision the brood at higher rates than they would 
Chapter 4 - Begging intensity of great spotted cuckoo nestlings

normally do, increasing energy expenditure and possibly reducing annual survival (Hoover \& Reetz 2006).

When parasitic chicks are smaller than their host, however, two contrasting scenarios may occur. On the one hand, brood parasites may profit from the "begging assistance" of their larger host nest-mates, if they are eventually able to obtain most of the food brought to the nest thanks to their exaggerated levels of begging (Kilner et al. 2004). On the other hand, the intense begging of a parasitic chick may stimulate parents to visit the nest more often, which may in turn benefit host chicks if they can successfully compete for food with the parasite (Kilner et al. 2004; Rivers et al. 2010). However, the generality of these hypotheses is currently difficult to assess because too few studies have focussed on the effect of parasites' begging strategies in systems where parasites are similar or smaller in size than host nest-mates. Here we investigate how the presence of a great spotted cuckoo chick affects the provisioning decisions of adult carrion crows and the begging behaviour of their offspring, which are larger than the parasite. It has been shown that great spotted cuckoo chicks exhibit an exaggerated begging behaviour in relation to their level of hunger, although their begging intensity varies with their short-term needs and is therefore informative on their condition (Soler et al. 1999a, 2012). Great spotted cuckoos generally parasitize magpies and succeed in outcompeting their chicks for food, often making them starve to death (Soler et al. 1995b, 1996), but this does not occur in nests of carrion crows, which nestlings are often raised successfully alongside the cuckoo ( Canestrari et al. 2009; Roldán et al. 2013; Soler et al. 2002) 
In this study, we ask whether the large carrion crow chicks may benefit from the presence of the parasite, which may stimulate the parents but eventually fail in outcompeting its host nest-mates. By comparing parasitized and unparasitized nests where chicks were individually recognizable, we specifically addressed the following questions: a) do great spotted cuckoo and crow chicks sharing the same nest beg at different intensities? b) How do parasitized adults allocate the food brought to the nest among parasitic and own chicks? c) Are crow chicks in parasitized and unparasitized nests provisioned at different rates and/or do they differ in their begging behaviour?

\section{MATERIAL AND METHODS}

\section{Study area and population}

We carried out this study in a $45 \mathrm{Km}^{2}$ rural area in Northern Spain $\left(42^{\circ} 37^{\prime}\right.$ $\mathrm{N}, 5^{\circ} 26^{\prime} \mathrm{W}$ ) where crows breed cooperatively in about $75 \%$ of territories (Baglione et al. 2002a). All breeding units occupy and defend year round all-purpose, nonoverlapping territories that are recognizable across years (Baglione et al. 2005). Groups (3-9 individuals) contain retained offspring of both sexes that stay on the natal territory with one or both parents for up to four years (Baglione et al. 2002a, 2005) and/or immigrants (mainly males) that are related with the resident breeder of the same sex (Baglione et al. 2003) and can share reproduction with the breeding pair (Baglione et al. 2002c). Both retained offspring and immigrants may contribute to chick provisioning, with a maximum of three helpers per nest 
(Canestrari et al. 2005), increasing breeders' reproductive success (Canestrari et al. 2008a). Throughout this study (2004-2007), brood parasitism by the great spotted cuckoo fluctuated in this population between $11.9 \%$ and $67.7 \%$ in crow nests. Typically, one to three cuckoo eggs are laid in parasitized nests (average $=$ 1.53, Canestrari et al. 2009). Unassisted pairs are parasitized more frequently than cooperative groups, whereas cuckoos' fledging probability is independent from host group size. On average, crow reproductive success does not decrease in parasitized nests (Canestrari et al. 2009).

\section{Nest survey and video-recording}

At the beginning of each breeding season (end of March), all territories were surveyed to find nests, record laying date, clutch size, presence and number of parasitic eggs, and crow group size and composition (for details on nests and group surveys see (Baglione et al. 2005; Canestrari et al. 2008a, 2009, 2011). Between 2004 and 2007, we video-recorded 7 parasitized and 6 non-parasitized nests, where care-givers were individually banded with colour rings and/or patagial wing-tags that did not affect survivorship (Canestrari et al. 2005, 2007), by placing camouflaged micro-cameras $1.5 \mathrm{~m}$ away from the nests (see Canestrari et al. 2005 for details on video-recording methods). Sampled nests contained one to five crow chicks (35 chicks in total), plus one cuckoo chick in every parasitized nests. For each nest, we collected 1-3 recording bouts of 4 hours in different days (for a total of 149 hours) when crow chicks were 10-15 days old. In total, we obtained information on 2988 nest visits. In 10 nests, crow chicks were made 
Chapter 4 - Begging intensity of great spotted cuckoo nestlings

individually recognizable with white marks painted on the top of their head. In the remaining 3 nests we collected a single continuous recording bout (4-8 hours per nest) where we could recognize individual chicks by their size and by following their movements in the nest throughout the video-recorded session.

\section{Analysis of video-recordings}

Recordings were run until adult(s) reached the nest, and then analyzed still by-still to collect data on begging and provisioning behaviour. For each nest visit, we noted the identity of the carer, the begging behaviour of each nestling, whether or not they were fed and how many feeds each one received. For each nest visit, begging was scored for the following variables: (1) 'Order': the relative begging sequence, that is, the order in which each nestling begged for food upon adult arrival; (2) 'Position': the relative position of each chick in the nest with respect to the adult and the other nest mates (closest, intermediate, farthest); (3) 'Intensity': measured along a categorical gradient used in most studies (Redondo and Castro 1992; Kilner 2002) from 0 (chick awake but not begging) to 4 (begging with the neck and legs completely extended); (4) "Latency": the time elapsed between adult arrival and the nestling starting to beg.

\section{Statistical analyses}

We used Generalized Linear Mixed Models with binomial distribution and logit link function (GLMM), and Linear Mixed Models (LMM) with Restricted Maximum Likelihood (REML) to analyse all data, using GENSTAT 12.0. Potential 
Chapter 4 - Begging intensity of great spotted cuckoo nestlings

explanatory variables that returned p values $>0.1$ were sequentially eliminated until the model only included relevant terms. Significant probability values were derived from having all relevant terms fitted in the model together (minimal model), whereas $\mathrm{p}$ values of dropped terms were obtained by individually reintroducing each term into the minimal model (Crawley 2002). Only interactions that were biologically meaningful were entered in the models. In the results, values for non-significant interactions were omitted.

Measures of begging behaviour. Different measures of begging often convey redundant information (Horn \& Leonard 2002; Kilner 2002). We tested correlation among our four measures of begging (see above) with a Multivariate Linear Mixed Model including chick and territory identity as random terms, and found indeed that begging measures were positively correlated (Table 1 ). We therefore used only begging intensity for subsequent analyses.

Crow vs cuckoo begging intensity. With a LMM, we compared the begging intensities of cuckoo and crow chicks (calculated as the average begging intensity of each individual chick throughout all video-recorded observations) by fitting chick species, number of care-givers and total brood size (number of crow chicks + number of cuckoo chicks) as explanatory variables, and nest identity and year as random terms. 
Table 4.1. Correlation table of the begging measures.

\begin{tabular}{|c|c|c|c|c|c|}
\hline & & Order & Position & Intensity & Latency \\
\hline Order & $\begin{array}{l}P \text { value } \\
\text { d.f. } \\
\text { F value }\end{array}$ & --- & & & \\
\hline Position & $\begin{array}{l}P \text { value } \\
\text { d.f. } \\
\text { F value }\end{array}$ & $\begin{array}{c}0.006 \\
1,1597.3 \\
7.65\end{array}$ & --- & & \\
\hline Intensity & $\begin{array}{l}P \text { value } \\
\text { d.f. } \\
\text { F value }\end{array}$ & $\begin{array}{c}<0.001 \\
1,1592.6 \\
153.99\end{array}$ & $\begin{array}{c}0.039 \\
1,1678.7 \\
4.28\end{array}$ & --- & \\
\hline Latency & $\begin{array}{l}P \text { value } \\
\text { d.f. } \\
\text { F value }\end{array}$ & $\begin{array}{c}<0.001 \\
1,1291.5 \\
313.38\end{array}$ & $\begin{array}{c}<0.001 \\
1,1378.9 \\
18.29\end{array}$ & $\begin{array}{c}<0.001 \\
1,1315.1 \\
41.49\end{array}$ & --- \\
\hline
\end{tabular}

Provisioning decisions in parasitized nests. In order to determine whether crow care-givers preferred feeding either species, we looked at which chick was fed in each nest visits. The dichotomous dependent variable (fed, unfed) was analysed with a Generalized Linear Mixed Model (GLMM) with a dichotomous error structure and identity link function where chick species, begging intensity, total brood size, category of the carer (breeder or helper) and interaction between adult category and chick species were entered as explanatory variables. Nest identity, adult identity, chick identity and year were entered as random terms. 
Subsequently, we compared the hourly frequency of being fed per crow $v s$ cuckoo chick. In the LMM we fitted chick species, number of care givers and total brood size as explanatory variables, and nest identity and year as random terms. In this analysis, we looked at how many times per hour any given chick received food (feeding event), without considering the actual number of "feeds" (i.e. each act of delivering food in a chick's gape that can be repeated several times for the same chick in any given visit, and that is a good proxy of the total amount of food delivered in crows, see Canestrari et al. 2005). This is because adult crows clearly used different techniques when feeding a crow chick or a cuckoo, which is considerably smaller than any host nest mate and therefore needs the prey item to be broken several times before being able to swallow it. Therefore, the same food item could require only one transfer when delivered to a crow chick, while it might be delivered, retrieved, broken and delivered back several times before it could be swallowed by a cuckoo, confounding the count of actual feeds. We believe that the number of feeding events per hour represents a better estimation of adult provisioning choice when comparing chicks of different species sharing the same nests. Note that the two models described in this section are complementary. In the nest visit based analysis (GLMM), we looked at host preference for feeding either crow or cuckoo chicks controlling for begging intensity during any given nest visit, whereas the second model (LMM) investigated the eventual feeding rate of crow and cuckoos chicks that may differ as a consequence of their different begging strategies. 
Chapter 4 - Begging intensity of great spotted cuckoo nestlings

Crow begging intensity and feeding rate in parasitized vs non-parasitized nests. We investigated whether crow chicks with and without parasitic nest-mates differed in begging by using begging intensity (calculated as average begging intensity per chick) as dependent variable in a LMM, and fitting presence or absence of parasitic chicks, total brood size and number of care-givers, as explanatory terms. Nest identity, and year were entered as random terms. In order to test whether the total begging intensity of a brood (i.e. the sum of the average begging values of all the chicks in a nest) increased with the presence of a parasitic chick, we fitted in a LMM total brood size and presence/absence of a cuckoo chick as explanatory variables and year as random term. Subsequently, in a GLMM, we tested whether, in each visit, crow chicks were more likely to be fed when sharing a nest with a parasitic chick, after controlling for begging intensity. Brood size, begging intensity and presence of a parasitic chick were fitted as explanatory terms, whilst nest identity, year, chick identity and adult identity were entered as random terms. Finally, we compared the eventual feeding rate of crow chicks in parasitized and non parasitized nests, fitting in a LMM number of care-givers and total brood size as explanatory variables, and nest identity and year as random terms. In the latter analysis, we could look at actual "feeds" because comparison was done within the crow species (see above). 
Chapter 4 - Begging intensity of great spotted cuckoo nestlings

\section{Ethical note}

We used camouflaged micro-cameras (size: $4 \times 2 \times 2 \mathrm{~cm}$ ) commonly used for security systems and video-recorders placed at the bottom of the nest tree. Videocamaras, recorders and cables were carefully camouflaged using branches and natural vegetation. The birds never showed any visible reaction to the video cameras and video recorded nests did not show a higher rate of brood failure compared to control non-video sampled nests (see Canestrari et al. 2005 for details). Chicks were marked with non-toxic white markers, which lasted about 5 days, and provoked no visible reactions from brood-mates or adults (such as aggression, pecking, or nest desertion). All marked chicks were regularly fed after the treatment. All bird manipulations raised no ethical or conservation concerns and were authorized by Junta de Castilla y León

\section{RESULTS}

Begging intensity in parasitized nests. In parasitized nests, cuckoo chicks begged more intensively than host chicks $(F=18.94$, d.f. $=1,17.6, \mathrm{p}<0.001$; effect size \pm SE crow $=0$, cuckoo $=0.74 \pm 0.17$, Fig. 1 a), while total brood size and the number of care-givers had no significant effect $(\mathrm{F}$ total brood size $=2.147$, d.f. $=1,3.7, \mathrm{p}=$ 0.22 , effect size $\pm \mathrm{SE}=0.15 \pm 0.1 ; \mathrm{F}$ number of care-givers $=1.78$, d.f. $=1,9.8, \mathrm{p}=$ 0.21 , effect size $\pm \mathrm{SE}=-0.13 \pm 0.09$ )

Provisioning decisions in parasitized nests. Breeders and helpers did not significantly differ in their provisioning decisions when they had the choice 
between a crow or a cuckoo chick, as indicated by the lack of significant interaction between adult category and chick species $(F=0.9$, d.f. $=1,641.7, p=0.3)$. After controlling for begging intensity $(F=201.46$, d.f. $=1,900.4, p<0.001$, effect size $\pm S E=1.33 \pm 0.09)$ and for the negative effect of brood size $(F=12.05$, d.f. $=1,4.3, p$ $=0.023$, effect size $\pm \mathrm{SE}=-0.61 \pm 0.17$ ), crow chicks had significantly higher probabilities to be fed by care-givers at any given visit compared to cuckoo chicks $(F=10.74$, d.f. $=1,20.9, p=0.004 ;$ effect size $\pm S E$ crow $=0$, cuckoo $=-0.84 \pm 0.25$, Fig 1b). However, due to the fact that cuckoo chicks begged more intensively than crow chicks (see above), they were eventually provisioned at similar rates of host nest-mates $(F=0.1$, d.f. $=1,18.6, p=0.76$; effect size \pm SE crow $=0$, cuckoo $=-0.14$ \pm 0.45 , Fig 1c). The number of care-givers positively affected the frequency of feeding events per chick $(F=5.9$, d.f. $=1,2.1, p=0.015$; effect size $\pm S E=0.36 \pm$ 0.14), which decreased with total brood size ( $F=5.26$, d.f. $=1,4.3, p=0.02$; effect size \pm S.E. $=-0.37 \pm 0.16$ ) 
Figure 4.1. Average \pm SE observed begging intensity of cuckoo and crow chicks in parasitized nests (a). Dots represent predicted values of the model. Average observed probability of being fed in each nest visit of individual cuckoo (filled bars) and crow (open bars) chicks according to their begging intensity in parasitized nests. Dots and squares represent predicted values of the model for crows and cuckoos respectively (b). Average \pm SE observed number of feeding events per hour to cuckoo and crow chicks in parasitized nests (c).
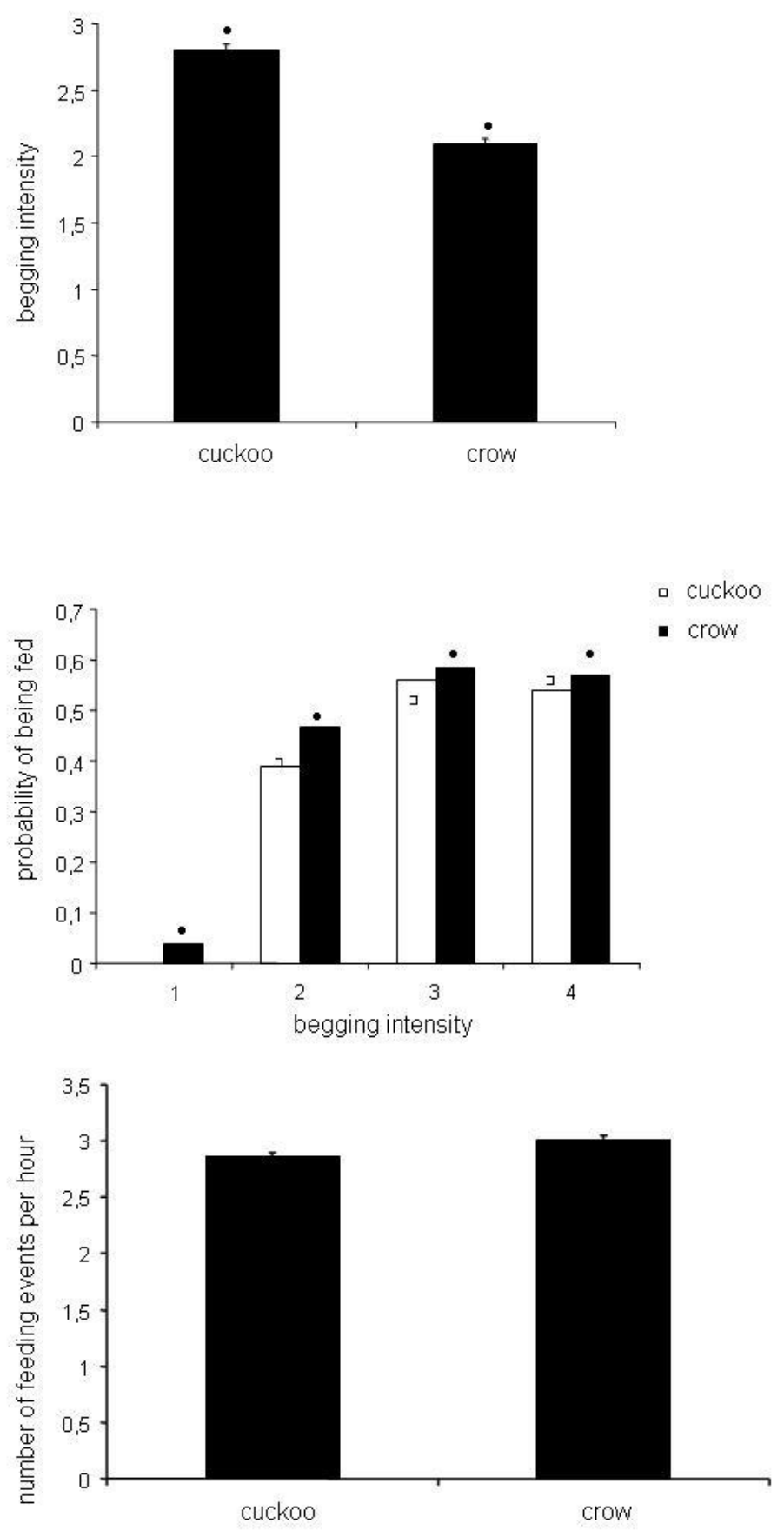

C 
Chapter 4 - Begging intensity of great spotted cuckoo nestlings

Crow begging intensity in parasitized and non parasitized nests. Begging behaviour of crow chicks was influenced by the presence of cuckoo nest-mates. Crow chicks raised alongside a cuckoo chick begged less intensely than those in non-parasitized broods $(\mathrm{F}=13.48$, d.f.. $=1,34.6, \mathrm{p}<0.001$, effect size \pm SE non parasitized $=0$, parasitized $=-0.38 \pm 0.1$; Fig. 2 a). Total brood size and number of care-givers did not significantly affect begging intensity (brood size $F=0.26$, d.f. $=1,12.7 p=0.6$, effect size $\pm S E=0.03 \pm 0.06$; number of care-givers $F=0.83$, d.f. $=1,32.9, p=0.4$, effect size $\pm \mathrm{SE}=-0.05 \pm 0.06$ ). Total begging intensity of a brood was positively correlated with the total number of chicks in the nest $(F=65.97$, d.f. $=1,7.5, p<$ 0.001 ; effect size \pm S.E. $=2.4 \pm 0.29$ ) and was not significantly affected by the presence of a cuckoo chick $(F=0.91$, d.f. $=1,9.3, p=0.92$; effect size \pm S.E. $=-0.08 \pm$ $0.76)$.

Provisioning of crow chicks in presence and absence of cuckoos. Crow chicks raised alongside a cuckoo chick were more likely to be fed in each given visit compared with crows raised in non-parasitized nests $(F=6.5$, d.f. $=1,8.5, p=0.03$; effect size \pm S.E. $=2.25 \pm 0.09$; Fig. $2 \mathrm{~b}$ ) after controlling for the positive effect of begging intensity $(F=359.84$, d.f. $=1,2685.4, p<0.001 ;$ effect size \pm S.E. $=0.39 \pm 0.12)$ and the negative effect of total brood size $(F=24.40$, d.f. $=1,12.2, p<0.001$; effect size \pm S.E. $=-0.16 \pm 0.03$ ). However, crow chicks in parasitized nests begged at lower intensity than those in non-parasitized ones (see above), and so they were eventually fed at a similar rate $(F=2.08$, d.f. $=1,10.1, p=0.18$; Fig 2c). In general, provisioning rate per crow chick decreased with the total number of crow nestlings ( $F=11.17$, d.f. $=1,11.3, p=0.006$, effect size $\pm S . E=-0.52 \pm 0.15)$, and 
Chapter 4 - Begging intensity of great spotted cuckoo nestlings

increased with the number of care-givers $(F=6.01$, d.f. $=1,8.3, p=0.04$, effect size \pm S.E $=0.46 \pm 0.19$ ) 
Figure 4.2. Average $\pm S E$ observed begging intensity of crow chicks in parasitized and non-parasitized nests. Dots represent predicted values of the model. (a). Average observed probability of being fed in each nest visit of individual crow chicks in parasitized (filled bars) and non-parasitized (open bars) nests according to their begging intensity. Dots and squares represent predicted values of the model for parasitized and non-parasitized nests respectively. (b). Average \pm SE observed number of feeds per hour delivered to crow chicks in parasitized and non parasitized nests (c).
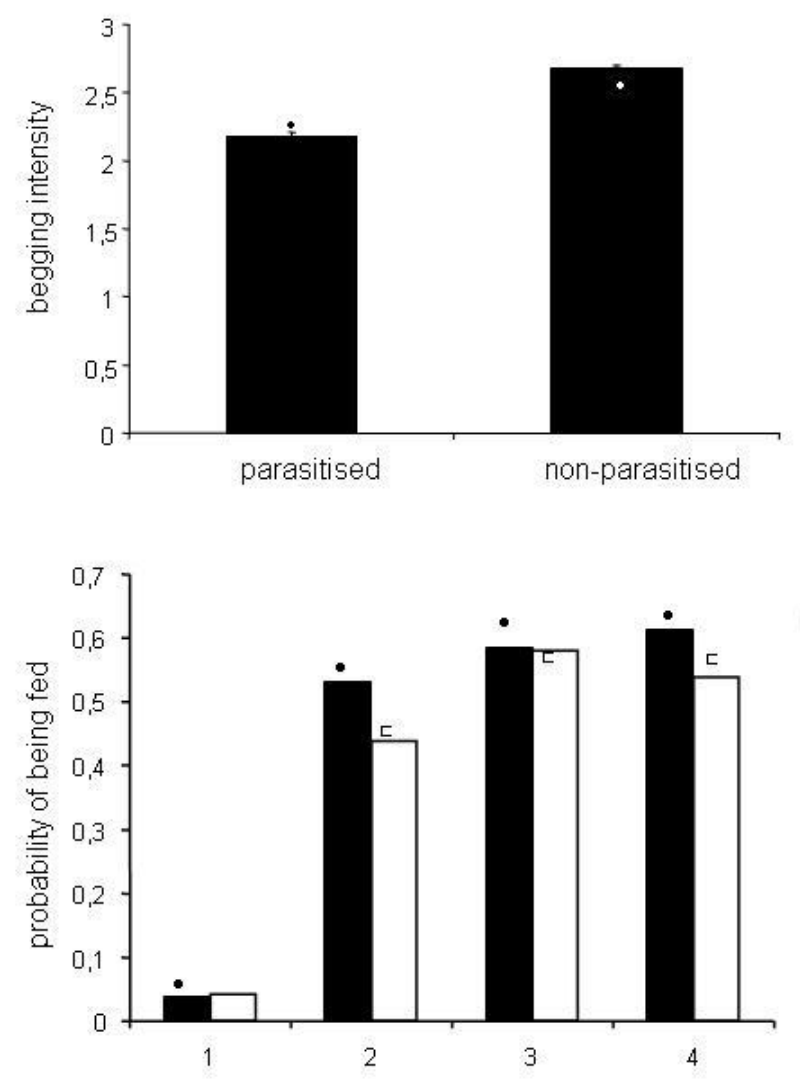

- parasitised

b

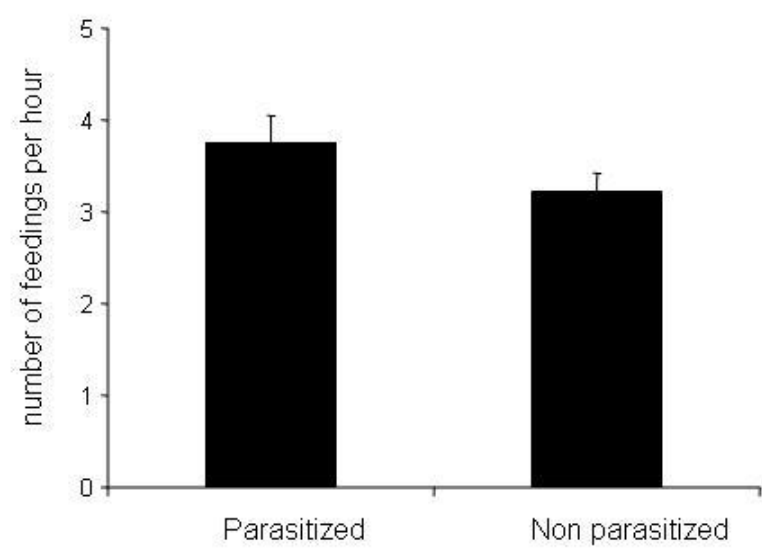


Chapter 4 - Begging intensity of great spotted cuckoo nestlings

\section{DISCUSSION}

\section{Food allocation in parasitized nest}

Great spotted cuckoo chicks raised alongside carrion crow chicks were not able to monopolize adults' food provisioning. Begging intensity being equal, crow care-givers (no matter if breeders or helpers) preferred to feed crow over cuckoo nestlings. However, because cuckoo chicks begged, on average, at higher intensities compared to host nest-mates, parasitic and host chicks were eventually fed at similar rates. This suggests that cuckoo's exaggerated begging is not effective in outcompeting the crow chicks in scramble competition for food, at least when the latter have grown larger than the parasite (our observations were carried out when the crow nestlings were 10/15 days old), which is in agreement with previous results showing that most nests with cuckoos successfully fledge some crows (Soler et al. 2002; Roldán et al. 2013; Canestrari et al. 2014). Our data are also consistent with the idea that size is critical to obtain food in a nest of begging chicks (Price \& Ydenberg 1995; Lichtenstein \& Sealy 1998; Rivers 2007), as shown for example in nests parasitized by shiny cowbirds (Molothrus bonariensis) and brown-headed cowbirds (Molothrus ater), where adults provisioned the larger nestlings irrespective of their species, showing no general preference for either parasitic or own chicks (Dearborn \& Lichtenstein 2002). However, a true preference for feeding own chicks cannot be dismissed in crows based on present data. Contrarily, it has been shown that magpies favour their offspring in experimental conditions where magpies and great spotted cuckoo chicks are matched in size (Soler et al. 1995b; Soler \& de Neve 2012). Further studies that 
experimentally control for the effect of chick size are needed in more species to fully understand provisioning rules of parasitized birds.

Great spotted cuckoos were fed at rates comparable to those of host chicks, unlike other Molothrus brood parasites, which do worse than larger host nestmates in obtaining food from adults (Dearborn \& Lichtenstein 2002). The exaggerated begging behaviour exhibited by great spotted cuckoo chicks in crow nests allowed them to overcome the size disadvantage, but it is not likely to be an adaptation to this particular host. Previous studies indicate that, for similar levels of hunger, great spotted cuckoos also beg at relatively higher intensity than magpies (Soler 2002; Soler et al. 2012), which are similar in size and therefore are not superior competitors. Furthermore, great spotted cuckoo chicks learn to modify their begging structure in nests of the two different hosts in order to increase efficiency in exploiting adults of different species (Roldán et al. 2013). Begging strategies in the great spotted cuckoo are therefore better explained as a general adaptation to their parasitic life, where they compete with similar or larger size nest-mates. Current theory explains exaggerated begging in brood parasites as a consequence of reduced indirect costs of scramble competition for food (Briskie et al. 1994), but this hypothesis may not apply to our study species. Parasitic chicks of many species do not share the nest with their relatives (Kilner \& Davies 1999; Lichtenstein 2001; Spottiswoode et al. 2012), and therefore do not benefit from increased survival of their nest mates, as it happens in a brood of siblings or half-siblings. In great spotted cuckoos, however, the presence of more than one parasitic egg in the same nest is relatively common (Soler et al. 1998, 2002; Canestrari et al. 2009). Ongoing genetic research on relatedness among chicks 
Chapter 4 - Begging intensity of great spotted cuckoo nestlings

raised in the same nest will help elucidate the evolution of begging in this nonevicting cuckoo species.

It has been suggested that, when parasites are smaller than their hosts, they might benefit from sharing the nest with one or two host chicks in order to obtain assistance in stimulating the parents to bring food to the nest, if they are eventually able to monopolize food delivery(Kilner et al. 2004). We found that great spotted cuckoo chicks are not favoured by their crow foster parents, so it is unlikely that they could benefit from the presence of crow chicks. However, a proper test of this hypothesis should compare food intake of cuckoo chicks raised alone or alongside crow nest-mates. This could not be done in this study and represents an interesting follow-up of this research. Interestingly, a recent experimental study showed that great spotted cuckoos tend to grow better when raised alone than together with one or two magpie chicks (Soler \& de Neve 2013). It is therefore unlikely that great spotted cuckoos could benefit from the presence of a larger host chick in a nest, although, as said, a compelling experimental study is still missing.

\section{Effect of a cuckoo chick on begging and food intake of crow chicks}

Based on data on brown thrashers (Toxostoma rufum) parasitized by brown-headed cowbirds, Rivers et al. (2010) proposed that host chicks that are larger than the parasite may benefit from the begging effort of the latter by decreasing their begging intensity without negative consequences on food intake. The generality of this hypothesis is unclear because so far very few studies have 
Chapter 4 - Begging intensity of great spotted cuckoo nestlings

focussed on brood parasites using larger hosts. Boncoraglio et al. (2009) found a contrasting pattern in a comparative study on 31 host species of brown-headed cowbirds in North America, where host begging loudness increased with parasitism pressure irrespective of host/parasite relative size. Our data, however, support the idea that a brood parasite can favour larger-size host chicks. At equal begging intensity, crow nestlings raised alongside a great spotted cuckoo were more likely to be fed than those in unparasitized broods. However, the former begged, on average, less intensively than the latter. As a result, crows with cuckoos received the same amount of food than crows without the parasite (a pattern that is consistent with the fact that crow fledgling mass is similar in parasitized and non parasitized nests, see (Canestrari et al. 2009)), but with less begging effort. Plausibly, the presence of a very active begging cuckoo allowed crows to reduce their own begging effort without compromising the stimulation of adult carers (indeed total begging intensity did not significantly differ between parasitized and unparasitized broods, after controlling for brood size) and without losing feeds, as cuckoos were at a disadvantage in the competition for food. Reducing begging intensity is likely to be beneficial for crow chicks. Although the energy expenditure of begging seems to be small in relation to general metabolism (Soler et al. 1999a), it has been shown that intense levels of begging reduce chick growth (RodriguezGirones et al. 2001) and immune response (Moreno-Rueda \& Redondo 2011). 
Chapter 4 - Begging intensity of great spotted cuckoo nestlings

\section{What is the cost of sharing the nest with a parasite for crow chicks?}

As shown above, crow chicks were fed at similar rates in parasitized and unparasitized nests, but begged less when sharing a nest with a great spotted cuckoo. If begging is costly, as several studies suggest, we may ask whether having a cuckoo nest mate represents a net advantage for crow chicks. To answer this question, any benefit of reduced begging must be balanced against the cost of losing siblings in earlier nest stages. Indeed, it has been shown that the great spotted cuckoo reduces crow hatching success (Soler et al. 2002) and/or nestling survival (Canestrari et al. 2014), most likely in the first 10 days of life when brood reduction occurs (Canestrari et al. 2008a). Therefore, for crow nestlings, the presence of the cuckoo has counteracting effects, that need to be carefully quantified to assess the true cost of sharing the nest with a "cheat". This study highlights a further complexity of the relationship between cuckoos and crows that adds up to recent findings (Canestrari et al. 2014) showing that, for crows, being parasitized conveys both costs (reduced fledgling production in nests that escape predation) and benefits (reduced nest predation due to a defensive secretion that great spotted cuckoo chicks void when touched and that deters mammalian and avian predators) that vary seasonally (Canestrari et al. 2014). The case of the great spotted cuckoo parasitizing a larger host shows that avian brood parasite/host interactions may have unexpected outcomes that need to be taken into account for a better understanding of co-evolutionary processes.

I am grateful to Gisela Boixadera and Gloria Robles for help in analysing the video recordings, and to Rudy Valfiorito for help in the field. This study was financially supported by Spanish Ministry of Education and Science/FEDER 
Chapter 4 - Begging intensity of great spotted cuckoo nestlings

(research project CGL2007-61940/BOS to MS), the Spanish Ministry of Science and Innovation and the Spanish Ministry of Economy and Competitivity through projects CGL2008-01829BOS and CGL2011-27260 to VB.

This chapter is based on the following publication, which is currently in preparation:

Bolopo, D., Canestrari, D., Roldán, M., Soler, M. \& Baglione, V. The high begging intensity of great-spotted cuckoo nestlings favours crow nest-mates. 


\title{
CHAPTER 5:
}

\section{Nest sanitation in cooperatively breeding carrion crows}

\author{
ABStract \\ A clean nest is important for successful breeding in most bird species, \\ because parasites and bacterial infestations can reduce nestling survival. In \\ cooperatively breeding species, care-givers may either share nest and chick \\ sanitation activities, or they may specialize in different tasks related to chick care, \\ such as food provisioning, nest sanitation, and territory and nest defence. Here we \\ show that in cooperative groups of carrion crow Corvus corone corone breeding \\ females carry out the vast majority of sanitation tasks, i.e. nest and chick cleaning \\ and fluffing-up of the nest inner layer, whereas other group members contribute \\ relatively little to these activities, with the exception of faecal sac removal which is \\ carried out by any adult present at the nest during excretion. We suggest that such \\ specialization occurs because a clean nest is beneficial not only for the brood, but \\ also for breeding females, which perform all incubation and brooding and are \\ therefore more exposed to nest parasites. This idea is supported by the fact that \\ individuals that were experimentally food supplemented during the breeding \\ season, and were therefore in better body conditions, reduced the time allocated to \\ nest sanitation activity. We suggest that extending the study of division of labour \\ to different tasks other than chick provisioning is important to widen our \\ understanding of the evolution and maintenance of cooperative breeding.
}


Chapter 5 - Nest sanitation in cooperatively breeding carrion crows

\section{INTRODUCTION}

A clean nest is crucial for successful breeding in most birds because bacteria and parasites may kill embryos or nestlings, reduce their growth or augment offspring demand for food, forcing parents to increase provisioning (Poiani 1993; Christe et al. 1996; Hurtrez-Bousses et al. 1998, 2000). Most studies have focussed on faecal sac removal (McGowan 1995), showing that it hinders microbial infestation and makes the nest less conspicuous to predators (Weatherhead 1984, 1988; Petit \& Petit 1987; Petit et al. 1989; Lang et al. 2002). Birds, however, perform other nest sanitation behaviours, like inspecting and preening the chicks and prodding, pulling, fluffing up or shaking vigorously the nest structure to remove the parasites (see review by Guigueno and Sealy 2012). These tasks are demanding in terms of time and energy and may reduce the time that parents can devote to other activities, like feeding, resting or chick provisioning (Christe et al. 1996). For example, female great tits (Parus major) reduced significantly their sleeping time to fight the parasites, when their nests where experimentally infested (Christe et al. 1996).

The risk of parasite transmission in nests of cooperatively breeding birds may be particularly high because of the presence of multiple carers (Poulin 1991; Poiani 1992). Group members should therefore respond by increasing nest sanitation, which could be affordable because parental duties are shared among several individuals. Furthermore, carers may specialize in different tasks, as it occurs for example in eusocial insects and mammals, where labour is divided within the colony (Wilson 1980; Jarvis 1981; Huang \& Robinson 1996). However, 
these hypotheses are currently difficult to test because studies on cooperatively (non-eusocial) breeding species typically have focussed on allofeeding, and few studies have investigated other important components of parental care (but see Heinsohn and Cockburn (1994) and Hailman et al. (1994) for helpers' contribution to incubation and sentinel behaviour, respectively). In relation to division of labour within group members, Arnold et al. (2005) found that among helpers, in the cooperatively breeding groups of bell miners, $18 \%$ performed only mobbing, $20 \%$ just provisioned the chicks and the rest carried out both tasks. Regarding nest sanitation, Pacheco et al. (2008) described that breeding females of cooperative breeding groups of bell miners, provided the greatest antiparasite effort against larvae of a parasitic fly that infested the nestlings. Both studies showed certain degree of task specialization of social group members in tasks other than allofeeding, which suggests they are important to the breeding success of the group. A full understanding of cooperation at the nest requires a more comprehensive view of the role of helpers (Baglione et al. 2010), because their contribution to any activity related to young rearing may have profound consequence on group stability and the dynamics of cooperation.

We studied nest sanitation in a population of cooperatively breeding carrion crows Corvus corone corone in northern Spain. Based on videorecorded observations at the nest, first we describe sanitation behaviours and analyze the factors that influence individual contribution to every particular task. We expected a positive effect of the number of carers on sanitation rate, because parasite transmission in passerines increases with group size (Poulin 1991; Poiani 1992) and individuals in larger groups may afford allocating more time to nest/chick 
cleaning. Second, by combining data on sanitation and chick provisioning, we investigated whether labour is divided within the group and whether individuals specialize in any particular task.

Finally we asked whether nest sanitation is flexible and responds to current conditions, in particular territory food availability. In a controlled experiment we supplemented 11 territories with food during the breeding season, reducing the costs of caring for the young (Canestrari et al. 2007). If individuals face a trade off between nest sanitation and other parental (chick provisioning) or self maintenance activities (feeding) that depend on food availability, we expect cleaning behaviours to increase in experimentally supplemented territories compared to controls.

\section{MATERIAL AND METHODS}

\section{Study area and population}

Since 1995 we have been studying a population of carrion crow in a $45 \mathrm{~km}^{2}$ rural area in NW Spain $\left(42^{\circ} 37^{\prime} \mathrm{N}, 5^{\circ} 26^{\prime} \mathrm{W}\right)$. Crows build large nests (ca. $40 \mathrm{~cm}$ external diameter) in the upper third of trees (oaks Quercus pyrenaica, poplars Populus nigra, willows Salix spp, holm oaks Quercus ilex and pines Pinus spp). The nest structure consists of 3 layers: a base, made of strong branches, an intermediate layer formed by thinner branches, stems and roots, and an inner part composed by animal hair (mostly sheep and other domestic animals), moss, herbs and sometimes soft anthropogenic material. 
In this population, crows breed cooperatively in the $75 \%$ of the territories and form cohesive groups of up to 9 individuals that comprise a breeding pair, its philopatric offspring and/or immigrants closely related to the breeder of the same sex (Baglione et al. 2002a, 2003). Although females can delay natal dispersal and occasionally immigrate and help in other territories, sex ratio in the groups is typically male biased. Sexually mature immigrants may share reproduction with the dominant pair, whereas non-dispersing offspring do not, so avoiding incest (Baglione et al. 2002b). Non-breeders contribute to defend the territory, built the nest, and feed the chicks and the incubating female. However, some group members refrain from helping in any task, being five the maximum number of caregivers found in a group (Canestrari et al. 2005). Breeders feed the chicks at higher rate than non-breeding helpers and, among helpers, males contribute more than females (Canestrari et al. 2005). Allofeeding increases annual reproductive success (Canestrari et al. 2008a) but it is costly for carers which lose weight proportionally to their effort (Canestrari et al. 2007). In this long-lived species, both breeders and helpers invest into self maintenance rather than increasing chick provisioning when food availability is experimentally augmented during the breeding season, showing the importance of reducing the high costs of parental care (Canestrari et al. 2007).

\section{Bird banding}

Adult crows were captured using two compartment walk-in traps and a snap trap (3 x 3m) specifically designed for this species (Baglione et al. 2002a), 
whereas nestlings were taken from the nest just before fledging. All birds were marked with a unique combination of plastic colour rings and/or patagial wing tags $(6.5 \times 3.5 \mathrm{~cm})$. We collected $50-200 \mu \mathrm{l}$ of blood from the brachial vein for DNA extraction and P2/P8 molecular sexing (Griffiths et al. 1998). All bird manipulations were authorised by Junta de Castilla y León and caused no damage to the birds (Canestrari et al. 2007)

\section{Data collection}

Data were collected in 2000, 2003, 2004, 2006 and 2007 in 46 groups/nests. The sample comprised 69 breeders (36 males and 33 females) and 51 non breeders (34 males and 17 females), all individually recognizable. The breeding female of each group continues brooding for 2 weeks after hatching and brood size ranged between 1 to 6 chicks. At the beginning of the breeding season, we monitored all territories to record group size and to locate the nests (for details see Canestrari et al. 2008). We used camouflaged micro video cameras placed 2$2.5 \mathrm{~m}$ away from the nests to record individual provisioning rate and nest sanitation (Canestrari et al. 2005). Recording bouts (4-8 hours long) were distributed randomly between 6:00 am and 8:00 pm. Brood age at the time of video-recording ranged from 2 to 36 days old. In every nest visit, we measured the total time allocated to sanitation tasks (see below) by every recognisable individual, as well as the number of feeds delivered to the chicks ("feed" is defined here as every act of delivering food to a chick's open gape and it is a suitable proxy for the caring effort, see Canestrari et al. 2005) and the number of chicks faecal sacs disposed (either eaten or carried away). Seven nests were parasitized by the 
Chapter 5 - Nest sanitation in cooperatively breeding carrion crows

great spotted cuckoo (Clamator glandarius), which is a brood parasite that specializes on corvids (Canestrari et al. 2009). The presence of cuckoo chicks was taken into account in the analyses (see below).

We identified three different sanitation behaviours: 1) Chick cleaning: the caregiver inspects the chicks and removes ectoparasites and dirt. (2) Nest cleaning: the carer eat or carry away food leftovers, faeces, insects, broken or spoiled pieces of the nest structure, and dead chicks. (3) Nest fluffing up: the adult grabs the inner layer of the nest with its beaks and pull it quickly, vigorously and repeatedly.

\section{Food supplementation experiment}

At the beginning of the breeding seasons 2003 and 2004 we randomly chose 12 territories and supplemented them every day with canned dog food (brand DIA, chicken and beef flavour), which proportion of meat and vegetables (78.8\% and $21.2 \%$, respectively) resemble the proportion of animal and vegetal components of natural crow diet (from $82.6-17.4 \%$ to $41.7-58.3 \%$, respectively (Canestrari et al. 2007)). The food was delivered in the middle of the territory (about 200m away from the nest), from the beginning of the breeding season (after the nest was completed but before egg laying) until the chicks fledged or the nest failed. All non supplemented territories served as control. In experimental territories, we confirmed with video-recordings at the feeding spot that all target birds had access to the supplemental food. Usually, all food was consumed or stored within 20min after our departure. Due to nest failure, we eventually collected data on 11 supplemented territories and 35 control territories. 
Chapter 5 - Nest sanitation in cooperatively breeding carrion crows

\section{Statistical analyses}

We analyzed data with Linear Mixed Models (LMMs) fitted with the Imer function from Ime4 library in R statistical software (R Development Core Team 2008; Crawley 2013). Individual identity, nested in territory identity, and year were fitted as random terms in all models to account for repeated measures of the same individuals and territories. Initially, we run LMMs using maximum likelihood (ML), including all potential explanatory variables. Subsequently, we used Akaike Information Criteria (AIC) to reduce the model. We sequentially removed those variables that significantly increased the AIC value according to Log-likelihood Ratio Test (LRT). The final optimal model was the one with the lowest AIC, regardless of the $p$ values of the variables included. This model was re-run with restricted maximum likelihood (REML) and final p values of fitted terms were obtained with LRT. Final $p$ values of dropped terms were obtained with the same test, by reintroducing them individually into the optimal model run with REML (Crawley 2013). All models were checked for homocedasticity of variance and normality of residuals.

First we analyzed the factors affecting individual total duration of nest sanitation per hour of observation, summing up the time spent in the three different sanitation tasks (i.e. nest cleaning, chick cleaning and nest fluffing up) and we repeated the same analysis only for broods older than 15 days (when breeding female is no longer brooding). Then, we checked whether the average time of the visits was influenced by the experimental treatment. Afterwards, we investigated each sanitation task separately. All these response variables were log transformed 
Chapter 5 - Nest sanitation in cooperatively breeding carrion crows

for normality. Finally, we tested which factors influenced individual (square root transformed) faecal sac removal frequency (number of faecal sacs removed/hour). In all models, we fitted the following variables as fixed terms: sex, status (breeder/ helper), provisioning effort (i.e. number of feeds delivered per hour), brood size, brood age, number of nest carers, presence/absence of great spotted cuckoo chicks, experimental treatment (food supplemented/control), and the interactions sex * status, sex*experiment and status*experiment. In the results, values for nonsignificant interactions are omitted.

\section{RESULTS}

Breeding females invested in sanitation more than any other group member, as shown by the significant interaction between sex and status on total nest sanitation time $\left(\chi^{2}=22.99, p<0.0001\right.$, Fig. 1a, Table 1) and we obtained the same result when analyzing data including only broods older than 15 days $\left(\chi^{2}=\right.$ $11.25, p=0.004)$. Females also tended to decrease their effort when food was experimentally provided (see interaction sex*experiment, $\chi^{2}=3.252, p=0.071$, in

Fig. 2a, Table 1). We also found a positive correlation between total sanitation time and both chick provisioning rate $\left(\chi^{2}=38.46, p<0.0001\right)$ and brood size $\left(\chi^{2}=6.21\right.$, $p=0.013)$.

Nest visits of the breeding females were longer than for the rest of the members as shows the significant interaction between sex and status $\left(\chi^{2}=39.73, p\right.$ $=<0.0001$, Table 6). As brood age and brood size increased, the duration of the visits significantly decreased $\left(\chi^{2}=27.54, p<0.0001 ; \chi^{2}=12.54, p=0.0004\right.$, 
respectively). The food supplementation experiment did not influenced the average length of the visits to the nest $\left(\chi^{2}=0.82, p=0.365\right)$ of any individual.

When we considered the three different sanitation tasks separately, we found that breeding females contributed more than the rest of the individuals to chick cleaning (sex*status: $\chi^{2}=9.09, p=0.011$, Fig. $1 \mathrm{~b}$, Table 2), and significantly decreased their effort when food was experimentally provided (interaction sex*experiment, $\chi^{2}=6.082, p=0.048$, Fig. $2 b$, Table 2). Chick cleaning was highly positively correlated with provisioning effort $\left(\chi^{2}=9.055, p=0.003\right)$ and with brood age $\left(\chi^{2}=12.476, p=0.0004\right.$; Table 2$)$.

Nest cleaning was mainly performed by females regardless of their status $\left(\chi^{2}=18.286, p<0.0001\right.$, Fig. $1 c$, Table 3$)$ and decreased with brood size $\left(\chi^{2}=\right.$ $22.994, p<0.0001)$. All carers, regardless of sex and/or status, reduced the time allocated to nest cleaning when food was experimentally provided $\left(\chi^{2}=4.389, p=\right.$ 0.036, Fig. 2c, Table 3). Again, group members that provisioned the chicks most also allocated more time to this activity $\left(\chi^{2}=46.394, p<0.0001\right)$.

Nest fluffing up was carried out mainly by the breeding female (sex*status: $\chi^{2}=29.357, p<0.0001$, Fig. $1 d$, Table 4), who tended to decrease the effort in experimentally fed territories (interaction sex*experiment $\chi^{2}=5.142, p=0.076$, Fig. 2d, Table 4). Nest fluffing up also decreased significantly with brood age $\left(\chi^{2}=\right.$ $6.305, p=0.012)$ and tended to increase with chick provisioning rate $\left(\chi^{2}=3.465, p\right.$ $=0.063)$.

Breeding males disposed fecal sacs more than breeding females, but the pattern reversed among non breeders, as shown by the significant interaction 
sex*status $\left(\chi^{2}=51.591, p<0.0001\right.$, Fig. 3 , Table 5). Fecal sacs disposal rate also increased significantly with chick provisioning rate $\left(\chi^{2}=111.31, p=<0.0001\right)$, brood age $\left(\chi^{2}=18.658, p<0.0001\right)$ and brood size $\left(\chi^{2}=18.975, p<0.0001\right)$, while tended to decrease if the nest was parasitized $\left(\chi^{2}=3.108, p=0.078\right)$. The number of carers never showed a significant effect on any sanitation task considered (Tables $1-5)$. 
Table 5.1. Factors affecting total sanitation time spent by carers. Variables included in the minimal model in bold.

\begin{tabular}{|c|c|c|c|}
\hline & \multicolumn{3}{|c|}{ Total sanitation } \\
\hline & Chisq & p-value & Estimate \pm SE \\
\hline brood size & 6.212 & 0.013 & $-0.062 \pm 0.025$ \\
\hline provisioning & 38.456 & $<0.0001$ & $0.083 \pm 0.013$ \\
\hline sex*status & 22.994 & $<0.0001$ & $-0.511 \pm 0.142$ \\
\hline sex*treatment & 3.252 & 0.071 & $-0.259 \pm 0.142$ \\
\hline brood age & 1.595 & 0.207 & $-0.005 \pm 0.004$ \\
\hline carers & 0.693 & 0.405 & $-0.033 \pm 0.041$ \\
\hline cuckoo absent & & & 0.000 \\
\hline present & 0.231 & 0.631 & $-0.045 \pm 0.097$ \\
\hline $\begin{array}{l}\text { Initial AIC value } \\
845.45\end{array}$ & $\overline{\text { bles ar }}$ & $\overline{\text { iteracti }}$ & $\overline{\mid l \text { in the model): }}$ \\
\hline Minimal model $A$ & 839.76 & & \\
\hline
\end{tabular}


Table 5.2. Factors affecting chick cleaning time spent by carers. Variables included in the minimal model in bold.

\begin{tabular}{|l|c|c|c|}
\hline \multicolumn{4}{|c|}{ Chick cleaning } \\
\hline \hline & Chisq & p-value & Estimate \pm SE \\
\hline \hline brood age & $\mathbf{1 2 . 4 7 6}$ & $\mathbf{0 . 0 0 0 4}$ & $\mathbf{0 . 0 0 7 \pm 0 . 0 0 2}$ \\
\hline carers & $\mathbf{2 . 9 0 2}$ & $\mathbf{0 . 0 8 8}$ & $\mathbf{0 . 0 3 7 \pm 0 . 0 2 2}$ \\
\hline provisioning & $\mathbf{9 . 0 5 5}$ & $\mathbf{0 . 0 0 3}$ & $\mathbf{0 . 0 1 9 \pm 0 . 0 0 6}$ \\
\hline sex*status & $\mathbf{9 . 0 9 9}$ & $\mathbf{0 . 0 1 1}$ & $\mathbf{- 0 . 1 6 4 \pm 0 . 0 7 8}$ \\
\hline sex*treatment & $\mathbf{6 . 0 8 2}$ & $\mathbf{0 . 0 4 8}$ & $\mathbf{- 0 . 1 9 1 \pm 0 . 0 7 5}$ \\
\hline brood size & 1.456 & 0.228 & $-0.019 \pm 0.015$ \\
\hline cuckoo present & 0.076 & 0.782 & $-0.020 \pm 0.053$ \\
\hline \multicolumn{2}{|c|}{} & & \\
\hline \hline Initial AIC value (all variables and 3 interactions included in the model): 77.29 \\
\hline Minimal model AIC value: 73.06
\end{tabular}


Table 5.3. Factors affecting nest sanitation time spent by carers. Variables included in the minimal model in bold.

\begin{tabular}{|c|c|c|c|}
\hline \multicolumn{4}{|c|}{ Nest cleaning } \\
\hline & Chisq & p-value & Estimate \pm SE \\
\hline brood size & 22.994 & $<0.0001$ & $-0.094 \pm 0.018$ \\
\hline treatment control & & & 0.000 \\
\hline experiment & 4.389 & 0.036 & $-0.124 \pm 0.056$ \\
\hline provisioning & 46.394 & $<0.0001$ & $0.755 \pm 0.187$ \\
\hline $\begin{array}{ll}\text { sex } & \text { male }\end{array}$ & & & 0.000 \\
\hline female & 18.286 & $<0.0001$ & $0.220 \pm 0.046$ \\
\hline brood age & 0.587 & 0.444 & $0.002 \pm 0.003$ \\
\hline carers & 0.055 & 0.815 & $0.017 \pm 0.029$ \\
\hline cuckoo absent & & & 0.000 \\
\hline present & 0 & 1 & $0.011 \pm 0.074$ \\
\hline breeding status $\quad$ breeder & & & 0.000 \\
\hline helper & 0.436 & 0.509 & $-0.031 \pm 0.048$ \\
\hline \multicolumn{4}{|c|}{ Initial AIC value (all variables and 3 interactions included in the model): 459.3} \\
\hline Minimal model AIC value: 4 & & & \\
\hline
\end{tabular}


Table 5.4. Factors affecting nest fluffing up time spent by carers. Variables included in the minimal model in bold.

\begin{tabular}{|l|c|c|c|}
\hline \multicolumn{3}{|c|}{ Nest fluffing } \\
\hline \hline \multicolumn{1}{|c|}{ chisq } & p-value & Estimate \pm SE \\
\hline \hline brood age & $\mathbf{6 . 3 0 5}$ & $\mathbf{0 . 0 1 2}$ & $\mathbf{- 0 . 0 0 9 \pm 0 . 0 0 4}$ \\
\hline cuckoo & & & $\mathbf{0 . 0 0 0}$ \\
\hline provisioning & $\mathbf{2 . 2 5 1}$ & $\mathbf{0 . 1 3 4}$ & $\mathbf{- 0 . 1 2 3 \pm 0 . 0 8 5}$ \\
\hline sex*status & $\mathbf{3 . 4 6 5}$ & $\mathbf{0 . 0 6 3}$ & $\mathbf{0 . 0 2 2 \pm 0 . 0 1 2}$ \\
\hline sex*treatment & $\mathbf{2 9 . 3 5 7}$ & $<\mathbf{0 . 0 0 0 1}$ & $\mathbf{- 0 . 5 1 1 \pm 0 . 1 2 8}$ \\
\hline brood size & $\mathbf{5 . 1 4 2}$ & $\mathbf{0 . 0 7 6}$ & $\mathbf{- 3 . 0 1 7 \pm 0 . 1 2 9}$ \\
\hline carers & 0.567 & 0.451 & $-0.017 \pm 0.025$ \\
\hline \hline Initial AIC value (all variables and 3 interactions included in the model): 734.43 \\
\hline Minimal model AIC value: 730.25 & & & \\
\hline
\end{tabular}


Table 5.5. Factors affecting fecal sacs removal rate of the carers. All variables included in the minimal model.

\begin{tabular}{|c|c|c|c|}
\hline \multicolumn{4}{|c|}{ Removal rate } \\
\hline & Chisq & p-value & Estimate \pm SE \\
\hline brood age & 18.658 & $<0.0001$ & $0.006 \pm 0.001$ \\
\hline brood size & 18.975 & $<0.0001$ & $0.046 \pm 0.010$ \\
\hline carers & 1.893 & 0.159 & $-0.024 \pm 0.015$ \\
\hline cuckoo absent & & & 0.000 \\
\hline present & 3.108 & 0.078 & $-0.059 \pm 0.037$ \\
\hline provisioning & 111.31 & $<0.0001$ & $0.052 \pm 0.005$ \\
\hline treatment control & & & 0.000 \\
\hline experiment & 2.406 & 0.121 & $-0.050 \pm 0.028$ \\
\hline sex*status & 51.591 & $<0.0001$ & $0.105 \pm 0.048$ \\
\hline \multicolumn{4}{|c|}{ Initial AIC value (all variables and 3 interactions included in the model): -324.72} \\
\hline Minimal model AIC value & 8.05 & & \\
\hline
\end{tabular}


Table 5.6. Factors affecting the average length of the visits to the nest. Variables included in the minimal model in bold.

\begin{tabular}{|c|c|c|c|}
\hline \multicolumn{4}{|c|}{ Average visit time } \\
\hline & Chisq & p-value & Estimate \pm SE \\
\hline brood age & 27.54 & $<0.0001$ & $-0.023 \pm 0.004$ \\
\hline brood size & 12.54 & 0.0003 & $-0.101 \pm 0.028$ \\
\hline sex*status & 39.73 & $<0.0001$ & $-0.428 \pm 0.156$ \\
\hline cuckoo absent & & & 0.000 \\
\hline present & 3.05 & 0.081 & $0.179 \pm 0.104$ \\
\hline provisioning & 1.07 & 0.302 & $0.014 \pm 0.014$ \\
\hline treatment control & & & 0.000 \\
\hline experiment & 0.82 & 0.365 & $0.087 \pm 0.092$ \\
\hline carers & 0.78 & 0.377 & $-0.036 \pm 0.044$ \\
\hline \multicolumn{4}{|c|}{ Initial AIC value (all variables and 3 interactions included in the model): 892.73} \\
\hline Minimal model AIC valu & 391.51 & & \\
\hline
\end{tabular}


Figure 5.1. Model estimates of the mean \pm standard error of time (seconds per hour) spent on each type of sanitation by sex and breeding status. Males are represented by black bars and females by white bars. Samples sizes were: breeder males 35, breeder females 33, helper males 34, helper females 17.
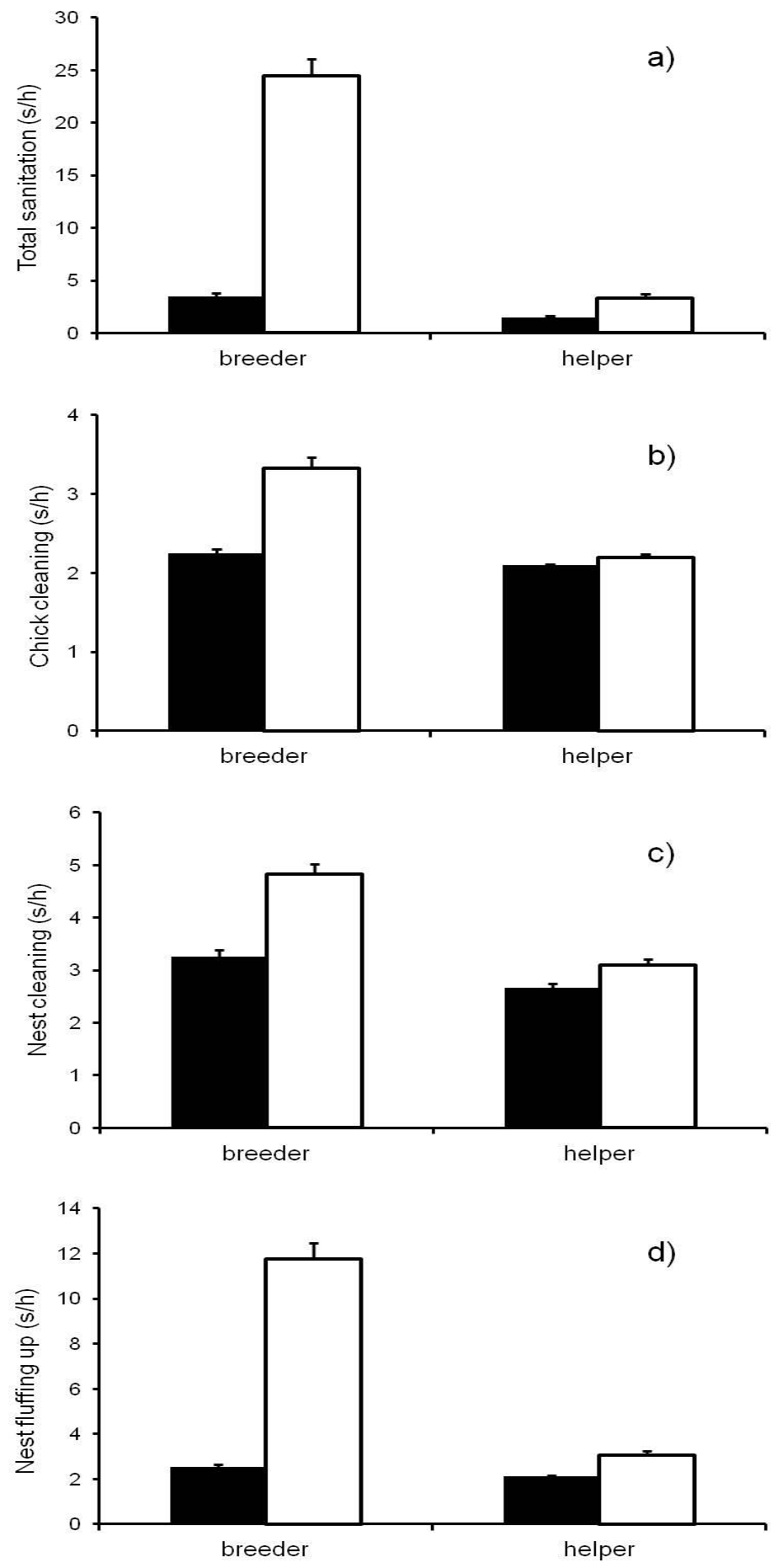
Figure 5.2. Model estimates of the mean \pm standard error of time (seconds per hour) spent on each type of sanitation by sex and experimental condition. Males are represented by black bars and females by white bars. Samples sizes were: males control 57, females control 37, males experiment 15, females experiment 16.
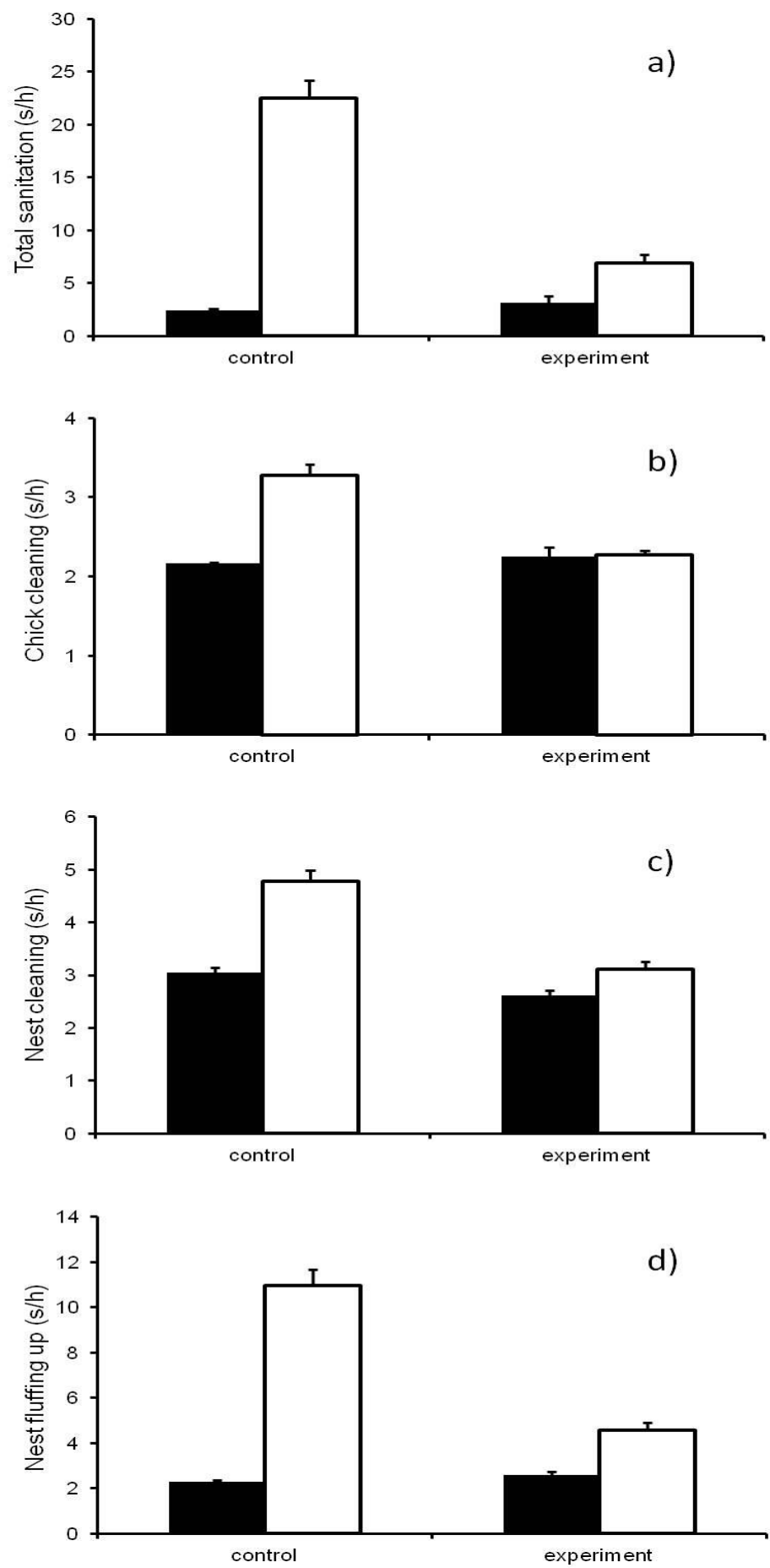
Figure 5.3. Model estimates of the mean \pm standard error of fecal disposal rate (fecal sacs removed per hour) by sex and breeding status . Males are represented by black bars and females by white bars. Samples sizes are given above the bars. Samples sizes were: breeder males 36, breeder females 33, helper males 34, helper females 17.

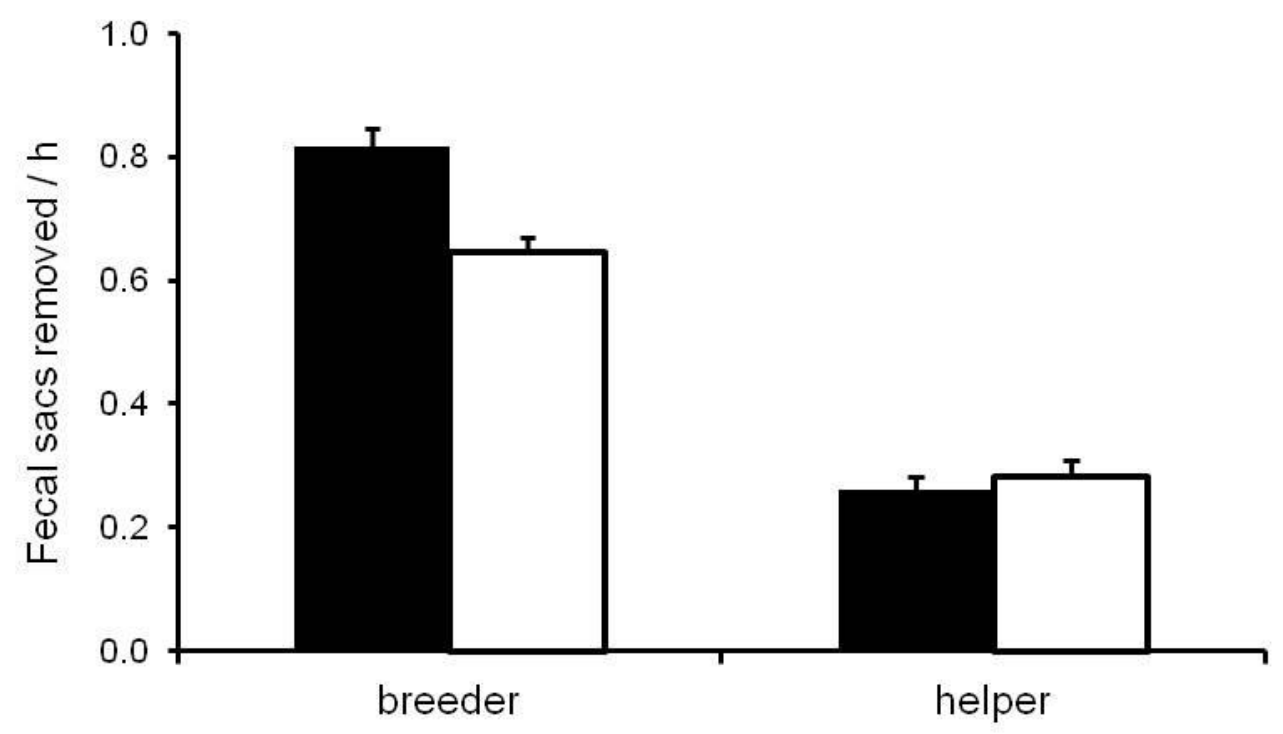


Chapter 5 - Nest sanitation in cooperatively breeding carrion crows

\section{DISCUSSION}

Chick cleaning increased with brood age, probably because the risk of ectoparasites or bacterial infestations increased as chick grew feathers. Nest fluffing, on the contrary, decreased over the nestling period, surely impeded by the growing weight and size of the brood. Besides, carers sometimes removed nest's inner layer when chicks were about 20 days old and were fully feathered, probably to favour chick thermoregulation when the weather warmed up and to get rid of dirt and parasites. Finally, nest cleaning decreased in larger broods, suggesting an individual trade-off between sanitation and other tasks related to chick care or self maintenance. This is consistent with the hypothesis of Christie et al (1996), who proposed such a trade-off to explain why, in nests where the number of ectoparasites was experimentally increased, female great tits decreased sleeping time to increase cleaning activities.

The number of carers attending a nest had no significant effect on the individual effort allocated to any sanitation task, suggesting that the risk of infestation did not increase with the number of helpers at the nest. This is plausible, because adult crows in suboptimal conditions dramatically decrease or cease feeding the nestlings (Baglione et al. 2010), so that active carers are probably in good health and do not threaten the brood with parasites.

\section{Division of labour among group members?}

Among members of cooperative crow groups, chick cleaning and nest fluffing-up were carried out mainly by breeding females, whereas all female care- 
Chapter 5 - Nest sanitation in cooperatively breeding carrion crows

givers, regardless the breeding status, were more active than males in nest cleaning. Males, in general, contributed little to sanitation activities, with the exception of faecal sac removal. This time-inexpensive task, however, was invariably carried out by any adult present at the nest at the moment of chick defecation, which typically occurred immediately after feeding, so that the high male contribution was a consequence of his high nest visiting rate. Overall, in this society, sanitation activities were mainly a female duty, although males were not incapable of doing sanitation tasks, as they carried out a small proportion of all activities described.

A clear division of labour among members did not occur in crow groups, as indicated by the fact that the individuals that were more active in chick provisioning also spent more time in sanitation activities. Conversely, in noisy miners (Manorina melanocephala), helpers that provision the chicks at higher rates contribute less to mobbing and vice versa, with some individuals fully specialized in either activity (Arnold et al. 2005). More data are needed to test whether, in cooperative crows, specialization occurs in other activities such as vigilance, and territory and nest defence, which are not considered in this work. However, preliminary observations suggest that defence tasks are carried out mainly by breeding group members (Baglione et al. 2002a), which are also the most active in chick provisioning and nest sanitation. This suggests that division of labour between breeders and helpers does not occur in crow groups, and that breeding adults invest highly in all activities related to chick care. 
Chapter 5 - Nest sanitation in cooperatively breeding carrion crows

\section{Why did breeding females clean more?}

Our study shows that the greatest effort in nest sanitation was done by the breeding female. Crow breeders, especially females, are very sensitive to the costs of reproduction and minimise them by finely adjusting their investment between the current brood and self-maintenance, reducing current nestling caring effort whenever possible (Canestrari et al. 2007, 2010, 2011). Therefore, we suggest that the important contribution to sanitation by breeding females may be beneficial not only for the chicks, but also for the adult. Individuals that carry out egg incubation and chick brooding are more exposed than others to the risk of getting ectoparasites or bacterial infections from a dirty nest, and are therefore expected to benefit more from increasing sanitation activities. Consistently with this idea, incubation and brooding are exclusive to crow breeding females, which are those showing the greatest effort in cleaning activities. A similar pattern was found in cooperatively breeding bell miners, where the greatest antiparasite effort was done by the breeding female (Pacheco et al. 2008), and in the magellanic woodpeckers (Campephilus magellanicus) where the male carries out most of the brooding and the nest sanitation (Chazarreta et al. 2011). Furthermore, a recent review by Guigueno and Sealy (2012), also confirmed that ectoparasite removal is mainly performed by the brooding individuals.

It can be argued that breeding females invest more time in nest sanitation because they spend more time in the nest incubating and brooding, so they have more chance to do so. However, breeding females have never been recorded carrying out sanitation tasks while brooding. Therefore, sanitation in breeding females involves a trade off with any other activity, like for any other group 
Chapter 5 - Nest sanitation in cooperatively breeding carrion crows

member. In addition the analysis of data including only broods older than 15 days dismissed this explanation, showing that breeding females kept on carrying out most of the sanitation even once brooding was over.

If nest sanitation has a "selfish" component of protecting incubating/brooding individuals from diseases, adults in better conditions (and therefore more resistant to parasites) may reduce sanitation time in favour of other activities, such as foraging, territory defence or sentinel behaviour. Our experimental data support this hypothesis, in contrast with our initial prediction. We have previously shown that food supplementation during the breeding season improves adult crow body-condition (Canestrari et al. 2007). In this study, fed crows, particularly breeding females, significantly reduced sanitation time compared to non food-supplemented ones. The effort saved by fed crows did not translate into a higher nestling provisioning rate (Canestrari et al. 2007) and was therefore allocated to other activities not measured in this study, most likely related to self maintenance, which is paramount for crow female breeders (Canestrari et al. 2010).

To summarize, our study uncovered a higher dedication by females in nest sanitation, which is one important component of cooperatively nestling care. Ongoing research on territory defence, vigilance and sentinel behaviour will widen our view on the dynamics of cooperation in the carrion crow, leading to a better understanding of the function of each member of the group. We believe that such a comprehensive approach, which extends beyond allofeeding behaviour, will be crucial for explaining the evolution and maintenance of cooperative breeding in birds. 
Thanks to José M. Marcos for help in the field and to Hugo Robles and Javier Seoane for statistical advice. . This study was financially supported by the Spanish Ministry of Science and Innovation and the Spanish Ministry of Economy and Competitivity through projects CGL2008-01829BOS and CGL2011-27260 to VB.

This chapter is based on the following publication, which is currently in preparation:

Bolopo, D., Canestrari, D., Baglione, V. Nest sanitation in cooperative breeding carrion crows. 


\section{CONCLUSIONS AND FUTURE RESEARCH}

Avian obligated brood parasites have been extensively studied, although they represent only about $1 \%$ of all avian species (Davies 2000). Hauber \& Dearborn (2003) indeed indicated that brood parasites are clearly overrepresented in terms of publications. They proposed that the extraordinary array of characteristics belonging to the uncommon but successful reproductive habits of these parasites, and the fact that host-parasite interactions are classic examples of co-evolutionary arms races, explain the general interest in cuckoos, cowbirds and other "cheating" species.

This thesis highlights the behavioural flexibility of the great spotted cuckoo and the complexity of its interaction with one of its hosts, the carrion crow. Systems like this one, where the host is larger than the parasite, have received little attention but, as this work shows, they may exhibit unexpected patterns that need to be taken into account for a full understanding of evolutionary arms races.

Besides, the thesis raises new questions and opens new research lines. More data are needed to describe the social mating system of the great spotted cuckoo and radio-tracking techniques may be used to describe the use of space and territorial behaviour of both males and females. This may shed further light on the possible costs and benefits of monogamous versus polygamous mating in this species. Experimental manipulations may provide further support to the hypothesis that crow chicks, at certain age, may benefit from the presence of a begging cuckoo in the nest and may provide insights on the consequences that 
raising a parasite may have on the body condition, survival and future fitness of adult crows. Regarding nest sanitation, it would be interesting to analyse the composition of the parasitic community that crow nests host and to determine the exact function and effectiveness of each sanitation behaviour performed by adults. Furthermore, focussing on cooperative tasks other than allofeeding and nest sanitation, such as territory defence, vigilance and sentinel behaviour will widen our view on the dynamics of cooperation in the carrion crow, leading to a better understanding of the function of each member of the group. 


\section{ACKNOWLEDGEMENTS}

First of all I would like to thank my supervisors, Vittorio Baglione and Daniela Canestrari for all these years of advice and support. Special thanks to Rafa Garnica for finding them for me.

I am grateful to all "Baglione’s brains”: Elisa Chiarati, Rubén Vera, Cristina Núñez and Claudia Wascher, for sharing experiences, comments and their company on this travel. Many thanks to Gloria, Gianluca and Matthias who helped me with the field work. Special thanks to Bene who always came to the rescue when needed and to Miguel for his invaluable help capturing cuckoos (...among other unfortunate creatures) and for making fieldwork of 15 hours a day funnier than ever. Thanks to Hugo Robles and Javier Seoane for helping me to fight statistics and R, and win (most of the time) and to Carlos Ciudad for his help taming ArcGis. I am very grateful to Marta Vila who carried out the "so-farimpossible" sexing of the cuckoos.

Many thanks to Nick Davies and the department of animal behaviour of the Cambridge University for their sympathy, advice, lectures, seminars, cookies and cakes during my stay. Also, massive thanks to Cris, Fran, Armando and Jiaqi, for their company and friendship far from home. 
I am grateful to Manolo Soler and Juan Gabriel Martínez for their help, comments, advice and supervision during my stays at the University of Granada. Many thanks to all the people of the department of zoology; especially to Oscar, Sara, Juan Diego, Oli and Nacho who never let me get bored.

Many thanks to Ronald Noë and Eörs Szathmary for inviting me to the TECT-INCORE summer schools that allowed me to meet so many amazing people and get their advice, opinion and critiques!

I am also grateful to Thomas Bungyar for inviting me to visit the University of Vienna and the Konrad Lorenz Institute, an inspiring place for behavioural biologists. Special thanks to Markus Böckel who took care of me during the visit.

Many super special thanks to Fran who supported me through the good and the bad in the final stages without complaint.

Finally, I am grateful to the University of Valladolid for supporting my $\mathrm{PhD}$ with a scholarship. 


\section{REFERENCES}

Alderson, G. W., Gibbs, H. L. \& Sealy, S. G. 1999a. Parentage and kinship studies in an obligate brood parasitic bird, the brown-headed cowbird (Molothrus ater), using microsatellite DNA markers. Journal of Heredity, 90, 182-190.

Alderson, G. W., Gibbs, H. L. \& Sealy, S. G. 1999b. Determining the reproductive behaviour of individual brown-headed cowbirds using microsatellite DNA markers. Animal Behaviour, 58, 895-905.

Arcese, P., Smith, J. N. M. \& Hatch, M. I. 1996. Nest predation by cowbirds and its consequences for passerine demography. Proceedings of the National Academy of Sciences of the United States of America, 93, 4608-4611.

Arias de Reyna, L. 1998. Coevolution of great spotted cuckoo and its hosts. In: Parasitic Birds and Their Hosts, Studies in Coevolution, (Ed. by S. I. Rothstein \& S. K. Robinson), pp. 129-142. Oxford: Oxford University Press.

Arnold, K. E., Owens, I. P. F. \& Goldizen, A. W. 2005. Division of labour within cooperatively breeding groups. Behaviour, 142, 1577-1590.

Baglione, V., Marcos, J. M. \& Canestrari, D. 2002a. Cooperatively breeding groups of Carrion Crow (Corvus corone corone) in northern Spain. Auk, 119, 790-799.

Baglione, V., Marcos, J. M., Canestrari, D. \& Ekman, J. 2002b. Direct fitness benefits of group living in a complex cooperative society of carrion crows, Corvus corone corone. Animal Behaviour, 64, 887-893.

Baglione, V., Canestrari, D., Marcos, J. M., Griesser, M. \& Ekman, J. 2002c. History, environment and social behaviour: experimentally induced cooperative breeding in the carrion crow. Proceedings of the Royal Society of London Series BBiological Sciences, 269, 1247-1251.

Baglione, V., Canestrari, D., Marcos, J. M. \& Ekman, J. 2003. Kin selection in cooperative alliances of carrion crows. Science, 300, 1947-1949.

Baglione, V., Marcos, J. M., Canestrari, D., Griesser, M., Andreotti, G., Bardini, C. \& Bogliani, G. 2005. Does year-round territoriality rather than habitat saturation explain delayed natal dispersal and cooperative breeding in the carrion crow? Journal of Animal Ecology, 74, 842-851.

Baglione, V., Canestrari, D., Marcos, J. M. \& Ekman, J. 2006. Experimentally increased food resources in the natal territory promote offspring philopatry and helping in cooperatively breeding carrion crows. Proceedings of the Royal Society BBiological Sciences, 273, 1529-1535.

Baglione, V., Canestrari, D., Chiarati, E., Vera, R. \& Marcos, J. M. 2010. Lazy group members are substitute helpers in carrion crows. Proceedings of the Royal Society B-Biological Sciences, 277, 3275-3282. 
Barnard, P. \& Markus, M. B. 1989. Male Copulation Frequency and Female Competition for Fertilizations in a Promiscuous Brood Parasite, the Pin-Tailed Whydah Vidua-Macroura. Ibis, 131, 421-425.

Betts, F. 1966. Notes on Some Resident Breeding Birds of Southwest Kenya. Ibis, 108, 513-\&.

Birkhead, T. R. 1991. The magpies: the ecology and behaviour of black-billed and yellow-billed magpies [...] [...]. San Diego, CA: Academic Press.

Bolopo, D., Canestrari, D. \& Baglione, V. 2009. Corneja negra - Corvus corone. In: Enciclopedia Virtual de los Vertebrados Españoles, Salvador, A., Bautista, L. M. (Eds.) edn. Madrid: Museo Nacional de Ciencias Naturales.

Boncoraglio, G., Saino, N. \& Garamszegi, L. Z. 2009. Begging and cowbirds: brood parasites make hosts scream louder. Behavioral Ecology, 20, 215-221.

Briskie, J., Naugler, C. \& Leech, S. 1994. Begging Intensity of Nestling Birds Varies with Sibling Relatedness. Proceedings of the Royal Society B-Biological Sciences, 258, 73-78.

Bronstein, J. 1994. Conditional Outcomes in Mutualistic Interactions. Trends in Ecology \& Evolution, 9, 214-217.

Canestrari, D., Marcos, J. M. \& Baglione, V. 2005. Effect of parentage and relatedness on the individual contribution to cooperative chick care in carrion crows Corvus corone corone. Behavioral Ecology and Sociobiology, 57, 422-428.

Canestrari, D., Marcos, J. M. \& Baglione, V. 2007. Costs of chick provisioning in cooperatively breeding crows: an experimental study. Animal Behaviour, 73, 349357.

Canestrari, D., Marcos, J. M. \& Baglione, V. 2008a. Reproductive success increases with group size in cooperative carrion crows, Corvus corone corone. Animal Behaviour, 75, 403-416.

Canestrari, D., Chiarati, E., Marcos, J. M., Ekman, J. \& Baglione, V. 2008 b. Helpers but not breeders adjust provisioning effort to year-round territory resource availability in carrion crows. Animal Behaviour, 76, 943-949.

Canestrari, D., Marcos, J. M. \& Baglione, V. 2009. Cooperative breeding in carrion crows reduces the rate of brood parasitism by great spotted cuckoos. Animal Behaviour, 77, 1337-1344.

Canestrari, D., Vera, R., Chiarati, E., Marcos, J. M., Vila, M. \& Baglione, V. 2010. False feeding: the trade-off between chick hunger and caregivers needs in cooperative crows. Behavioral Ecology, 21, 233-241. 
Canestrari, D., Marcos, J. M. \& Baglione, V. 2011. Helpers at the nest compensate for reduced maternal investment in egg size in carrion crows. Journal of Evolutionary Biology, 24, 1870-1878.

Canestrari, D., Vila, M., Marcos, J. M. \& Baglione, V. 2012. Cooperatively breeding carrion crows adjust offspring sex ratio according to group composition. Behavioral Ecology and Sociobiology, 66, 1225-1235.

Canestrari, D., Bolopo, D., Turlings, T. C. J., Röder, G., Marcos, J. M. \& Baglione, V. 2014. From Parasitism to Mutualism: Unexpected Interactions Between a Cuckoo and Its Host. Science, 343, 1350-1352.

Chazarreta, M. L., Ojeda, V. S. \& Trejo, A. 2011. Division of labour in parental care in the Magellanic Woodpecker Campephilus magellanicus. Journal of Ornithology, 152, 231-242.

Cheney, K. L. \& Cote, I. M. 2005. Mutualism or parasitism? The variable outcome of cleaning symbioses. Biology Letters, 1, 162-165.

Christe, P., Richner, H. \& Oppliger, A. 1996. Of great tits and fleas: sleep baby sleep... Animal Behaviour, 52, 1087-1092.

Clayton, D. H. \& Moore, J. 1997. Host-parasite evolution: general principles and avian models. Oxford University Press (OUP).

Cramp, S. 1985. Birds of Europe and middle east and north of Africa, vol 4. Terns to woodpeckers. Oxford: Oxford University Press.

Cramp, S. \& Perrins, C. M. 1994. The Birds of the Western Paleartic. Oxford: Oxford University Press.

Crawley, M. J. 2002. Statistical Computing: An Introduction to Data Analysis Using S-Plus. Wiley.

Crawley, M. J. 2013. The R Book. John Wiley \& Sons.

Cronin, E. W. \& Sherman, P. W. 1977. A resource-based mating system: the orange-rumped honeyguide. Living Bird, 15, 5-32.

Davies, N. B. 1999. Cuckoos and cowbirds versus hosts: Co-evolutionary lag and equilibrium. Ostrich, 70, 71-79.

Davies, N. B. 2000. Cuckoos, cowbirds and other cheats. London: T. \& A.D. Poyser.

Davies, N. B. 2011. Cuckoo adaptations: trickery and tuning. Journal of Zoology, 284, 1-14.

Davies, N. \& Brooke, M. 1988. Cuckoos Versus Reed Warblers - Adaptations and Counteradaptations. Animal Behaviour, 36, 262-284. 
Davies, N. B. \& Brooke, M. D. 1989. An Experimental-Study of Co-Evolution Between the Cuckoo, Cuculus-Canorus, and Its Hosts .1. Host Egg Discrimination. Journal of Animal Ecology, 58, 207-224.

Davies, N. B., Brooke, M. D. L. \& Kacelnik, A. 1996. Recognition errors and probability of parasitism determine whether reed warblers should accept or reject mimetic cuckoo eggs. Proceedings of the Royal Society B-Biological Sciences, 263, 925-931.

Davies, N. B., Kilner, R. M. \& Noble, D. G. 1998. Nestling cuckoos, Cuculus canorus, exploit hosts with begging calls that mimic a brood. Proceedings of the Royal Society B-Biological Sciences, 265, 673-678.

Dearborn, D. C. 1998. Begging behavior and food acquisition by brown-headed cowbird nestlings. Behavioral Ecology and Sociobiology, 43, 259-270.

Dearborn, D. C. \& Lichtenstein, G. 2002. Begging Behaviour and Host Exploitation in Parasitic Cowbirds. In: The evolution of begging, (Ed. by J. Wright \& M. L. Leonard), pp. 361-387. Springer Netherlands.

Duckworth, J. 1991. Responses of Breeding Reed Warblers AcrocephalusScirpaceus to Mounts of Sparrowhawk Accipiter-Nisus, Cuckoo Cuculus-Canorus and Jay Garrulus-Glandarius. Ibis, 133, 68-74.

Emlen, S. \& Oring, L. 1977. Ecology, Sexual Selection, and Evolution of Mating Systems. Science, 197, 215-223.

Fleischer, R., Murphy, M. \& Hunt, L. 1985. Clutch Size Increase and Intraspecific Brood Parasitism in the Yellow-Billed Cuckoo. Wilson Bulletin, 97, 125-127.

Fridolfsson, A. K. \& Ellegren, H. 1999. A simple and universal method for molecular sexing of non-ratite birds. Journal of Avian Biology, 30, 116-121.

Gibbs, H. L., Sorenson, M. D., Marchetti, K., Brooke, M. D., Davies, N. B. \& Nakamura, H. 2000. Genetic evidence for female host-specific races of the common cuckoo. Nature, 407, 183-186.

Godfray, H. 1995. Signaling of Need Between Parents and Young - ParentOffspring Conflict and Sibling Rivalry. American Naturalist, 146, 1-24.

Griffiths, R., Double, M., Orr, K. \& Dawson, R. 1998. A DNA test to sex most birds. Molecular Ecology, 7, 1071-1075.

Grim, T. \& Honza, M. 2001. Does supernormal stimulus influence parental behaviour of the cuckoo's host? Behavioral Ecology and Sociobiology, 49, 322-329.

Guigueno, M. F. \& Sealy, S. G. 2012. Nest sanitation in passerine birds: implications for egg rejection in hosts of brood parasites. Journal of Ornithology, 118. 
Hailman, J. P., McGowan, K. J. \& Woolfenden, G. E. 1994. Role of Helpers in the Sentinel Behaviour of the Florida Scrub Jay (Aphelocoma c. coerulescens). Ethology, 97, 119-140.

Hatchwell, B. J. 1999. Investment strategies of breeders in avian cooperative breeding systems. American Naturalist, 154, 205-219.

Hauber, M. E. \& Dearborn, D. C. 2003. Parentage without parental care: What to look for in genetic studies of obligate brood-parasitic mating systems. Auk, 120, 113.

Heinsohn, R. \& Cockburn, A. 1994. Helping is Costly to Young Birds in Cooperatively Breeding White-Winged Choughs. Proceedings of the Royal Society of London. Series B: Biological Sciences, 256, 293-298.

Honza, M., Voslajerova, K. \& Moskat, C. 2007. Eviction behaviour of the common cuckoo Cuculus canorus chicks. Journal of Avian Biology, 38, 385-389.

Hoover, J. P. \& Reetz, M. J. 2006. Brood parasitism increases provisioning rate, and reduces offspring recruitment and adult return rates, in a cowbird host. Oecologia, 149, 165-173.

Horn, A. G. \& Leonard, M. L. 2002. Efficacy and the Design of Begging Signals. In: The Evolution of Begging, (Ed. by J. Wright \& M. L. Leonard), pp. 127-141. Springer Netherlands.

Huang, Z. Y. \& Robinson, G. E. 1996. Regulation of honey bee division of labor by colony age demography. Behavioral Ecology and Sociobiology, 39, 147-158.

Hurtrez-Bousses, S., Blondel, J., Perret, P., Fabreguettes, J. \& Renaud, F. 1998. Chick parasitism by blowflies affects feeding rates in a Mediterranean population of blue tits. Ecology Letters, 1, 17-20.

Hurtrez-Bousses, S., Renaud, F., Blondel, J., Perret, P. \& Galan, M. -J. 2000. Effects of ectoparasites of young on parents' behaviour in a Mediterranean population of Blue Tits. Journal of Avian Biology, 31, 266-269.

Jarvis, J. 1981. Eusociality in a Mammal - Cooperative Breeding in Naked Mole-Rat Colonies. Science, 212, 571-573.

Jones, O. R. \& Wang, J. 2010. COLONY: a program for parentage and sibship inference from multilocus genotype data. Molecular Ecology Resources, 10, 551555.

Jones, D. A., Gibbs, H. L., Matsuda, T., Brooke, M. D., Uchida, H. \& Bayliss, M. J. 1997. The use of DNA fingerprinting to determine the possible mating system of an obligate brood parasitic bird, the Cuckoo Cuculus canorus. Ibis, 139, 560-562. 
Kalinowski, S. T., Taper, M. L. \& Marshall, T. C. 2007. Revising how the computer program CERVUS accommodates genotyping error increases success in paternity assignment. Molecular Ecology, 16, 1099-1106.

Kilner, R. M. 2002. The Evolution of Complex Begging Displays. In: The Evolution of Begging, (Ed. by J. Wright \& M. L. Leonard), pp. 87-106. Springer Netherlands.

Kilner, R. M. 2005. The evolution of virulence in brood parasites. Ornithological Science, 4, 55-64.

Kilner, R. M. \& Davies, N. B. 1999. How selfish is a cuckoo chick? Animal Behaviour, 58, 797-808.

Kilner, R. \& Johnstone, R. A. 1997. Begging the question: Are offspring solicitation behaviours signals of needs. Trends in Ecology \& Evolution, 12, 11-15.

Kilner, R. M. \& Langmore, N. E. 2011. Cuckoos versus hosts in insects and birds: adaptations, counter-adaptations and outcomes. Biological Reviews, 86, 836-852.

Kilner, R. M., Madden, J. R. \& Hauber, M. E. 2004. Brood parasitic cowbird nestlings use host young to procure resources. Science, 305, 877-879.

Krüger, 0. 2007. Cuckoos, cowbirds and hosts: adaptations, trade-offs and constraints. Philosophical Transactions of the Royal Society B: Biological Sciences, 362, 1873-1886.

Krüger, 0. 2011. Brood parasitism selects for no defence in a cuckoo host. Proceedings of the Royal Society B-Biological Sciences, 278, 2777-2783.

Landa, A. \& Tommeras, B. A. 1997. A test of aversive agents on wolverines. Journal of Wildlife Management, 61, 510-516.

Lang, J. D., Straight, C. A. \& Gowaty, P. A. 2002. Observations of fecal sac disposal by Eastern Bluebirds. Condor, 104, 205-207.

Langmore, N. E. \& Kilner, R. M. 2007. Breeding site and host selection by Horsfield's bronze-cuckoos, Chalcites basalis. Animal Behaviour, 995-1004.

Langmore, N. E., Hunt, S. \& Kilner, R. M. 2003. Escalation of a coevolutionary arms race through host rejection of brood parasitic young. Nature, 422, 157-160.

Langmore, N. E., Adcock, G. J. \& Kilner, R. M. 2007. The spatial organization and mating system of Horsfield's bronze-cuckoos, Chalcites basalis. Animal Behaviour, 74, 403-412.

Lehner, P., Krumm, R. \& Cringan, A. 1976. Tests for Olfactory Repellents for Coyotes and Dogs. Journal of Wildlife Management, 40, 145-150.

Lichtenstein, G. 2001. Selfish begging by screaming cowbirds, a mimetic brood parasite of the bay-winged cowbird. Animal Behaviour, 61, 1151-1158. 
Lichtenstein, G. \& Sealy, S. G. 1998. Nestling competition, rather than supernormal stimulus, explains the success of parasitic brown-headed cowbird chicks in yellow warbler nests. Proceedings of the Royal Society B-Biological Sciences, 265, 249-254.

Lotem, A., Nakamura, H. \& Zahavi, A. 1995. Constraints on Egg Discrimination and Cuckoo Host Coevolution. Animal Behaviour, 49, 1185-1209.

Macedo, R. 1992. Reproductive Patterns and Social-Organization of the Communal Guira Cuckoo (guira-Guira) in Central Brazil. Auk, 109, 786-799.

Mahler, B., Adamson, Y. S., Di Giacomo, A. G., Confalonieri, V. A. \& Reboreda, J. C. 2009. Utilization of a new host in the screaming cowbird Molothrus rufoaxillaris, a host specialist brood parasite: host switch or host acquisition? Behavioral Ecology and Sociobiology, 63, 1603-1608.

Malausa, T., Gilles, A., Meglecz, E., Blanquart, H., Duthoy, S., Costedoat, C., Dubut, V., Pech, N., Castagnone-Sereno, P., Delye, C., Feau, N., Frey, P., Gauthier, P., Guillemaud, T., Hazard, L., Le Corre, V., Lung-Escarmant, B., Male, P.-J. G., Ferreira, S. \& Martin, J.-F. 2011. High-throughput microsatellite isolation through 454 GS-FLX Titanium pyrosequencing of enriched DNA libraries. Molecular Ecology Resources, 11, 638-644.

Marchetti, K., Nakamura, H. \& Gibbs, H. L. 1998. Host-race formation in the common cuckoo. Science (New York, N.Y.), 282, 471-472.

Martínez, J. G., Soler, J. J., Soler, M. \& Burke, T. 1998a. Spatial patterns of egg laying and multiple parasitism in a brood parasite: a non-territorial system in the great spotted cuckoo (Clamator glandarius). Oecologia, 117, 286-294.

Martínez, J. G., Burke, T., Dawson, D., Soler, J. J., Soler, M. \& Moller, A. P. 1998 b. Microsatellite typing reveals mating patterns in the brood parasitic great spotted cuckoo (Clamator glandarius). Molecular Ecology, 7, 289-297.

McGowan, K. J. 1995. A test of whether economy or nutrition determines fecal sac ingestion in nesting corvids. Condor, 97, 50-56.

Moksnes, A., Roskaft, E. \& Tysse, T. 1995. On the Evolution of Blue Cuckoo Eggs in Europe. Journal of Avian Biology, 26, 13-19.

Moreno-Rueda, G. \& Redondo, T. 2011. Begging at high level simultaneously impairs growth and immune response in southern shrike (Lanius meridionalis) nestlings. Journal of Evolutionary Biology, 24, 1091-1098.

Moskát, C., Rosendaal, E. C., Boers, M., Zölei, A., Bán, M. \& Komdeur, J. 2011. Post-ejection nest-desertion of common cuckoo hosts: a second defense mechanism or avoiding reduced reproductive success? Behavioral Ecology and Sociobiology, 65, 1045-1053. 
Nicholls, J. A., Double, M. C., Rowell, D. M. \& Magrath, R. D. 2000. The evolution of cooperative and pair breeding in thornbills Acanthiza (Pardalotidae). Journal of Avian Biology, 31, 165-176.

Oien, I., Moksnes, A. \& Roskaft, E. 1995. Evolution of Variation in Egg Color and Marking Pattern in European Passerines - Adaptations in a Coevolutionary ArmsRace with the Cuckoo, Cuculus-Canorus. Behavioral Ecology, 6, 166-174.

Pacheco, M. L., McDonald, P. G., Wright, J., Kazem, A. J. N. \& Clarke, M. F. 2008. Helper contributions to antiparasite behavior in the cooperatively breeding bell miner. Behavioral Ecology, 19, 558-566.

Parker, G. A., Royle, N. J. \& Hartley, I. R. 2002. Begging scrambles with unequal chicks: interactions between need and competitive ability. Ecology Letters, 5, 206215.

Payne, R. 1969. Nest Parasitism and Display of Chestnut Sparrows in a Colony of Grey-Capped Social Weavers. Ibis, 111, 300-\&.

Payne, R. B. 1973. Individual Laying Histories and the Clutch Size and Numbers of Eggs of Parasitic Cuckoos. The Condor, 75, 414.

Payne, R. B. 1977. Ecology of Brood Parasitism in Birds. Annual Review of Ecology and Systematics, 8, 1-28.

Payne, R. B. 2005. The cuckoos. New York: Oxford University Press.

Payne, R., Payne, L. \& Rowley, I. 1985. Splendid Wren Malurus Splendens Response to Cuckoos - an Experimental Test of Social-Organization in a Communal Bird. Behaviour, 94, 108-127.

Payne, R. B., Payne, L. L., Woods, J. L. \& Sorenson, M. D. 2000. Imprinting and the origin of parasite-host species associations in brood-parasitic indigobirds, Vidua chalybeata. Animal Behaviour, 59, 69-81.

Petit, D. R. \& Petit, L. J. 1987. Fecal sac dispersal by prothonotary warblers: Weatherheads hypothesis reevaluated. Condor, 89, 610-613.

Petit, K. E., Petit, L. J. \& Petit, D. R. 1989. Fecal sac removal: Do the pattern and distance of dispersal affect the chance of nest predation? Condor, 91, 479-482.

Poiani, A. 1992. Ectoparasitism as a Possible Cost of Social-Life - a ComparativeAnalysis Using Australian Passerines (passeriformes). Oecologia, 92, 429-441.

Poiani, A. 1993. Reproductive-Biology of the Bell Miner (Manorina melanophrys, Meliphagidae) at Healesville, South-Eastern Victoria. Wildlife Research, 20, 579598.

Poulin, R. 1991. Group-Living and Infestation by Ectoparasites in Passerines. Condor, 93, 418-423. 
Price, P. 1977. General Concepts on Evolutionary Biology of Parasites. Evolution, 31, 405-420.

Price, K. \& Ydenberg, R. 1995. Begging and Provisioning in Broods of Asynchronously-Hatched Yellow-Headed Blackbird Nestlings. Behavioral Ecology and Sociobiology, 37, 201-208.

R Development Core Team. 2008. R: A language and environment for statistical computing. R Foundation for Statistical Computing.

R Development Core Team. 2010. R: A language and environment for statistical computing. Vienna, Austria.

Rivers, J. W. 2007. Nest mate size, but not short-term need, influences begging behavior of a generalist brood parasite. Behavioral Ecology, 18, 222-230.

Rivers, J. W., Loughin, T. M. \& Rothstein, S. I. 2010. Brown-headed cowbird nestlings influence nestmate begging, but not parental feeding, in hosts of three distinct sizes. Animal Behaviour, 79, 107-116.

Rodriguez-Girones, M. A., Zuniga, J. M. \& Redondo, T. 2001. Effects of begging on growth rates of nestling chicks. Behavioral Ecology, 12, 269-274.

Roldan, M. \& Soler, M. 2011. Parental-care parasitism: how do unrelated offspring attain acceptance by foster parents? Behavioral Ecology, 22, 679-691.

Roldán, M. 2011. Cría cooperativa y parasitismo de cría en la corneja negra. PhD Dissertation, Granada: Granada.

Roldán, M., Martín-Gálvez, D., Rodríguez, J. \& Soler, M. 2013. Breeding biology and fledgling survival in a Carrion Crow Corvus corone population of southern Spain: a comparison of group and pair breeder. Acta Ornithologica, 48, 221-235.

Roskaft, E., Moksnes, A., Stokke, B. G., Bicik, V. \& Moskat, C. 2002. Aggression to dummy cuckoos by potential European cuckoo hosts. Behaviour, 139, 613-628.

Rothstein, S. 1990. A Model System for Coevolution - Avian Brood Parasitism. Annual Review of Ecology and Systematics, 21, 481-508.

Rothstein, S. I. \& Robinson, S. K. 1998. Parasitic Birds and Their Hosts: Studies in Coevolution. Oxford University Press.

Rousset, F. 2008. GENEPOP â? ${ }^{\text {TM }}$ 007: a complete re-implementation of the GENEPOP software for Windows and Linux. Molecular Ecology Resources, 8, 103106.

Sato, T. 1986. A brood parasitic catfish of mouthbrooding cichlid fishes in Lake Tanganyika. Nature, 323, 58-59. 
Schafer, E., Bowles, W. \& Hurlbut, J. 1983. The Acute Oral Toxicity, Repellency, and Hazard Potential of 998 Chemicals to One or More Species of Wild and Domestic Birds. Archives of Environmental Contamination and Toxicology, 12, 355382.

Sealy, S. G., McMaster, D. G. \& Peer, B. D. 2002. Tactics of obligate brood parasites to secure suitable incubators. In: Avian incubation: behaviour, environment and evolution, D. C. Deeming edn. pp. 254-269. Oxford: Oxford University Press.

Servedio, M. R. \& Hauber, M. E. 2006. To eject or to abandon? Life history traits of hosts and parasites interact to influence the fitness payoffs of alternative antiparasite strategies. Journal of Evolutionary Biology, 19, 1585-1594.

Siepielski, A. M. \& Benkman, C. W. 2007. Extreme environmental variation sharpens selection that drives the evolution of a mutualism. Proceedings of the Royal Society B-Biological Sciences, 274, 1799-1805.

Smith, N. 1968. Advantage of Being Parasitized. Nature, 219, 690-\&.

Soler, M. 1990. Relationships Between the Great Spotted Cuckoo ClamatorGlandarius and Its Corvid Hosts in a Recently Colonized Area. Ornis Scandinavica, 21, 212-223.

Soler, M. 2001. Begging behaviour of nestlings and food delivery by parents: the importance of breeding strategy. acta ethologica, 4, 59-63.

Soler, M. 2002. Breeding Strategy and Begging Intensity: Influences on Food Delivery by Parents and Host Selection by Parasitic Cuckoos. In: The Evolution of Begging, (Ed. by J. Wright \& M. L. Leonard), pp. 413-427. Springer Netherlands.

Soler, J. J. 2003. Críalo Europeo - Clamator glandarius. In: Enciclopedia Virtual de los Vertebrados Españoles, Carrascal, L. M., Salvador, A. (Eds.) edn. Madrid: Museo Nacional de Ciencias Naturales.

Soler, M. 2013. Long-term coevolution between avian brood parasites and their hosts. Biological reviews of the Cambridge Philosophical Society,

Soler, M. \& de Neve, L. 2012. Great Spotted Cuckoo Nestlings but not Magpie Nestlings Starve in Experimental Age-Matched Broods. Ethology, 118, 1036-1044.

Soler, M. \& de Neve, L. 2013. Brood mate eviction or brood mate acceptance by brood parasitic nestlings? An experimental study with the non-evictor great spotted cuckoo and its magpie host. Behavioral Ecology and Sociobiology, 67, 601607.

Soler, M. \& Soler, J. J. 1991. Growth and Development of Great Spotted Cuckoos and Their Magpie Host. Condor, 93, 49-54. 
Soler, J. J. \& Soler, M. 2000. Brood-parasite interactions between great spotted cuckoos and magpies: a model system for studying coevolutionary relationships. Oecologia, 125, 309-320.

Soler, M., Palomino, J. J., Martinez, J. G. \& Soler, J. J. 1994. Activity, Survival, Independence and Migration of Fledgling Great Spotted Cuckoos. The Condor, 96, 802-805.

Soler, J., Soler, M., Moller, A. \& Martinez, J. 1995a. Does the Great Spotted Cuckoo Choose Magpie Hosts According to Their Parenting Ability. Behavioral Ecology and Sociobiology, 36, 201-206.

Soler, M., Martinez, J., Soler, J. \& Moller, A. 1995b. Preferential Allocation of Food by Magpies Pica-Pica to Great Spotted Cuckoo Clamator Glandarius Chicks. Behavioral Ecology and Sociobiology, 37, 7-13.

Soler, M., Soler, J., Martinez, J. \& Moller, A. 1995c. Magpie Host Manipulation by Great Spotted Cuckoos - Evidence for an Avian Mafia. Evolution, 49, 770-775.

Soler, M., Martínez, J. G. \& Soler, J. J. 1996. Effects of brood parasitism by the Great Spotted Cuckoo on the breeding success of the Magpie host: An experimental study. Ardeola, 43,

Soler, M., Soler, J. J. \& Martinez, J. G. 1997. Great spotted cuckoos improve their reproductive success by damaging magpie host eggs. Animal Behaviour, 54, 12271233.

Soler, M., Soler, J. J., Martinez, J. G., Pérez-Contreras, T. \& Møller, A. P. 1998. Micro-evolutionary change and population dynamics of a brood parasite and its primary host: the intermittent arms race hypothesis. Oecologia, 117, 381-390.

Soler, M., Soler, J. J., Martinez, J. G. \& Moreno, J. 1999a. Begging behaviour and its energetic cost in great spotted cuckoo and magpie host chicks. Canadian Journal of Zoology-Revue Canadienne De Zoologie, 77, 1794-1800.

Soler, J. J., Soler, M., Perez-Contreras, T., Aragon, S. \& Moller, A. P. 1999 b. Antagonistic antiparasite defenses: nest defense and egg rejection in the magpie host of the great spotted cuckoo. Behavioral Ecology, 10, 707-713.

Soler, M., Soler, J. J. \& Moller, A. P. 2000. Effect of great spotted cuckoo presence on magpie rejection behaviour. Behaviour, 137, 213-220.

Soler, M., Soler, J. J., Pérez-Contreras, T. \& Martinez, J. G. 2002. Differential reproductive success of great spotted cuckoos Clamator glandarius parasitising magpies Pica pica and carrion crows Corvus corone: the importance of parasitism costs and host defences. Avian Science, 2, 25-32.

Soler, J. J., Martin-Galvez, D., Martinez, J. G., Soler, M., Canestrari, D., AbadGomez, J. M. \& Moller, A. P. 2011. Evolution of tolerance by magpies to brood 
parasitism by great spotted cuckoos. Proceedings of the Royal Society B-Biological Sciences, 278, 2047-2052.

Soler, M., de Neve, L., Roldan, M., Macias-Sanchez, E. \& Martin-Galvez, D. 2012. Do great spotted cuckoo nestlings beg dishonestly? Animal Behaviour, 83, 163169.

Soler, M., de Neve, L., Roncalli, G., Macías-Sánchez, E., Ibáñez-Álamo, J. D. \& Pérez-Contreras, T. 2014. Great spotted cuckoo fledglings are disadvantaged by magpie host parents when reared together with magpie nestlings. Behavioral Ecology and Sociobiology, 68, 333-342.

Spottiswoode, C. N. \& Koorevaar, J. 2012. A stab in the dark: chick killing by brood parasitic honeyguides. Biology Letters, 8, 241-244.

Spottiswoode, C., Kilner, R. \& Davies, N. B. 2012. Brood parasitism. In: The evolution of parental care, (Ed. by N. J. Royle, P. T. Smiseth, \& M. Kölliker), pp. 226 356. Oxford: Oxford University Press.

Stokke, B. G., Moksnes, A. \& Roskaft, E. 2002. Obligate brood parasites as selective agents for evolution of egg appearance in passerine birds. Evolution, 56, 199-205.

Strausberger, B. M., Ashley, M. V. \& Brittingham, M. 2003. Breeding biology of brood parasitic brown-headed cowbirds (Molothrus ater) characterized by parentoffspring and sibling-group reconstruction. The Auk, 120, 433-445.

Teuschl, Y., Taborsky, B. \& Taborsky, M. 1998. How do cuckoos find their hosts? The role of habitat imprinting. Animal Behaviour, 56, 1425-1433.

Vehrencamp, S., Bowen, B. \& Koford, R. 1986. Breeding Roles and Pairing Patterns Within Communal Groups of Groove-Billed Anis. Animal Behaviour, 34, 347-366.

Weatherhead, P. J. 1984. Fecal sac removal by tree swallows: the cost of cleanliness. Condor, 86, 187-191.

Weatherhead, P. J. 1988. Adaptive disposal of fecal sacs. Condor, 90, 518-519.

Welbergen, J. A. \& Davies, N. B. 2009. Strategic Variation in Mobbing as a Front Line of Defense against Brood Parasitism. Current Biology, 19, 235-240.

Westneat, D. F. 1987a. Extra-pair copulations in a predominantly monogamous bird: observations of behaviour. Animal Behaviour, 35, 865-876.

Westneat, D. F. 1987b. Extra-pair fertilizations in a predominantly monogamous bird: genetic evidence. Animal Behaviour, 35, 877-886.

Wheeleraceto, H., Porreca, F. \& Cowan, A. 1990. The Rat Paw Formalin Test Comparison of Noxious Agents. Pain, 40, 229-238. 
Wilson, E. 1980. Caste and Division of Labor in Leaf-Cutter Ants (hymenoptera, Formicidae, Atta) .1. the Overall Pattern in Atta-Sexdens. Behavioral Ecology and Sociobiology, 7, 143-156.

Woolfenden, B. E., Gibbs, H. L. \& Sealy, S. G. 2002. High opportunity for sexual selection in both sexes of an obligate brood parasitic bird, the brown-headed cowbird (Molothrus ater). Behavioral Ecology and Sociobiology, 52, 417-425.

Yokel, D. A. 1986. Monogamy and Brood Parasitism - an Unlikely Pair. Animal Behaviour, 34, 1348-1358. 


\section{SPANISH SUMMARY / RESUMEN EN ESPAÑOL}

El objetivo principal de esta tesis es profundizar en el estudio de las interacciones de la corneja negra Corvus corone corone con el críalo Clamator glandarius, un ave parásita de cría que pone los huevos en nidos de otras especies, los hospedadores, para que los incuben y críen los pollos junto a los suyos propios. En el Paleártico, su hospedador primario es la urraca Pica pica, mientras que la corneja es el secundario; sin embargo, en la población de estudio, situada en el norte de España, el críalo usa la corneja como hospedador primario, en vez de la urraca. Esta situación da la oportunidad de investigar en más detalle las interacciones parásito-hospedador entre la corneja y el críalo. Este sistema es especialmente interesante debido a una diferencia notable frente a la mayoría de los estudios realizados: la especie hospedadora es más grande que la parásita. Esta característica puede dar lugar a que el resultado de la interacción parásitohospedador presente diferencias significativas frente a sistemas en los que el tamaño de las especies es igual o la especie parásita es más grande. 
Spanish summary/Resumen en español

\section{Capítulo 2: Sistema reproductivo del críalo, un estudio comparativo.}

\section{Objetivos:}

(a) Descripción del sistema reproductivo del críalo en dos poblaciones distintas.

(b) Confirmación de la posible existencia de razas de críalo especializadas en un hospedador concreto (corneja o urraca).

Métodos: Se tomaron muestras de sangre de críalos adultos (capturados con redes japonesas) y de pollos (encontrados en los nidos de los hospedadores), en dos poblaciones distintas: León, al norte de España en 2009 y 2010, y Guadix en el sur, en 2010. Se desarrollaron nuevos marcadores genéticos (microsatélites) para el críalo. Con el programa COLONY se realizaron los análisis de parentesco con el ADN extraído de las muestras de sangre.

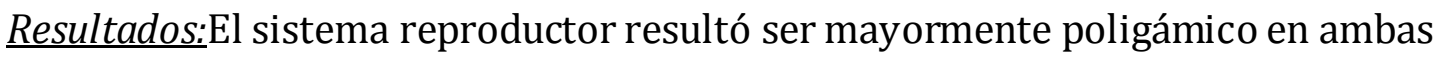
poblaciones, contrariamente a resultados previos en la población del sur, que mostraban un sistema prácticamente monogámico (Martínez et al. 1998b). Este resultado puede ser debido a diferencias en la densidad de población del críalo, ya que a mayor densidad, la probabilidad de encuentro entre machos y hembras aumenta y, por lo tanto, mayores son las posibilidades de apareamiento. Además, en las dos poblaciones se encontraron huevos de la misma hembra de críalo en nidos de los dos hospedadores, lo que descarta la hipótesis de que existan razas específicas para cada hospedador. 
Spanish summary/Resumen en español

\section{Capítulo 3: De parasitismo a mutualismo: inesperadas interacciones entre un} parásito de cría y su hospedador.

\section{Objetivos:}

(a) Investigar si la corneja puede beneficiarse de tener un pollo de críalo en el nido.

(b) Verificar si el posible beneficio se debe a las secreciones cloacales malolientes que producen los pollos de críalo cuando son molestados.

(c) Comprobar si dichas secreciones contienen compuestos repulsivos para los depredadores más frecuentes de los nidos de corneja.

Métodos: Se usaron datos recogidos durante 16 años para estudiar la correlación entre la presencia de pollos de críalo en el nido y la probabilidad de depredación. Se trasladaron pollos de críalo de nidos de corneja parasitados a otros no parasitados para comprobar los cambios en las probabilidades de ser depredados. Se tomaron muestras de las secreciones de los críalos para realizar pruebas de repulsión en especies modelo pertenecientes a los tres grupos de depredadores de nidos de corneja (córvidos, aves de presa y mamíferos). Se realizaron cromatografías de gases y espectrometrías de masas de las secreciones para identificar los posibles compuestos repelentes.

Resultados: El análisis de las bases de datos y el experimento de traslado de pollos de críalo mostraron que si la probabilidad de depredación es alta, el tener un críalo en el nido es beneficioso para el éxito reproductor de las cornejas. En las pruebas de repulsión se comprobó que en los tres grupos de depredadores las secreciones 
tuvieron un efecto repelente; probablemente debido a la presencia en ellas de ácidos, fenoles, índoles y compuestos de azufres, identificados en el análisis químico, que son ya conocidos por tener propiedades repelentes para mamíferos, aves o ambos grupos.

\section{Capítulo 4: La intensa petición de comida de los pollos de críalo favorece a los} pollos de corneja.

\section{Objetivos:}

(a) Comprobar si los pollos de críalo piden comida más intensamente que los pollos de corneja.

(b) Evaluar si la intensidad de petición de los pollos de críalo influye en el comportamiento de los adultos a la hora de repartir la comida en el nido.

(c) Estudiar si la presencia de un críalo en el nido afecta al comportamiento de petición de comida de los pollos de corneja o a la tasa de ceba de los adultos.

Métodos: Mediante video-grabaciones de la actividad en el nido, se estableció una escala categórica de las intensidades de petición de los pollos según su comportamiento. En cada visita de un adulto al nido se tomó nota de la intensidad de petición y de la comida recibida por cada pollo. El análisis estadístico de los datos se realizó mediante modelos mixtos usando Genstat 12.0.

Resultados: Los pollos de críalo pidieron comida más intensamente que los de corneja, sin embargo eso no hizo que los adultos los alimentaran más a menudo. Además, la exagerada petición de los críalos hizo que los pollos de corneja de 10 - 
15 días de edad redujeran su intensidad de petición sin que disminuyese la cantidad de comida recibida. Como resultado, se puede considerar que la presencia de un pollo de críalo en el nido beneficia más que perjudica a los pollos de corneja, por lo menos durante la segunda mitad de su desarrollo en el nido.

\section{Capítulo 5: Limpieza del nido en la corneja negra}

Otras especies parasitas que conviven con la corneja son aquellas que se encuentran en el nido, ya sean invertebrados ectoparásitos u organismos parásitos presentes en las heces de los pollos. Las infestaciones causadas por estas especies a menudo reducen el éxito reproductor de las aves afectando a la salud y al crecimiento de los pollos e incluso provocándoles la muerte. Además, este comportamiento de limpieza del nido se considera precursor de la capacidad de expulsión de huevos de los parásitos de cría.

\section{Objetivos:}

(a) Describir los comportamientos de limpieza del nido de las cornejas y analizar los factores que influyen en la contribución individual de cada miembro del grupo.

(b) Investigar si hay división de tareas (limpieza vs. alimentación) entre los cuidadores de los pollos.

(c) Comprobar si los cambios ambientales, en este caso la cantidad de comida disponible en cada territorio, influyen en la realización de las tareas de limpieza.

Métodos: Mediante video-grabaciones de la actividad en el nido se diferenciaron los tipos de limpieza que se llevaban a cabo y se midió el tiempo que cada cuidador 
Spanish summary/Resumen en español

invirtió en ellos, así como la cantidad de comida que llevaron al nido. Se añadió experimentalmente comida a algunos territorios de corneja para comprobar si afectaba al esfuerzo dedicado a limpieza por los miembros del grupo.

Resultados: Se identificaron tres tipos de limpieza: del nido, de los pollos y ahuecado del recubrimiento interior del nido. No se identificó una clara división de tareas entre los individuos que ayudan en el nido. La mayoría de estas tareas las llevó a cabo la hembra reproductora de cada territorio. Esto puede ser debido a que la hembra se beneficia especialmente de que el nido esté limpio, ya que al pasar mucho tiempo incubando, posiblemente corra mayor riesgo de contagio de infecciones que el resto de los miembros del grupo. Esto concuerda con el hecho de que en aquellos territorios suplementados con comida, lo cual mejora la condición física de los miembros del grupo y disminuye el riesgo de infecciones, el tiempo dedicado a la limpieza del nido se redujo. 